VIVIANE CAROLINE ABE

\title{
DETERMINAÇÃO DE PARÂMETROS DE OPERAÇÃO DE SISTEMA DE DISTRIBUIICÃ̃O DE AR FRIO PELO PISO EM AMBIENTES DE ESCRITÓRIOS
}

Dissertação apresentada à Escola

Politécnica da Universidade de São Paulo para a obtenção do título de Mestre em Engenharia

SÃO PAULO 
VIVIANE CAROLINE ABE

\section{DETERMINAÇÃO DE PARÂMETROS DE OPERAÇÃO DE SISTEMA DE DISTRIBUIICÃ̃O DE AR FRIO PELO PISO EM AMBIENTES DE ESCRITÓRIOS}

Dissertação apresentada à Escola Politécnica da Universidade de São Paulo para a obtenção do título de Mestre em Engenharia

Área de Concentração:

Engenharia de Construção Civil e Urbana

Orientador:

Prof $^{\mathrm{a}}$. Dr ${ }^{\mathrm{a}}$. Brenda Chaves Coelho Leite

SÃO PAULO 
Este exemplar foi revisado e alterado em relação à versão original, sob responsabilidade única do autor e com a anuência de seu orientador.

São Paulo, 29 de junho de 2007.

Assinatura do autor

Assinatura do orientador

\section{FICHA CATALOGRÁFICA}

Abe, Viviane Caroline

Determinação de parâmetros de operação de sistema de distribuição de ar frio pelo piso em ambientes de escritórios /

V.C. Abe. -- São Paulo, 2007.

$132 \mathrm{p}$.

Dissertação (Mestrado) - Escola Politécnica da Universidade de São Paulo. Departamento de Engenharia de Construção Civil.

1.Ar condicionado 2.Dinâmica dos fluidos 3.Análise numérica I.Universidade de São Paulo. Escola Politécnica. Departamento de Engenharia de Construção Civil II.t. 
Dedico este trabalho aos meus pais, Kiochim e Geni, aos meus irmãos Alexandre e Régis e ao meu amor Ernesto 


\section{AGRADECIMENTOS}

À minha orientadora, Prof ${ }^{\mathrm{a}}$. Dra. Brenda Chaves Coelho Leite, pela atenção, incentivo, apoio técnico e pessoal durante o todo o desenvolvimento desta pesquisa.

À Fundação de Amparo à Pesquisa do Estado de São Paulo (FAPESP) pela concessão da bolsa de mestrado e pelo apoio financeiro para a realização desta pesquisa.

À Escola Politécnica da Universidade de São Paulo, pela oportunidade de realização do curso de mestrado.

Aos professores Dr. Arlindo Tribess e Dr. Cheng Liang Yee pela contribuição e apoio à realização desta pesquisa.

Aos amigos Fábio Kenji Motezuki, Fábio Okamoto, Marcelo Pustelnik e Tales Adriano Ferreira, pela colaboração e suporte.

Ao Prof. Dr. Júlio Romano Meneghini por ter concedido a licença de uso dos softwares empregados neste trabalho e seu aluno Alessandro Alberto de Lima pelo auxílio no processo de instalação dos softwares.

Aos professores e amigos do Laboratório de CAD (LabCAD).do Departamento de Engenharia de Construção Civil da EPUSP, pelo incentivo e apoio à realização do trabalho. 


\section{RESUMO}

ABE, V.C. Determinação de parâmetros de operação de sistema de distribuição de ar frio pelo piso em ambientes de escritórios. 2007. 132 p. Dissertação (Mestrado) - Departamento de Engenharia de Construção Civil da Escola Politécnica da Universidade de São Paulo, São Paulo, 2007.

Atualmente, um dos principais requisitos para que um ambiente de escritório atenda plenamente às necessidades de uso e ocupação é a flexibilidade, mas com conforto. O sistema de distribuição de ar frio pelo piso (Underfloor Air Distribution System UFAD) está sendo utilizado nos edifícios de escritórios para garantir a flexibilização integrada do sistema com o mobiliário. Trata-se de um sistema que fornece ar frio proveniente de um plenum, através de difusores localizados nos painéis do piso elevado. Os difusores de ar podem ser ajustados, ou reposicionados pelos próprios usuários dos ambientes, possibilitando o controle das condições térmicas no entorno próximo, de acordo com suas preferências individuais. Embora o sistema de distribuição de ar pelo piso apresente diversas vantagens com relação ao sistema de distribuição de ar convencional, ainda há falta de informações objetivas e diretrizes de projeto padronizadas, havendo a necessidade de realização de mais pesquisas na área. A introdução da Dinâmica dos Fluidos Computacional (Computational Fluid Dynamics - CFD) apresentou uma alternativa para as pesquisas experimentais relacionadas ao estudo do escoamento do ar. Assim, para o desenvolvimento do presente estudo foram utilizados recursos de dinâmica dos fluidos computacional, com o uso do código FLUENT. O objetivo do presente trabalho é apresentar uma estratégia para a determinação dos parâmetros de operação de sistemas de distribuição de ar pelo piso aplicados a ambientes de escritórios. A estratégia baseiase no estabelecimento de inter-relações entre os principais parâmetros que definem o escoamento do ar em ambientes com o sistema de distribuição de ar pelo piso: a vazão de ar insuflado, a temperatura do ar insuflado e a diferença de pressão entre o plenum pressurizado e o interior do ambiente. O emprego da estratégia possibilita que o projetista identifique as diversas combinações entre os parâmetros de operação que resultem numa mesma condição desejada, permitindo assim a escolha da opção mais satisfatória. 
Palavras-chave: Ar condicionado. Dinâmica dos fluidos computacional. Análise Numérica. 


\section{ABSTRACT}

ABE, V.C. Determination of operation parameters of rooms with underfloor air distribution system. 2007. 132 p. Dissertation (Master Course) - Departamento de Engenharia de Construção Civil da Escola Politécnica da Universidade de São Paulo, São Paulo, 2007.

Nowadays, one of the main requirements of an office room to fully attend the use and occupation needs is the flexibility, but with comfort. The underfloor air distribution system is being used in the office buildings to guarantee the integrated flexibility of the system with the furniture layout. The system supplies cooled air to the room from a pressurized plenum, passing through air diffusers located in the raised floor panels. The air diffusers can be adjusted or relocated by the room users themselves, making possible the control of the thermal conditions in their surroundings, according to their individual preferences. Though the underfloor air distribution system presents a lot of advantages with regard to conventional overhead distribution systems, there is still a lack of objective information and standardized guidelines, and the necessity of accomplishment of more researches about the subject. The introduction of Computational Fluid Dynamics presented an alternative for the experimental tests related to the study of airflow in rooms. Thus, for the development of the present study a CFD tool was used, the code FLUENT. The purpose of the present work is to develop a strategy for the determination of the operation parameters of an underfloor air distribution system applied to office rooms. The strategy is based on the establishment of interrelations between the main parameters that define the airflow in rooms with the underfloor air distribution system: the input volume flux, the input air temperature and the pressure difference between underfloor plenum and the room. The use of this strategy enables the designer to identify several combinations of the operation parameters that result in one desired condition, allowing the choice of the most satisfactory option.

Key-words: Air conditioning (HVAC systems). Computational Fluid Dynamics. Numerical Analysis. 


\section{LISTA DE FIGURAS}

Figura 2.1 - Sistema convencional de distribuição de ar

Figura 2.2 - Esquema do escoamento do ar no interior de um ambiente com o sistema de distribuição de ar convencional

Figura 2.3 - Exemplo de difusor do tipo "swirl" (Jato espiralado) 38

Figura 2.4 - Plenum do piso 38

Figura 2.5 - Sistema de distribuição de ar pelo piso 40

Figura 2.6 - Esquema do escoamento do ar no interior de um ambiente com o sistema de ventilação por deslocamento

Figura 2.7 - Esquema do escoamento do ar no interior de um ambiente com o sistema de distribuição de ar pelo piso

Figura 2.8 - Esquema do escoamento do ar em sistemas UFAD operando com velocidade do jato de ar elevada

Figura 3.1 - Perspectiva da câmara de testes $\quad 44$

Figura 3.2 - Painel de lâmpadas $\quad 45$

Figura 3.3 - Simulador $\quad 46$

Figura 3.4 - Distribuição dos difusores de ar no piso. 46

Figura 3.5 - Indicação do difusor de ar escolhido para as medições do teste $\quad 47$

Figura 3.6 - Indicação dos pontos de medição (ao longo das linhas verticais) 48

Figura 3.7 - Indicação das distâncias dos pontos de medição com relação ao centro do difusor $\quad 48$

Figura 3.8 - Curvas resultantes das medições da temperatura do ar $\quad 49$

Figura 3.9 - Curvas resultantes das medições da velocidade do ar $\quad 49$

Figura 4.1 - Sistema de ventilação por deslocamento 62

Figura 4.2 - Sistema de distribuição de ar pelo piso 63

Figura 4.3 - Modelo geométrico da câmara de testes 70

Figura 4.4 - Representação da câmara de testes $\quad 70$

Figura 4.5 - Dimensões da câmara experimental 71

Figura 4.6 -Representação da malha 1 - Perspectiva $\quad 72$

Figura 4.7 -Representação da malha 1 - Vista do piso $\quad 73$

Figura 4.8 - Representação da malha 1 - Detalhe $1 \quad 73$

Figura 4.9 - Representação da malha 1 - Detalhe 2

Figura 4.10 - Indicação dos principais elementos da câmara de testes 75 
Figura 4.11 - Representação da velocidade tangencial imposta no difusor de ar 76

Figura 4.12 - Perda de carga nas grelhas de retorno e difusores de $150 \mathrm{~mm}$ e $200 \mathrm{~mm}$ 77

Figura 4.13 - Teste de independência de malha

Figura 5.1 - Pontos P1, P2 e P3 representam a combinação dos valores das três variáveis para cada simulação

82

Figura 5.2 - Definição do plano $\alpha$ por meio da ligação entre os pontos 83

Figura 5.3 - Plano $\alpha$

Figura 5.4 - Determinação do ponto P4 84

Figura 5.5 - Determinação do valor da variável "b" $\quad 84$

Figura 6.1 - Teste 1 - Pressão estática $(\mathrm{Pa}) \quad 87$

Figura 6.2 - Teste 2 - Pressão estática $(\mathrm{Pa}) \quad 87$

Figura 6.3 - Teste 3 - Pressão estática $(\mathrm{Pa}) \quad 88$

Figura 6.4 - Ligação entre os pontos resultantes 89

Figura 6.5 - Planos verticais de visualização $\quad 90$

Figura 6.6 -Planos verticais de visualização - Vista superior 91

Figura 6.7 - Pressão estática $(\mathrm{Pa})$ para o plano $X=130 \mathrm{~cm}$. 91

Figura 6.8 - Pressão estática $(\mathrm{Pa})$ para o plano $\mathrm{Y}=130 \mathrm{~cm}$

Figura 7.1 - Projeção do segmento de reta resultante do intervalo de temperaturas de 290 a 295K para a diferença de pressão de 25Pa 93

Figura 7.2 - Valores de vazão necessários para que, a uma dada temperatura, mantenha-se a diferença de pressão de 25Pa 94

Figura 7.3 - Linhas verticais que representam os pontos de medição 95

Figura 7.4 - Planos horizontais de visualização 95

Figura 7.5 - Temperatura $(K)$ no plano $x=130 \mathrm{~cm} \quad 96$

Figura 7.6 - Temperatura $(K)$ no plano $y=130 \mathrm{~cm} \quad 96$

Figura 7.7 - Temperatura $(K)$ no plano $y=200 \mathrm{~cm} \quad 97$

Figura 7.8 - Temperatura $(K)$ no plano $z=10 \mathrm{~cm} \quad 97$

Figura 7.9 - Temperatura $(K)$ no plano $z=60 \mathrm{~cm}$

Figura 7.10 - Temperatura $(K)$ no plano $z=110 \mathrm{~cm} \quad 98$

Figura 7.11 - Temperatura $(K)$ no plano $z=170 \mathrm{~cm}$

Figura 7.12 - Temperatura $(K)$ no plano $z=200 \mathrm{~cm}$

Figura 7.13 - Temperatura $(K)$ no plano $z=235 \mathrm{~cm} \quad 100$

Figura 7.14 - Perfis de temperatura do ar para os pontos C e G 100 
Figura 7.15 - Perfis de temperatura do ar para os pontos B, 10, 20 e 30

Figura 7.16 - Perfis de temperatura do ar para os pontos 40 a 70

Figura 7.17 - Perfis de temperatura do ar para os pontos 80 e $90 \quad 103$

Figura 7.18 - Velocidade do ar $(\mathrm{m} / \mathrm{s})$ no plano $x=130 \mathrm{~cm} \quad 105$

Figura 7.19 - Velocidade do ar $(\mathrm{m} / \mathrm{s})$ no plano $y=130 \mathrm{~cm} \quad 105$

Figura 7.20 - Velocidade do ar $(\mathrm{m} / \mathrm{s})$ no plano $z=10 \mathrm{~cm} \quad 106$

Figura 7.21 - Velocidade do $\operatorname{ar}(\mathrm{m} / \mathrm{s})$ no plano $z=60 \mathrm{~cm} \quad 106$

Figura 7.22 - Velocidade do ar $(\mathrm{m} / \mathrm{s})$ no plano $\mathrm{z}=110 \mathrm{~cm} \quad 107$

Figura 7.23 - Velocidade do ar $(\mathrm{m} / \mathrm{s})$ no plano $\mathrm{z}=170 \mathrm{~cm} \quad 107$

Figura 7.24 - Velocidade do ar (m/s) no plano $z=200 \mathrm{~cm} \quad 108$

Figura 7.25 - Velocidade do ar $(\mathrm{m} / \mathrm{s})$ no plano $\mathrm{z}=235 \mathrm{~cm} \quad 108$

Figura 7.26 - Perfis de velocidade do ar para os pontos C, G, B e 10

Figura 7.27 - Perfis de velocidade do ar para os pontos 20 a $50 \quad 110$

Figura 7.28 - Perfis de velocidade do ar para os pontos 60 a $90 \quad 111$

Figuras 7.29 - Perfis de temperatura do ar nos pontos $C$ e 30 para os modelos de densidade Boussinesq, gás Ideal, gás incompressível e densidade em função da temperatura, e para o modelo de turbulência RSM

Figuras 7.30 - Perfis de temperatura do ar nos pontos 60 e 90 para os modelos de densidade Boussinesq, gás Ideal, gás incompressível e densidade em função da temperatura, e para o modelo de turbulência RSM

Figuras 7.31 - Perfis de velocidade do ar nos pontos C, 30, 60 e 90 para os modelos de densidade Boussinesq, gás Ideal, gás incompressível e densidade em função da temperatura, e para o modelo de turbulência RSM

Figura 7.32 - Pressão estática $(\mathrm{Pa})$ para o plano $\mathrm{Y}=130 \mathrm{~cm}$-Modelo de densidade para gás ideal 


\section{LISTA DE TABELAS}

Tabela 6.1 - Resultados dos testes

Tabela 7.1 - Relação entre a temperatura e a densidade do ar 


\section{LISTA DE ABREVIATURAS E SIGLAS}

$\begin{array}{ll}\text { ABNT } & \text { Associação Brasileira de Normas Técnicas } \\ \text { CFD } & \text { Computational Fluid Dynamics } \\ \text { NBR } & \text { Norma Brasileira } \\ \text { RSM } & \text { Reynolds Stress Model } \\ \text { UFAD } & \text { Underfloor Air Distribution }\end{array}$




\section{LISTA DE SÍMBOLOS}

$a$

$\vec{A}$

$B$

$c_{p}$

$C_{1 \varepsilon}, C_{2 \varepsilon}, C_{3 \varepsilon}, C_{\mu}$

$C_{1}$

$C_{2}$

$C_{1}^{\prime}, C_{2}^{\prime}$

$C_{i j}$

$d$

$D_{L, i j}$

$D_{T, i j}$

F

$F_{i j}$

$g$

$g_{i}, g_{j}$

$g$

$G_{b}$

$G_{k}$

$G_{i j}$

$k$

$k_{t}$

$\mathrm{K}$

$M_{t}$

$M_{\text {w }}$
Velocidade do som

Vetor da área da superfície

Fluxo flutuante da fonte de calor

Calor específico à pressão constante

Constantes do modelo de turbulência $k-\varepsilon$

Constante de deformação lenta devido à pressão

Constante de deformação rápida devido à pressão

Constantes de reflexão da parede

Termo de convecção

Distância normal à parede

Termo de difusão molecular

Termo de difusão de turbulência

Termo de empuxo

Termo de produção pelo sistema de rotação

Aceleração da gravidade

Componentes cartesianas da aceleração da gravidade

Gravidade reduzida

Geração de energia cinética turbulenta devido aos efeitos da flutuabilidade da temperatura

Geração de energia cinética turbulenta devido ao gradiente de velocidade média

Termo de flutuação dos gradientes de temperatura

Energia cinética turbulenta

Condutividade térmica

graus Kelvin

Número de Mach

Peso molecular do gás 
$n$

$N_{\text {faces }}$

$p$

$p_{\text {op }}$

$P_{i j}$

$P r_{t}$

$Q$

$Q_{E}$

$Q_{p}$

$Q_{\text {out }}$

$R$

$S_{k}, S_{\mathcal{E}}, S_{\text {user }}$

$S$

$S_{i j}$

$S_{\phi}$

$t$

$T$

$T_{0}$

$T_{o}$

$u, v, w$

$u^{\prime}, v^{\prime}, w^{\prime}$

$u_{i}, u_{j}$

$\vec{v}$

V

$x, y, z$

$x_{i}, x_{j}, x_{k}$

y

$Y_{M}$
Coordenada local normal à parede

Número de faces da célula

Pressão hidrostática

Pressão operativa

Termo de produção de tensão

Número de Prandtl turbulento

Fluxo de ar introduzido no ambiente

Fluxo de reentrada do ar na camada inferior

Fluxo da pluma térmica

Fluxo de ar que sai do ambiente

Constante universal dos gases

Termos fonte definidos pelo usuário.

Módulo da taxa de deformação do tensor

Taxa média de deformação do tensor

Termo fonte de $\phi$ por unidade de volume

Tempo

Temperatura

Temperatura de referência

Temperatura operativa

Componentes da velocidade

Componentes da flutuação de velocidade

Componentes cartesianas da velocidade instantânea

Velocidade vetorial

Volume da célula

Direções das coordenadas cartesianas

Coordenadas cartesianas nas direções $i, j$ e $k$

Distância da parede

Dissipação da dilatação em escoamento compressível 


\section{LETRAS GREGAS}

$\alpha$

$\beta$

$\delta_{i j}$

$\varepsilon$

$\varepsilon_{i j}$

$\phi_{f}$

$\phi_{i j}$

$\phi_{i j, 1}$

$\phi_{i j, 2}$

$\phi_{i j, w}$

$\Gamma_{\phi}$

$\mu$

$\mu_{t}$

$v$

$\theta$

$\rho$

$\rho_{r}$

$\rho_{0}$

$\sigma_{k}$

$\sigma_{\varepsilon}$

$\tau_{0}$

$\Omega_{k}$

\section{SímBOLOS}

Média

$\nabla \phi$

$(\nabla \phi)_{n}$

$\partial$

Coeficiente de difusividade térmica do fluido

Coeficiente de expansão térmica

Delta de Kronecker

Taxa de dissipação da energia cinética turbulenta

Taxa de dissipação

Valor de $\phi$ na face $f$

Deformação devido à pressão

Deformação lenta devido à pressão

Deformação rápida devido à pressão

Termos de reflexão da parede

Coeficiente de difusão para $\phi$

Viscosidade do fluido

Viscosidade turbulenta

Viscosidade cinemática

Temperatura adimensional

Densidade do fluido

Densidade de referência

Densidade constante do fluxo

Número de Prandtl para a taxa de turbulência $k$

Número de Prandtl para a taxa de turbulência $\varepsilon$

Tensão de cisalhamento na parede

Velocidade angular na direção $k$

Magnitude de $\nabla \phi$ normal à face $f$

Derivada parcial 


\section{SUMÁRIO}

1 INTRODUÇÃO.........................................................19

1.1 Simulação Numérica de Sistema de Distribuição de Ar Pelo Piso.......21

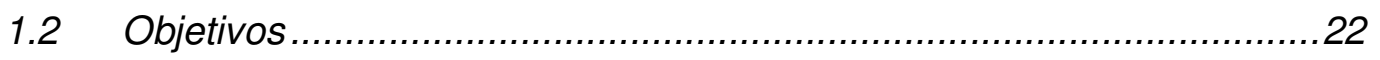

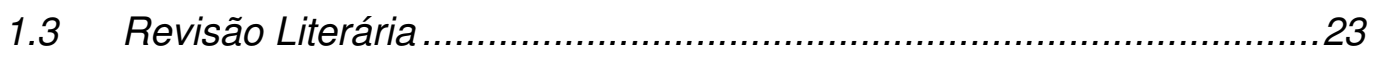

1.3.1 Sistemas de Distribuição de Ar pelo Piso ...............................23

1.3.2 Simulação Numérica do Escoamento do Ar em Sistemas de

Distribuição de Ar pelo Piso....................................................33

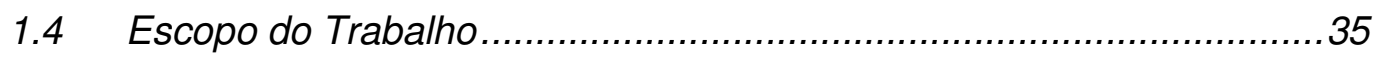

\section{SISTEMA DE DISTRIBUIÇÃO DE AR PELO PISO.......37}

2.1 Escoamento do Ar em Sistemas de Ventilação por Deslocamento .....41

2.2 Escoamento do Ar em Sistemas de Distribuição de Ar pelo Piso .........42

3 OBJETO DE ESTUDO …............................................44

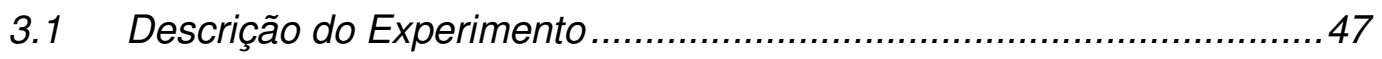

\section{SIMULAÇÕES NUMÉRICAS .....................................50}

4.1 Etapas da Simulação Numérica.......................................................51

4.2 Simulação Numérica no Interior de Ambientes com o Sistema de

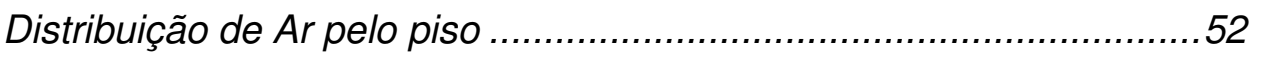

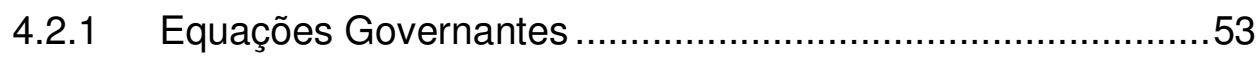

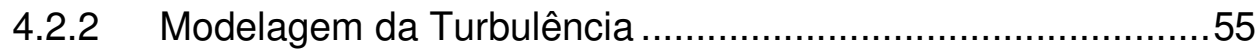

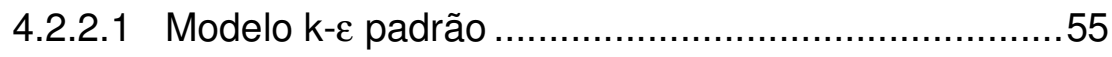

4.2.2.2 Modelo Reynolds Stress Model (RSM) ....................57

4.2.3 Tratamento do Fluxo Próximo à Parede …………….............59

4.2.4 Parâmetros Característicos ................................................... 60

4.2.4.1 Sistema de ventilação por deslocamento ..................61

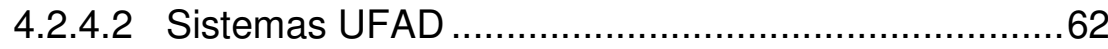

4.2.5 Propriedades Físicas do Fluido .......................................... 64 
4.2.5.1 Modelo de Boussinesq ...........................................64

4.2.5.2 Lei do gás ideal incompressível.................................65

4.2.5.3 Densidade em função da temperatura (piecewiselinear function): .........................................................65

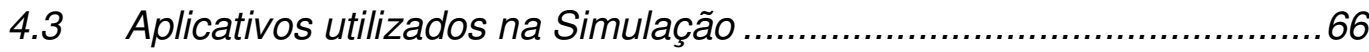

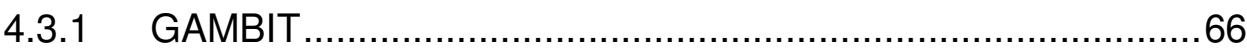

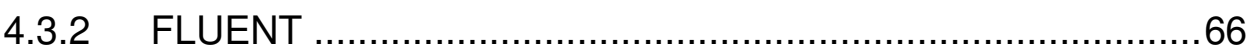

4.4 desenvolvimento das Simulações numéricas ......................................68

4.4.1 Hipóteses e Simplificações Adotadas........................................69

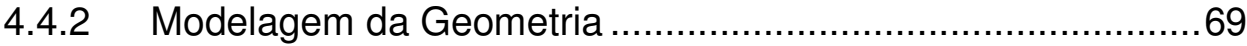

4.4.3 Geração da Malha ................................................................

4.4.4 condições de contorno ........................................................74

4.4.4.1 Difusor de ar ...................................................... 75

4.4.5 Propriedades Físicas do Fluido .........................................77

4.4.6 Modelo de Turbulência ...........................................................77

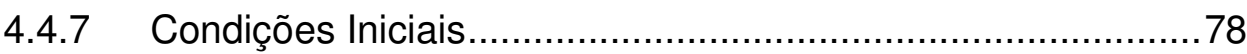

4.4.8 Método de Solução Numérica .............................................78

4.4.9 Critério de Convergência .......................................................79

4.4.10 Teste de Independência de Malha .......................................79

5 ESTRATÉGIA PROPOSTA..........................................82

6 VERIFICAÇÃO DA ESTRATÉGIA PROPOSTA............86

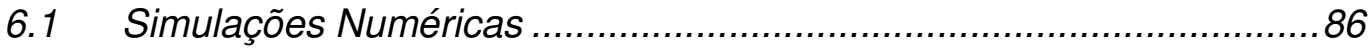

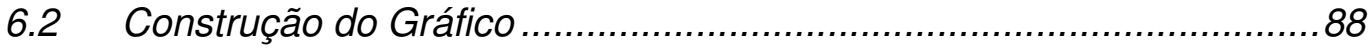

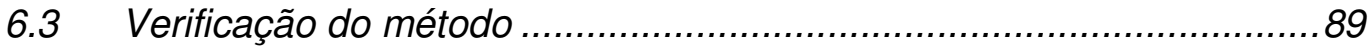

6.3.1 Resultados da Verificação .....................................................

\section{ANÁLISE DOS RESULTADOS ..........................................}

7.1 Análise dos Perfis de Velocidade e Temperatura do ar ......................94

7.1.1 Temperatura do ar .................................................................

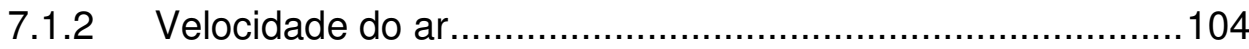


7.2 Análise dos Modelos de Densidade do Ar ....................................112

7.2.1 Resultados............................................................... 113

7.2.1.1 Temperatura do ar ............................................. 113

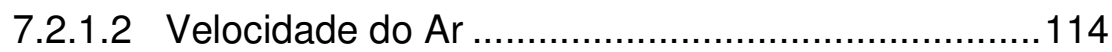

7.2.1.3 Pressão ...................................................... 116

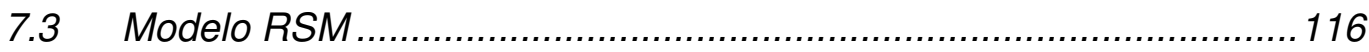

8 CONCLUSÕES E CONSIDERAÇÕES FINAIS ............118

8.1.1 Sugestões para Trabalhos Futuros .............................121

REFERÊNCIAS ..........................................................123 


\section{INTRODUÇÃO}

Desde a introdução do conceito de escritório aberto (landscape office), pela primeira vez na Europa, na década de 1950, o tipo de ocupação tem evoluído rapidamente de acordo com as mudanças na dinâmica do trabalho (VISCHER, 1989), requerendo, cada vez mais flexibilidade para mudanças de layout. Para atender a esta necessidade para o uso do espaço, esses edifícios adotam mobiliário com divisões internas móveis e de diferentes dimensões, o que possibilita arranjos diferenciados. Isto tem gerado sérios conflitos entre as propostas de ocupação (flexível) e de distribuição de ar condicionado por difusores no teto (fixa) (LEITE, 1997).

Este tipo de ocupação cria nos ambientes áreas densamente ocupadas por pessoas e/ou equipamentos, áreas de circulação praticamente sem dissipadores de calor e áreas perimetrais, ocupadas ou não, com radiação solar direta, que representam zonas térmicas diferentes dentro de um mesmo pavimento que não requerem as mesmas condições de conforto (ORNSTEIN et al., 1999). Nota-se assim, que a flexibilidade do espaço obtida pela planta livre dificulta a manutenção das condições de conforto aos usuários nos ambientes climatizados.

O conceito mais praticado para o projeto de sistemas de condicionamento de ar para edifícios de escritórios da atualidade contempla o suprimento de ar condicionado através de redes de dutos com difusores uniformemente distribuídos no teto. Este conceito prevê uma mistura completa de ar insuflado com 0 ar do ambiente, mantendo todo o volume a uma temperatura desejada, assegurando a taxa mínima de renovação do ar.

Uma estratégia de controle centralizado é usada para controlar a temperatura e/ou o volume de ar fornecido ao ambiente para manter uma distribuição de temperatura uniforme no espaço, devendo esta permanecer relativamente constante durante todo o tempo de ocupação. Na prática, o sistema convencional é operado para manter as condições do ambiente interno de acordo com os padrões especificados pela norma NBR - 6401/1980 (ABNT,1980).

Porém, para solucionar os problemas com conforto térmico em edifícios com lajes livres e layout flexível, a estratégia convencional de condicionamento do ambiente de maneira uniformizada pode não ser a solução mais apropriada. Uma 
nova tecnologia, com distribuição do ar pelo piso (plenum), tem sido aplicada para atender a essas preocupações.

Trata-se de um sistema que fornece ao ambiente ar resfriado proveniente de um plenum, através de difusores localizados no piso. O plenum é o espaço livre entre dois níveis de piso (laje e piso elevado), geralmente de pequena altura (cerca de $30 \mathrm{~cm})$.

Nos sistemas de distribuição de ar pelo piso, o ar é insuflado a baixas velocidades diretamente na zona ocupada. $O$ ar insuflado através dos difusores de piso é misturado com o ar ambiente e, à medida que entra em contato com as fontes de calor, sofre um aumento da temperatura e sobe por convecção natural.

Ambientes com o sistema de distribuição de ar pelo piso, são, por isso, caracterizados pela estratificação do ar em duas zonas: a região ocupada, que é a zona de mistura do ar, e a região acima desta, que é a zona de deslocamento do ar, que apresenta temperaturas mais elevadas e concentra uma maior percentagem de contaminantes (BAUMAN, 2003).

As principais características desse sistema são: promove a troca de calor com o ambiente mais rapidamente, pode climatizar apenas o volume de ar do espaço efetivamente ocupado, opera com temperaturas do ar mais elevadas do que as adotadas nos sistemas convencionais com insuflação pelo teto. Tais características podem permitir um menor gasto de energia, maior controle das condições de conforto pelos ocupantes, melhoria da eficiência da ventilação e qualidade do ar, com possibilidade de uso de $100 \%$ de ar externo, com melhoria da produtividade e da saúde dos ocupantes (SODEC e CRAIG, 1990; BAUMAN e WEBSTER, 2001; BAUMAN, 2003).

O sistema de ar condicionado com insuflação pelo piso (Underfloor Air Distribution - UFAD) também permite mudanças de localização dos difusores de ar devido à ausência de dutos, promovendo assim total flexibilidade. Essa característica resulta na redução dos custos associados aos freqüentes rearranjos de mobiliário. 


\subsection{SIMULAÇÃO NUMÉRICA DE SISTEMA DE DISTRIBUIÇÃO DE AR PELO PISO}

Embora o sistema de insuflação de ar pelo piso apresente diversas vantagens com relação ao sistema de climatização convencional, conforme citado anteriormente, ainda há falta de informações objetivas e diretrizes de projeto padronizadas (BAUMAN e WEBSTER, 2001; MATSUNAWA et al., 1995; CHARLES, 2002). Questões fundamentais relativas à estratificação do ar, às trocas térmicas entre o ar do plenum e a laje do piso e à influência do mobiliário no escoamento do ar, por exemplo, ainda precisam ser esclarecidas.

O escoamento do ar em sistema de distribuição de ar frio pelo piso caracteriza-se pela estratificação térmica em duas camadas, uma mais baixa, na zona ocupada, com temperaturas mais baixas e ar mais limpo, e outra mais elevada, com temperaturas mais elevadas e com maior concentração de poluentes. Essa estratificação térmica é resultado de dois fatores: (1) o ar é introduzido no ambiente a baixas velocidades, promovendo a mistura com o ar existente somente na zona ocupada e; (2) o ar aquecido pela troca de calor com as fontes sobem por convecção natural definindo o perfil de escoamento piso-teto, característico desse sistema de distribuição de ar.

Para se obter um determinado perfil de escoamento num ambiente, tendo em vista as características das cargas internas, as condições de operação do sistema, considerando-se a vazão, a temperatura do ar insuflado e a diferença de pressão entre o plenum e o ambiente, devem ser estabelecidas. Cada combinação dessas variáveis poderá resultar em diferentes perfis e essas combinações devem ser definidas para cada caso, ou, situação escolhida.

No presente estudo, propõe-se uma estratégia para a definição dos parâmetros de operação de sistema de distribuição de ar pelo piso, aplicado a ambientes de escritórios e com uma determinada carga térmica interna, a partir do estabelecimento de inter-relações de três variáveis: a vazão e a temperatura do ar insuflado e a diferença de pressão entre o plenum do piso e o interior do ambiente. A estratégia será proposta a partir de resultados de simulações numéricas feitas utilizando o FLUENT.

Este estudo é uma continuação dos trabalhos desenvolvidos por Leite (2003) e Pustelnik (2005). Leite (2003) avaliou o potencial de aplicação de um sistema de 
distribuição de ar pelo piso em edifícios de escritórios no Brasil, tendo em vista garantir condições de conforto térmico no interior dos ambientes. Para o desenvolvimento da pesquisa, uma câmara experimental foi montada, com características similares a um ambiente de escritório. Medições de temperatura e velocidade do ar foram realizadas para avaliar quais parâmetros de operação do sistema resultariam em condições de conforto térmico. No trabalho de Leite (2003) foram definidos os parâmetros de operação do sistema, considerando-se uma dada carga térmica interna.

Pustelnik (2005) realizou simulações numéricas do trabalho de Leite (2003). O autor inicialmente reproduziu um estudo de caso apresentado na literatura para verificar a correta utilização da ferramenta computacional e em seguida realizou simulações da câmara experimental. Segundo Pustelnik (2005) os resultados numéricos obtidos utilizando o FLUENT apresentaram boa concordância em alguns pontos analisados.

Sendo assim, neste trabalho, assume-se que as etapas de verificação e validação da ferramenta já foram realizadas no trabalho de Pustelnik (2005), ou seja, a avaliação do sistema de equações e os métodos numéricos implementados no simulador correspondem à sua descrição conceitual, bem como a avaliação do modelo matemático, que atende, relativamente bem, ao problema físico em questão.

\subsection{OBJETIVOS}

O presente estudo tem por objetivo desenvolver uma estratégia para a determinação de inter-relações entre os principais parâmetros que definem 0 escoamento do ar em ambientes com esse sistema de distribuição de ar: a vazão, a temperatura do ar insuflado e a diferença de pressão entre o plenum pressurizado e o interior do ambiente.

Para o desenvolvimento da estratégia foi utilizada uma ferramenta de dinâmica dos fluidos computacional. Por meio da ferramenta, foram simulados três casos, variando-se os valores de velocidade (vazão de ar) e temperatura na entrada de ar no interior do plenum. A simulação numérica de cada caso resultou em um valor para a diferença de pressão entre o plenum do piso e o interior do ambiente.

Os valores das três variáveis (vazão, temperatura e diferença de pressão) foram então transferidos para um gráfico tridimensional e resultaram em um plano 
que contém a combinação entre os parâmetros. Através do plano é possível estabelecer, a partir da relação de dois parâmetros o valor desejado para o terceiro parâmetro.

As inter-relações dos os parâmetros podem ser usadas para:

- Facilitar a operação do sistema de ar condicionado. A condição desejada no ambiente pode ser resultante de diversas combinações dos parâmetros de operação. A estratégia proposta possibilita a determinação das combinações possíveis, de modo rápido e eficaz;

- Determinar estratégias de controle do sistema de ar condicionado;

- Fornecer ao projetista do sistema de ar condicionado uma ferramenta que facilite a tomada de decisões de projeto.

O desenvolvimento e a verificação da estratégia se basearam em um teste realizado em uma câmara experimental com características semelhantes à de um ambiente de escritório, com o sistema de distribuição de ar pelo piso. No referido teste, foram medidos os valores de velocidade e temperatura do ar, próximos a um difusor de piso. As condições do ambiente durante a medição são consideradas ideais, ou seja, são as condições que se deseja manter no ambiente. A partir dessa condição ideal, a estratégia proposta auxilia o estabelecimento de possíveis parâmetros de operação para que as condições resultantes no ambiente sejam satisfeitas.

\subsection{REVISÃO LITERÁRIA}

\subsubsection{SISTEMAS DE DISTRIBUIÇÃO DE AR PELO PISO}

O sistema de distribuição de ar pelo piso foi introduzido pela primeira vez na década de 1950, na Europa, em salas com elevada carga térmica, como centros de processamento de dados, salas de controle e laboratórios. Na década de 1970 o sistema passou a ser utilizado também em ambientes de escritórios (SODEC e CRAIG, 1990), como uma alternativa para o resfriamento do ar no interior de ambientes, já que houve significativo aumento da carga térmica interna (equipamentos de escritórios e aumento da densidade de usuários nos ambientes de escritórios). 
$\mathrm{Na}$ década de 1980, fatores como o aumento da poluição do ar e a crescente preocupação com o uso racional da energia impulsionaram o emprego do sistema UFAD, porém, ainda restrito a países Europeus, Japão e África do Sul. Esses fatores incentivaram o desenvolvimento de pesquisas para avaliar se as condições térmicas resultantes no interior dos ambientes com este tipo de distribuição de ar de fato promoveriam condições de conforto térmico e qualidade do ar satisfatórios para os usuários desses ambientes.

Na América do Norte, o processo tem sido mais lento devido à resistência ao uso de uma nova tecnologia, à falta de informação objetiva e à padronização de diretrizes de projeto (BAUMAN e WEBSTER, 2001); fato que se repete no Brasil. Nos Estados Unidos, por exemplo, somente na década de 1990, houve um crescimento mais expressivo do interesse por essa tecnologia, em virtude dos benefícios que esse sistema oferece em relação aos sistemas convencionais com a distribuição de ar resfriado através de difusores localizados no teto (BAUMAN e WEBSTER, 2001).

Embora existam diversos resultados de pesquisas feitas para comprovar seu real desempenho, como por exemplo, os de Tuddenham (1986), Genter (1989), Arnold (1990), Hanzawa e Nagasawa (1990), Heinemeier et al. (1990), Sodec e Craig (1990), Spoormaker (1990), Shute (1992 e 1995), Faulkner et al. (1995), Matsunawa et al. (1995), McCarry (1995), Loudermilk (1999), Bauman e Webster (2001), Bielli (2002), Daly (2002), Webster et al. (2002a e 2002b), Bauman (2003), Leite e Tribess (2001, 2002a, 2002b e 2006), Leite (2003), Leite et al. (2003), Loudermilk (2003), Corgnati e Perino (2004), o sistema ainda é pouco conhecido e utilizado no Brasil.

Diversos estudos foram realizados para apresentar uma descrição geral do sistema, com o objetivo de divulgação desta nova tecnologia, como os de Genter (1989), Heinemeier et al. (1990) e Sodec e Craig (1990), Addison e Nall (2001), Bauman e Webster (2001); Daly (2002); Bauman (2003); Energy Design Resources (2004).

Tuddenham (1986), Arnold (1990), Spoormaker (1990), Shute (1992, 1995), Matsunawa et al. (1995) e McCarry (1995) apresentam estudos de caso que tratam de sua experiência adquirida com o projeto, instalação e avaliação pós-ocupação de edifícios com o sistema de distribuição de ar pelo piso. Esses trabalhos têm como 
objetivo principal expor aos demais pesquisadores as dificuldades encontradas e apresentar recomendações para projetos futuros.

A partir da década de 1990 houve um expressivo aumento do número de pesquisas sobre o sistema de distribuição de ar pelo piso. Tratam-se de pesquisas realizadas em câmaras experimentais, com ou sem a presença de ocupantes, estudos de caso em edifícios ocupados e, mais recentemente, simulações numéricas do escoamento do ar no interior de ambientes para avaliar, principalmente, o desempenho dos sistemas UFAD com relação à promoção de condições de conforto térmico, eficiência energética e qualidade do ar no interior de ambientes.

Akimoto et al. (1995) estudaram o perfil da estratificação do ar em um laboratório com sistema UFAD, relacionando a estratificação do ar com o sistema de iluminação artificial, a ocupação, a carga térmica dos equipamentos e a interferência causada pelas pessoas circulando no espaço. Os resultados da pesquisa confirmaram a existência de duas zonas de estratificação do ar, e uma pequena interferência na turbulência do ar, quando as pessoas estão circulando, mas que não interfere na estratificação do volume de ar. Constatou-se que o aumento do número de trocas de ar por hora no ambiente causou o aumento da altura da linha de estratificação do ar. Paralelamente, estudaram o perfil da distribuição do fluxo de ar, a qualidade do ar e a eficiência da ventilação no ambiente. Para tanto, consideraram uma taxa de 6 trocas de volume de ar por hora. Houve uma pequena melhoria da qualidade do ar no interior, se comparada a sistemas convencionais de insuflação de ar pelo teto.

Bauman et al. (1995) estudaram os efeitos do volume e da temperatura do ar insuflado, da direção de insuflação e das fontes de calor em um ambiente de escritório com um manequim térmico. Os pesquisadores constataram que, sob baixas velocidades de insuflação do ar, o sistema UFAD se assemelha ao sistema de ventilação por deslocamento. Além disso, concluíram que a altura da linha de estratificação depende da vazão de ar e da carga térmica interna, devendo, preferencialmente, ser mantida acima da zona de respiração.

Bauman et al. (1999) realizam experimentos para verificar o impacto que a altura do plenum, o número de difusores no piso e as obstruções existentes no interior do plenum causam na distribuição do ar no interior do ambiente. Os autores 
concluíram que o plenum pressurizado deve ter no mínimo $180 \mathrm{~mm}$ de altura livre (acima das obstruções, como cabos e dutos), e o ponto de insuflação de ar frio não pode ultrapassar a distância de $24 \mathrm{~m}$ de todas as paredes limítrofes do plenum, para que a distribuição do ar no interior do mesmo seja uniforme. A redução de $50 \%$ de difusores de ar no piso não provocou alterações significativas no escoamento do ar no interior do ambiente. O impacto das obstruções existentes no interior do plenum (cabos, estrutura do piso elevado, etc.) na distribuição de ar no mesmo é mais significativo à medida que a altura livre diminui.

Leite et al. (2000) apresentam em seu trabalho uma avaliação pós-ocupação de um edifício de escritórios que havia passado por um retrofit, tendo o seu sistema de distribuição de ar sido modificado para o sistema UFAD. Foram identificados alguns problemas, relacionados, principalmente à não compatibilização entre o projeto e a instalação, como a não adequação entre a distribuição dos difusores no piso e as alterações no layout de mobiliário. Assim, 43\% dos ocupantes sentiram-se insatisfeitos com as condições térmicas resultantes. Os autores alertam para o fato da necessidade de informar aos usuários sobre as possibilidades de alterar a posição dos difusores e de ajustar a vazão de ar insuflado.

Kim et al. (2001) descrevem o desenvolvimento de um novo difusor de ar de piso. O tipo de difusor mais comum em sistemas UFAD é "swirl" (jato espiralado), que tem como característica promover a troca de calor rápida entre o ar insuflado e o ar do ambiente. Os pesquisadores apresentam o difusor desenvolvido, que possibilita o ajuste dos componentes internos, de modo a controlar a vazão e o ângulo de descarga do fluxo de ar introduzido no interior do ambiente.

Webster et al. (2002a e 2002b) estudam o impacto da vazão e da temperatura do ar insuflado na estratificação do ar em ambientes com o sistema de distribuição de ar pelo piso instalado e carga térmica constante. Os resultados indicam que nos casos de baixa vazão de ar insuflado, há elevada estratificação do ar no interior do ambiente. A variação da temperatura de insuflação do ar resulta na mudança da altura de estratificação, para cima ou para baixo.

Em 2003, Bauman (2003) publica o livro "Underfloor Air Distribution (UFAD) - Design Guide" discutindo os principais aspectos do projeto, instalação e operação do sistema. O autor apresenta também uma síntese dos principais estudos realizados até o momento sobre o sistema em questão, citando inclusive os 
aspectos que ainda precisam ser pesquisados, tais como a possibilidade de condensação do ar no interior do plenum, estabelecimento de normas e diretrizes para projeto, instalação e operação do sistema, avaliação do custo-benefício para implantação do sistema, incorporando custos associados ao ciclo de vida das edificações, dentre outros.

Loudermilk (2003) apresenta um estudo sobre o projeto de sistemas de distribuição de ar pelo piso, enfatizando os cuidados que devem ser adotados na distribuição dos difusores em áreas perimetrais e áreas internas do ambiente, devido às diferenças na carga térmica existente nas diferentes zonas do ambiente.

Chae et al. (2004) comparam o desempenho do sistema de distribuição de ar pelo piso com o sistema de distribuição convencional para avaliar as condições de conforto térmico, eficiência da ventilação e consumo energético de ambos os sistemas. Medições experimentais foram realizadas em uma câmara experimental dotada de mobiliário de escritório e fontes de calor (computadores e pessoas). Os resultados indicam que o número de ocupantes insatisfeitos com a condição térmica interna é um pouco menor sob condições de insuflação de ar frio pelo teto, mas o sistema de distribuição de ar pelo piso fornece maior potencial para economia de energia.

Chao e Wan (2004) realizaram teste experimental em uma câmara semelhante a um escritório com o sistema de distribuição de ar pelo piso instalado. $\mathrm{Na}$ câmara, os difusores de ar e as grelhas de retorno foram instalados no piso. Os resultados indicam que a locação das grelhas de retorno têm impacto fundamental na distribuição de ar interno e, dependendo da sua posição podem resultar em áreas de ar estagnado.

Chou et al. (2004) realizam medições experimentais e simulações numéricas para comparar os sistemas de distribuição de ar pelo piso e os sistemas convencionais. Os resultados indicam que o sistema de distribuição de ar pelo piso apresenta menor consumo energético, além de promover melhor qualidade do ar no interior dos ambientes.

Linden et al. (2004) estudam o fluxo do ar no interior do plenum. Os resultados dos experimentos indicam que o fluxo de ar assume um comportamento bidimensional que não varia com a altura do plenum, mas é determinado pela posição da entrada de ar. 
Wan e Chao (2005) realizaram experimentos e simulações numéricas para estudar a estratificação térmica de ambientes com o sistema de distribuição de ar pelo piso, com fontes de calor. Os testes foram realizados para insuflação de ar por difusores no piso e retorno pelo teto e pelo piso.

Xu e Niu (2005) estudam a possibilidade de economia de gastos energéticos de sistemas de distribuição de ar pelo piso devido à diminuição da carga térmica que deve ser incluída no cálculo do sistema de resfriamento do ar, devido a estratificação térmica e à diminuição do volume de ar a ser resfriado.

Zukowsky (2005) apresenta uma fórmula para determinar um valor mínimo recomendado para a velocidade do ar insuflado para sistemas de distribuição de ar pelo piso que operam para aquecimento.

Do exposto anteriormente, é possível concluir que diversas pesquisas foram realizadas, para avaliar as principais características dos sistemas UFAD, tais como a estratificação do ar interno, comportamento do ar no interior do plenum, difusores de ar e eficiência energética.

Destacam-se também trabalhos relacionados à promoção de condições de conforto térmico no interior de ambientes com o sistema de distribuição de ar frio pelo piso.

Hanzawa e Nagasawa (1990) descrevem o experimento realizado em uma câmara de testes similar a um escritório, inclusive com a presença de usuários. A pesquisa tinha por objetivo o estabelecimento de parâmetros de uso para garantir condições de conforto aos usuários, sem causar desconforto local provocado por correntes de ar. Os resultados mostraram que para as condições empregadas o sistema oferece risco de formação de correntes de ar. Embora mais da metade das pessoas tenha classificado a presença de movimento de ar como satisfatória, 15\% dos ocupantes a classificaram como correntes de ar.

Bauman et al. (1991) realizaram um estudo em uma câmara de testes similar a um ambiente de escritório. Nela foram medidos os gradientes de temperatura do ar em duas estações de trabalho adjacentes. As medições resultaram em diferenças da ordem de $1^{\circ} \mathrm{C}$ a $2,5^{\circ} \mathrm{C}$ entre as estações. Como as condições de insuflação de ar para as duas estações de trabalho eram similares, os pesquisadores concluíram que a posição dos difusores no piso com relação ao mobiliário tinha interferido na condição térmica resultante, ou seja, a distribuição dos difusores no piso é fundamental para a condição térmica resultante no ambiente. Os autores também 
avaliaram o sistema de controle individual proporcionado pelo difusor de ar empregado na câmara experimental. Trata-se de um difusor dotado de quatro grelhas que possibilitam o ajuste da direção do jato de ar. Os autores concluíram que o difusor de ar empregado permite que os ocupantes tenham o controle sobre a vazão e a direção do ar insuflado, possibilitando assim o controle das condições térmicas de acordo com as suas preferências individuais.

Matsunawa et al. (1995) realizaram experimentos e simulações numéricas durante a fase de projeto para avaliar as condições de conforto térmico resultantes da instalação de um sistema de distribuição de ar pelo piso em um edifício inteligente (Smart Building). Após o término da obra, procedeu-se a avaliação pósocupação, com a realização de medições dos gradientes de velocidade e temperatura do ar. Foi identificada uma zona de desconforto causada pela turbulência do ar sobre o difusor até um raio de 0,80m em torno dele, na qual não se recomenda a permanência de pessoas durante longos períodos. As medições dos campos de velocidade do ar a partir de um raio de 0,70m ao redor do difusor resultaram em valores da ordem de $0,20 \mathrm{~m} / \mathrm{s}$, o que indica a não formação de correntes de ar. A diferença de temperatura entre a altura da cabeça do tornozelo medida em laboratório foi de $2,5^{\circ} \mathrm{C}$. Já no ambiente ocupado a diferença foi de apenas $1,3^{\circ} \mathrm{C}$. Os pesquisadores também avaliaram o grau de satisfação dos usuários. Alguns ocupantes relataram a sensação de correntes de ar no nível dos pés, devido à proximidade aos difusores ou à falta de ajuste da vazão de ajuste dos mesmos. Segundo os autores, o desempenho do sistema foi satisfatório, e as condições de conforto térmico foram alcançadas. No entanto, alertam para a necessidade de desenvolvimento de um maior número de pesquisas para promover a melhoria do sistema, já que alguns ocupantes relataram sentir desconforto local.

Sekhar e Ching (2002) avaliaram as condições de conforto térmico e qualidade do ar em um escritório com o sistema de distribuição de ar pelo piso. Os resultados indicam que níveis aceitáveis de qualidade do ar no interior do ambiente foram encontrados. Os pesquisadores identificaram uma forte correlação entre a velocidade do ar e outras variáveis, tais como temperatura do ar, umidade, PMV e PPD, concluindo que, a menos que os ocupantes do local estejam sentados longe dos difusores de ar no piso, o desconforto térmico localizado é inevitável devido à 
sensação de resfriamento indesejado no nível dos pés, causado pelas correntes de ar.

Leite (2003) avaliou o sistema de distribuição de ar pelo piso em uma câmara experimental projetada com características similares às de um escritório real e contou com a participação de usuários no processo de pesquisa. Além do sistema de distribuição de ar pelo piso, a pesquisadora avaliou o sistema de ventilação de tarefa, que permite o controle individual das condições térmicas. A pesquisadora definiu parâmetros para a elaboração de projetos e para a operação do sistema e concluiu que, se operado corretamente, o sistema promove melhorias nas condições de conforto térmico e eficiência energética, se comparado aos sistemas convencionais de distribuição de ar.

Nakamura e Fujikawa (2004) realizaram teste experimental com a presença de pessoas para estudar as condições térmicas resultantes em um ambiente com 0 sistema de distribuição de ar pelo piso associado ao sistema de ventilação de tarefa. No teste, os usuários tinham a possibilidade de controlar a vazão e a direção do jato de ar dos difusores. Os resultados indicaram que a maioria dos usuários considerou a condição térmica confortável devido à possibilidade do ajuste da direção do jato de ar.

A maior parte das pesquisas comprova a eficácia do sistema e os resultados indicam que, se o projeto e a instalação contemplam os conceitos adequados, a sua aplicação é a mais apropriada para atender aos requisitos de conforto para ambientes flexíveis.

Além do conforto térmico também a qualidade do ar no interior dos ambientes tem sido tema freqüente de pesquisas sobre o sistema de distribuição de ar frio pelo piso. Pelo fato da insuflação de ar ser dada por difusores localizados no piso, há grande preocupação com a possibilidade de suspensão da poeira localizada no piso do ambiente pelo jato de ar do difusor.

Kim e Homma (1992a; 1992b) realizaram experimento em uma câmara de testes com a presença de usuários, com o objetivo de levantar um método de ventilação que resultasse na melhoria da qualidade do ar interno com uso eficiente de energia. Os resultados indicaram que, caso os ocupantes sejam a única fonte de $\mathrm{CO}_{2}$, a taxa de ventilação deve ser de, no mínimo, 5,6 L/s de ar insuflado por pessoa, garantindo-se assim a manutenção da concentração de $\mathrm{CO}_{2}$ em até 
1000ppm na zona de respiração. Os pesquisadores concluíram que a temperatura de insuflação não deve ser maior do que a temperatura da sala, para manter a concentração de $\mathrm{CO}_{2}$ abaixo da zona de respiração, ou seja, o sistema de distribuição de ar pelo piso não é indicado para aquecimento. Kim e Homma (1992b) também relataram que a eficiência da ventilação para a retirada de contaminantes em um sistema UFAD chega a ser duas vezes maior que a de um sistema convencional, com distribuição de ar pelo teto.

Fukao et al. (2002) comparam dois ambientes semelhantes, porém um com sistema de distribuição de ar pelo piso e outro com sistema de distribuição de ar pelo teto, avaliando o desempenho térmico e qualidade do ar, em um edifício existente e ocupado. Os resultados mostraram que as medições físicas foram praticamente similares nas duas áreas, embora os pesquisadores tenham notado uma menor concentração de partículas em suspensão no ambiente com sistema UFAD. Os ocupantes (aproximadamente 35 em cada área) da área com UFAD relataram não sentir a presença de poluição (82\% de satisfação), resultado um pouco superior se comparado aos ocupantes da área com sistema convencional (70\% de satisfação). Com relação à qualidade do ar no interior, os resultados foram semelhantes $(84 \% \mathrm{e}$ $72 \%)$. Contudo, ambos os sistemas mostraram baixos níveis de concentração de poluentes, com um grau de satisfação elevado para os dois sistemas. Medidas da eficiência da ventilação na renovação de ar mostraram que o desempenho da ventilação UFAD foi melhor que o de teto.

Shute (1995) apresenta o resultado de quatro anos de observação de um edifício em Toronto com o sistema UFAD. No entanto, as medições para análise da quantidade de partículas em suspensão revelaram que os valores apresentados são similares aos dos valores médios de edifícios com sistema convencional de insuflação de ar pelo teto. O mesmo resultado foi atingido por Fisk et al. (2004) que também avaliaram um edifício com sistema UFAD. Os resultados apresentados por Fisk et al. (2004) indicaram que a eficiência da ventilação para a renovação do ar foi similar à de um edifício com sistema convencional de insuflação pelo teto.

Faulkner et al. (1995) compararam a eficiência da ventilação para a renovação de ar entre o sistema de distribuição de ar pelo piso e o sistema convencional de distribuição de ar pelo teto em uma câmara experimental similar a um escritório. Os resultados da pesquisa mostram que o sistema de distribuição de 
ar pelo piso apresentou melhor eficiência da ventilação já que a idade do ar na zona de respiração foi de cerca de 20 a 40\% menor que a idade do ar que ocorreria com o sistema de distribuição convencional de ar frio. Os pesquisadores ainda verificaram o impacto de uma fonte geradora de poluição (fumaça de cigarro) nas demais estações de trabalho e comprovaram que as estações de trabalho adjacentes à fonte poluidora também são atingidas pela fumaça. Os dados de concentração de partículas de fumaça mostraram uma redução de 10\%, no nível de respiração, se comparados ao sistema convencional de mistura. Contudo, em diversos testes, a idade do ar na zona de respiração foi considerada aproximadamente igual à idade que ocorreria para uma sala com sistema convencional (mistura total).

$\mathrm{O}$ efeito da redução das taxas de $\mathrm{CO}_{2}$ no ambiente também foi relatado por Corgnati e Perino (2004), em estudo realizado em um edifício de escritórios com sistema UFAD. Os resultados mostraram que a concentração de $\mathrm{CO}_{2}$ se manteve abaixo do valor limite $\left(\Delta \mathrm{CO}_{2} \leq 700 \mathrm{ppm}\right)$ em todos os espaços medidos, e as taxas de troca do ar foram consideradas totalmente satisfeitas.

Com relação à qualidade do ar, até o momento, as pesquisas têm mostrado que os sistemas UFAD apresentam apenas uma pequena melhoria do nível de concentração de poluentes, se comparado aos sistemas convencionais de distribuição de ar pelo teto que promovem a mistura do ar interno.

Do exposto acima, é possível perceber que esforços estão sendo feitos para esclarecer as principais questões do sistema de distribuição de ar pelo piso. A maior parte das pesquisas realizadas trata da avaliação do desempenho do sistema, principalmente com relação às condições de conforto térmico resultantes no interior dos ambientes.

Dentre os demais temas estudados, merecem destaque: a qualidade do ar interno, o comportamento do escoamento do ar em ambientes com fontes de calor e a estratificação térmica resultante no interior dos ambientes, o potencial de economia de energia do sistema, comparações entre o desempenho dos sistemas de distribuição de ar pelo piso e o sistema convencional de distribuição de ar pelo teto.

Entretanto, diversos pontos ainda precisam ser esclarecidos. Não existem, por exemplo, diretrizes de projeto padronizadas para a distribuição dos difusores no piso, considerando a influência do mobiliário e das fontes de calor (pessoas e 
equipamentos de escritório), bem como a diversidade de tipos de difusores de ar que resultam em diferentes comportamentos do fluxo de ar.

Também merecem atenção temas como: o impacto da transferência de calor entre zonas adjacentes, o efeito do tipo do difusor de ar no consumo de energia final, o potencial de economia de energia em edificações no Brasil, estudos sobre a transferência de calor na laje de edifícios e a possibilidade de economia de energia pelo armazenamento térmico da laje, a localização do ponto ótimo de entrada de ar frio no interior do plenum, transferência de calor das placas de piso elevado para o interior do ambiente, viabilidade econômica do sistema, que geralmente apresenta maior custo de instalação inicial, porém redução de custos para reconfiguração espacial e consumo energético.

No entanto, o maior entrave para a disseminação desta tecnologia é a falta de normas específicas e de diretrizes de projeto que orientem instaladores no projeto do sistema.

\subsubsection{SIMULAÇÃO NUMÉRICA DO ESCOAMENTO DO AR EM SISTEMAS DE DISTRIBUIÇÃO DE AR PELO PISO}

Diversos estudos foram conduzidos para avaliar o escoamento do ar em ambientes ventilados mecanicamente, utilizando recursos de CFD, como os de Murakami et al. (1989), Chen et al. (1995), Gan (1995), Matsunawa et al. (1995), Loomans (1998 e 1999), Rosa (2001), Zeng et al. (2001), Collignan et al. (2002), Tibaut e Wiesler (2002), Posner et al. (2003), Zhao et al (2003), Teodosiu et al. (2003), Abanto et al. (2004), Gao e Niu (2004), Matsumoto et al. (2004), Nielsen (2004), Lin et al. (2005a, 2005b).

Os recursos de CFD também têm sido empregados para estudar o comportamento do escoamento do ar em sistemas de distribuição de ar pelo piso.

Murakami et al. (1992) realizaram simulações numéricas para avaliar a eficiência da ventilação do sistema de distribuição de ar pelo piso em uma sala com elevada carga térmica. Os resultados das simulações numéricas apresentaram diferenças com relação às medições experimentais, da ordem de $10 \%$ para a velocidade do ar insuflado e, de $20 \%$ para a temperatura, considerados de boa concordância pelos pesquisadores. 
Matsunawa et al. (1995) realizaram simulações numéricas para pré-estimar as condições de conforto térmico de um sistema de distribuição de ar condicionado pelo piso em um edifício de escritórios.

De Carli et al. (2000) realizaram simulações numéricas de ambientes com o sistema de distribuição de ar pelo piso simulando condições reais de uso e operação, para comparação dos resultados das simulações com os resultados das medições experimentais.

Xu e Niu (2003) utilizaram técnicas de CFD para estudar a caracterização dos difusores de piso do tipo swirl para a realização de simulações numéricas mais precisas e confiáveis.

Lin e Linden (2005) utilizaram uma ferramenta de CFD para testar modelos teóricos para a correta predição do escoamento do ar em salas com o sistema de distribuição de ar pelo piso. Os pesquisadores utilizaram simulações numéricas para examinar os efeitos da variação dos três parâmetros do sistema: o fluxo convectivo das fontes internas de calor, a vazão de ar insuflado e o fluxo do momento do difusor de ar.

Pustelnik (2005) realizou simulação numérica de um ambiente com distribuição de ar pelo piso, e comparou os resultados da simulação com dados de medições experimentais. O estudo contribuiu especialmente na indicação do modelo de turbulência a ser empregado em problemas de escoamento de ar em sistemas de distribuição de ar pelo piso, já que o autor comparou diversos modelos.

Wan e Chao (2005) avaliaram a distribuição do perfil de escoamento do ar em um ambiente com distribuição de ar pelo piso, com retorno ora pelo piso, ora pelo teto. Os resultados das simulações numéricas foram comparados com resultados de medições experimentais, com boa concordância entre os valores, o que, segundo os autores, indica que a ferramenta pode ser usada para predição do desempenho do sistema.

Xu e Niu (2004) usam uma ferramenta de dinâmica de fluidos computacional para comparar dois tipos de difusores de piso: o difusor quadrado do tipo jet air (jato de ar na direção das aletas que compõem a grelha do difusor), com quatro grelhas ajustáveis, e o difusor do tipo swirl (jato de ar espiralado). Os resultados das simulações indicaram que ambos os difusores são adequados para manter a estratificação do ar na sala. Porém, no caso dos difusores do tipo swirl, a mistura do 
ar insuflado com o ar da sala é mais rápida, resultando em uma menor diferença de temperatura entre os níveis dos pés e da cabeça.

Zukowski (2005) apresentou o estudo de uma nova fórmula para determinar um valor mínimo recomendado para a velocidade de insuflação de ar para aquecimento através dos difusores de ar de um sistema de distribuição de ar pelo piso, localizados próximos às janelas, utilizando, para tanto, uma ferramenta de CFD.

Nota-se que ainda há poucos estudos sobre o sistema de distribuição de ar pelo piso que utilizam como ferramenta de trabalho as simulações numéricas. Esse fato se deve à dificuldade de obtenção de dados detalhados provenientes de experimentos, já que os resultados das simulações numéricas necessariamente devem ser confrontados com dados experimentais. Erros na definição das condições de contorno, no estabelecimento das propriedades físicas dos materiais, na escolha do modelo de turbulência e os próprios erros numéricos resultantes da má solução das equações diferenciais parciais da ferramenta podem fornecer dados incorretos, que não correspondem, absolutamente, ao fenômeno físico real.

O uso das ferramentas de CFD, no geral, tem sido recomendado por pesquisadores, para o estudo do escoamento do ar e como ferramenta de projeto, principalmente com o aumento da capacidade computacional resultante de avanços tecnológicos que viabilizam a realização das simulações para um maior grupo de pesquisadores.

\subsection{ESCOPO DO TRABALHO}

O capítulo 1 deste trabalho apresenta a justificativa para a realização do presente estudo, abordando a falta de informações sobre o sistema de distribuição de ar pelo piso e o potencial de uso de ferramentas de dinâmica dos fluidos computacional no estudo do escoamento do ar no interior de ambientes. A revisão literária contempla os dois principais temas em estudo: o sistema de distribuição de ar pelo piso e as simulações numéricas do escoamento do ar em ambientes com o sistema de distribuição de ar pelo piso.

O capítulo 2 trata do sistema de distribuição de ar pelo piso, apresentando as características específicas do escoamento do ar em ambientes com o sistema instalado. 
No capítulo 3 apresenta-se a câmara experimental desenvolvida por Leite (2003), bem como a descrição do teste experimental realizado por Leite (2004).

O capítulo 4 apresenta a fundamentação teórica para a realização das simulações numéricas que serviram de base para a determinação da estratégia proposta, com a apresentação das equações governantes, dos modelos de turbulência empregados e dos parâmetros característicos do escoamento do ar em ambientes com o sistema de distribuição de ar pelo piso. Também são apresentadas as ferramentas utilizadas para a simulação numérica.

O capítulo 5 descreve a estratégia desenvolvida para o estabelecimento dos parâmetros de operação de sistemas de distribuição de ar pelo piso.

O capítulo 6 apresenta a verificação da estratégia proposta, com a descrição dos procedimentos adotados para a realização das etapas que compõem a estratégia.

No capítulo 7 são apresentadas considerações adicionais sobre 0 comportamento do escoamento do ar resultante da simulação numérica, bem como os resultados da adoção de diferentes modelos de densidade do ar, já que nos sistemas de distribuição de ar pelo piso a densidade exerce influência fundamental no comportamento do fluxo de ar. O capítulo 8 contém as considerações finais e algumas sugestões de trabalhos futuros. 


\section{SISTEMA DE DISTRIBUIÇÃO DE AR PELO PISO}

Nos sistemas convencionais de distribuição de ar, o ar frio é distribuído por meio de uma rede de dutos, cujas terminações são os difusores de ar localizados no forro dos ambientes. $\mathrm{O}$ ar sai dos difusores a uma determinada velocidade e com baixa temperatura sendo então misturado com o ar ambiente até que se atinja a temperatura considerada de conforto. Neste sistema, não há possibilidade de atender às preferências individuais de conforto térmico dos ocupantes do ambiente (Figura 2.1).

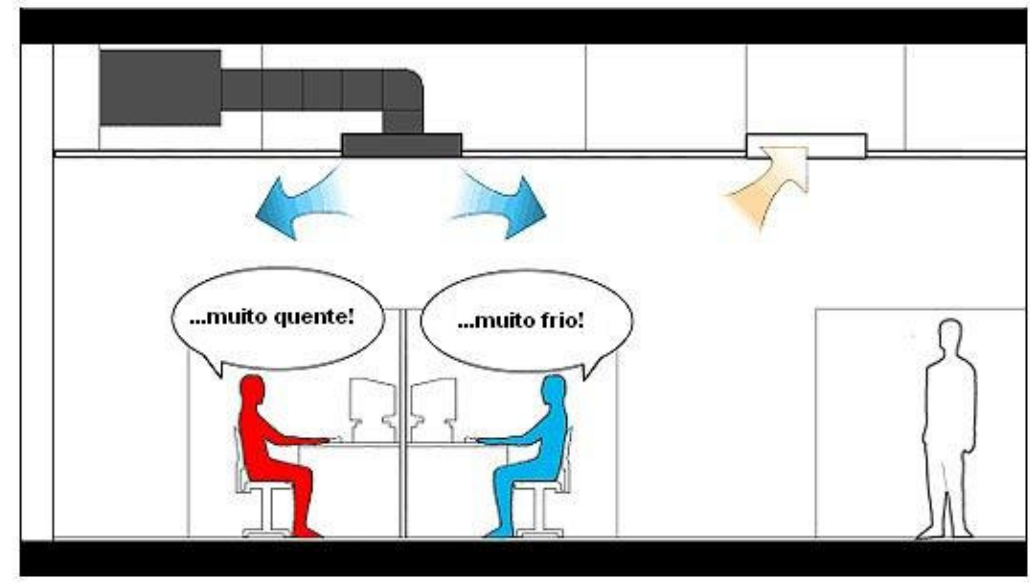

Figura 2.1 - Sistema convencional de distribuição de ar (FONTE: http://www.cbe.berkeley.edu/underfloorair/thermalcomfort.htm)

Nos sistemas de distribuição de ar convencionais, as velocidades de insuflação são elevadas para que haja uma rápida mistura do ar insuflado com o ar do ambiente possibilitando que a temperatura do ar insuflado se aproxime rapidamente da temperatura do ar ambiente.

Neste sistema há mistura total do ar insuflado com o ar ambiente (Figura 2.2) e todo o volume de ar no espaço ocupado é mantido à uma determinada temperatura (setpoint), impossibilitando que preferências individuais de conforto térmico sejam atendidas. Essa mistura promove a diluição dos poluentes em todo o espaço. 


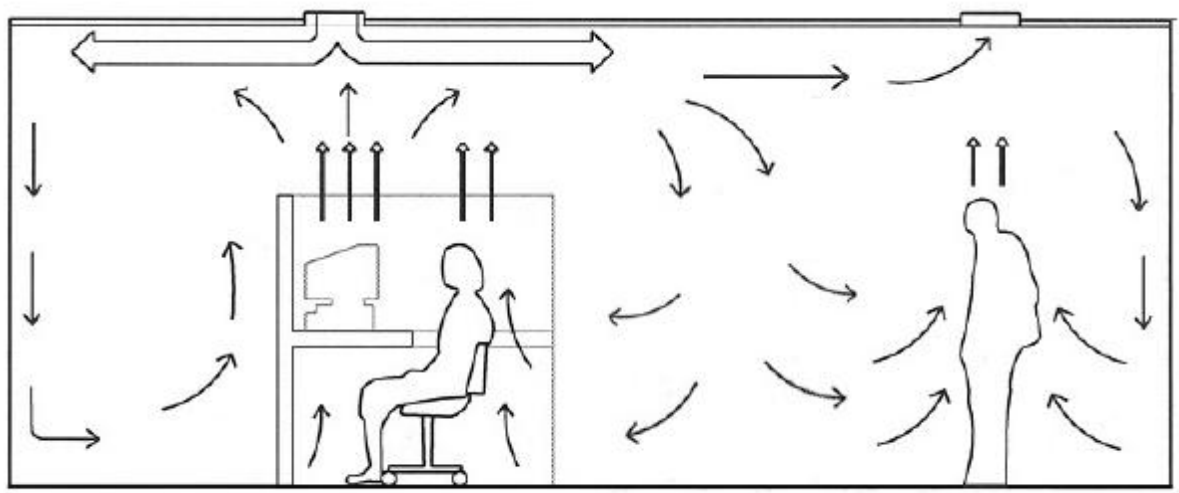

Figura 2.2 - Esquema do escoamento do ar no interior de um ambiente com o sistema de distribuição de ar convencional (FONTE: BAUMAN, 2003)

O sistema de distribuição de ar frio pelo piso é caracterizado pela introdução de ar resfriado no ambiente através de difusores de ar localizados no piso (Figura 2.3). Os equipamentos usados para refrigeração do ar são os mesmos dos sistemas convencionais de distribuição de ar pelo teto (BAUMAN, 2003). No entanto, nos sistemas de distribuição de ar pelo piso o ar frio que sai da unidade primária de resfriamento do ar (Air-handling Unit) é introduzido no plenum do piso do ambiente.

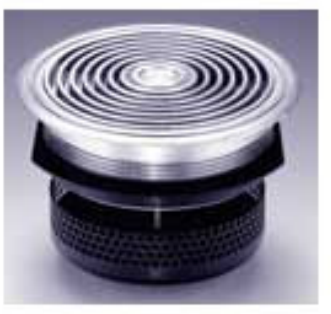

Figura 2.3 - Exemplo de difusor do tipo "swirl" (Jato espiralado) (FONTE: http://www.trox.es)

O plenum do piso é o espaço entre a laje de concreto do pavimento e os painéis do piso elevado (Figura 2.4), geralmente com cerca de 30 a $45 \mathrm{~cm}$ de altura.

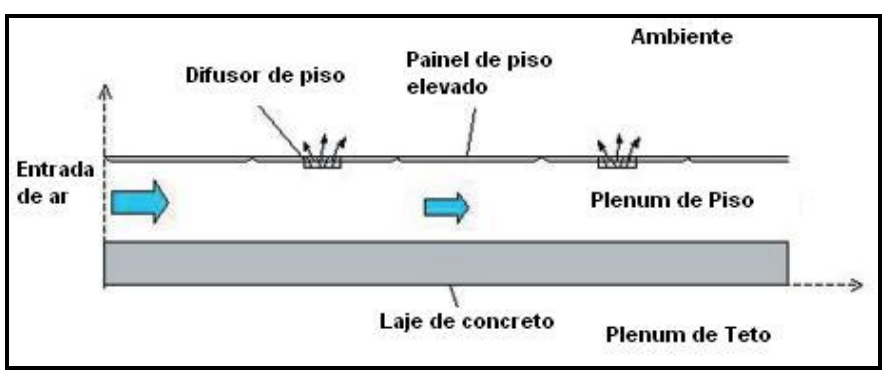

Figura 2.4 - Plenum do piso (FONTE:

http://www.cbe.berkeley.edu/underfloorair/thermalcomfort.htm) 
Segundo Leite (2003) os sistemas de distribuição de ar pelo piso variam entre si quanto à pressão de ar no plenum em relação ao ambiente, ao modo de insuflamento de ar frio pela unidade primária, ao grau de centralização de equipamentos, ao método de controle do sistema e à localização e natureza dos equipamentos terminais.

A pressão de ar no plenum pode seguir três critérios (BAUMAN, 2003): (1) plenum pressurizado (sistema com pressão positiva) recebendo ar de uma unidade primária de resfriamento e introduzindo ar condicionado no ambiente através de difusores de ar passivos; (2) plenum de pressão zero, com insuflação de ar no interior do ambiente através de difusores ativos (com ventiladores acoplados); e (3) em alguns casos, similarmente aos sistemas convencionais, dutos com terminais (difusores de ar) são instalados no interior do plenum para distribuição do ar. Segundo Leite (2003), o sistema dutado não é muito utilizado, já que limita a flexibilidade na mudança de layout, uma das principais características do sistema de distribuição de ar pelo piso.

Nos dois primeiros casos (plenum com pressão positiva e plenum com pressão zero), o ar entra em contato direto com a laje e é introduzido no ambiente através dos difusores de ar no piso.

Como os difusores de piso estão próximos aos ocupantes, o ar é insuflado a baixas velocidades e a temperatura de insuflação é mais elevada do que a dos sistemas convencionais de insuflação pelo teto, para evitar o desconforto local. Além disso, os difusores localizados dentro das estações de trabalho, geralmente são ajustáveis, fornecendo a oportunidade de controle pelos usuários (Figura 2.5).

Ao contrário dos sistemas convencionais que promovem a mistura completa do ar interior, nos sistemas de distribuição de ar pelo piso, há uma estratificação da temperatura do ar interno, com valores mais elevados e maior nível de poluentes acima da zona de respiração dos ocupantes (BAUMAN, 2003). 


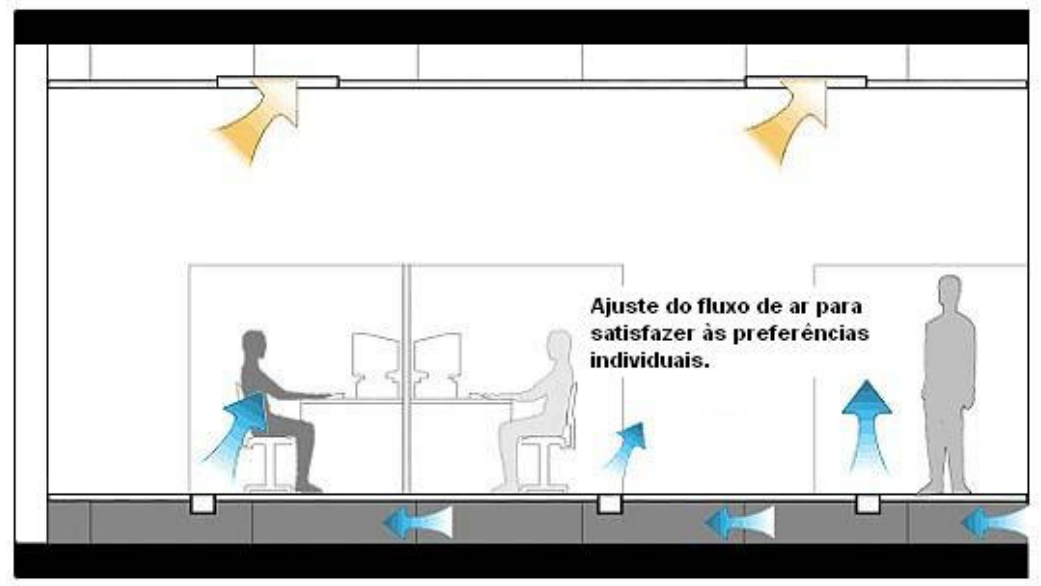

Figura 2.5 - Sistema de distribuição de ar pelo piso (FONTE: http://www.cbe.berkeley.edu/underfloorair/thermalcomfort.htm)

As velocidades de insuflação nos difusores são suficientes para realizar a mistura somente na zona ocupada e as cargas convectivas originadas dentro da região mais alta não se misturam com a massa de ar da zona ocupada. Como resultado, a carga de calor sensível na massa de ar ocupada é reduzida, o que permite a redução da vazão de ar de insuflação para efeitos de cálculos (ADDISON e NALL, 2001).

O ar insuflado no ambiente entra em contato com as fontes de calor internas (pessoas e equipamentos) e tem sua temperatura elevada. $\mathrm{O}$ ar aquecido sai do ambiente através de grelhas de retorno, geralmente localizadas no teto, resultando em um escoamento na direção "piso-teto", que tira vantagem da convecção natural. $\mathrm{O}$ ar de retorno entra no plenum superior formado entre o forro e a laje e pode voltar inteiramente à unidade primária (após ser filtrado e resfriado) para ser introduzido novamente no plenum do piso, ou pode ser dividido, com parte se direcionando até a unidade condicionadora e parte retornando a uma caixa de mistura para ser misturado ao ar primário oriundo daquela unidade (LEITE, 2003).

Os sistemas de distribuição de ar pelo piso, sob baixas velocidades de ar insuflado, podem apresentar um comportamento semelhante aos de ventilação por deslocamento (Displacement Ventilation). Assim, são apresentadas a seguir, as características desses dois sistemas. 


\subsection{ESCOAMENTO DO AR EM SISTEMAS DE VENTILAÇÃO POR DESLOCAMENTO}

A distribuição do ar no sistema de ventilação por deslocamento pode se dar tanto pelo piso, de modo semelhante ao sistema de distribuição pelo piso, como por aberturas localizadas na parede, próximas ao nível do piso dos ambientes.

A principal diferença entre o sistema de ventilação por deslocamento e 0 sistema de distribuição de ar pelo piso é a maneira com a qual o ar é introduzido no espaço. No sistema de ventilação por deslocamento, o ar é introduzido a uma velocidade mais baixa que a dos sistemas de distribuição de ar pelo piso. Por apresentar uma temperatura mais baixa que a do ar do ambiente, o ar tende a descer e permanecer no nível do piso. Contudo, à medida que entra em contato com as fontes de calor, a temperatura do ar é elevada e sobe em direção ao teto, beneficiando-se da convecção natural e carregando as partículas em suspensão (Ver figura 2.6).

Esse comportamento ascendente do ar em ambientes com o sistema de ventilação por deslocamento cria uma estratificação da temperatura no interior dos ambientes, em duas camadas, divididas pelas altura de estratificação (Stratification Height - SH). A camada inferior contém o ar mais frio e a camada superior contém o ar aquecido e com maior quantidade de poluentes. A grande vantagem desse sistema é que o ar quente e mais poluído que sobe para a camada superior não retorna para a camada inferior devido à diferença na densidade do ar (o ar quente da camada superior é menos denso, tendendo a subir).

As plumas térmicas que se desenvolvem sobre as fontes de calor têm um papel fundamental em ambientes com o sistema de ventilação por deslocamento. $O$ ar ao redor das fontes de calor é aquecido e sobe por convecção natural, configurando o perfil de escoamento piso-teto. 


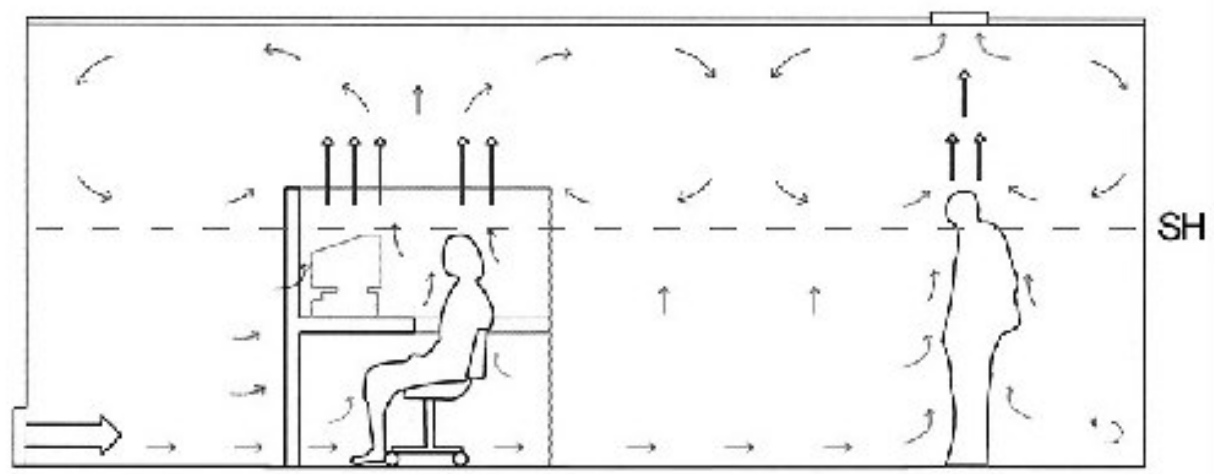

Figura 2.6 - Esquema do escoamento do ar no interior de um ambiente com o sistema de ventilação por deslocamento (FONTE: BAUMAN, 2003)

No caso do sistema de ventilação por deslocamento o piso elevado não é item obrigatório, já que o ar pode ser introduzido no ambiente através de aberturas na parede.

\subsection{ESCOAMENTO DO AR EM SISTEMAS DE DISTRIBUIÇÃO DE AR PELO PISO}

No caso do sistema de distribuição de ar pelo piso, o ar é insuflado a uma velocidade mais elevada do que a dos sistemas de ventilação por deslocamento, promovendo maior mistura do ar insuflado com o ar ambiente. Essa mistura do ar, causa o rápido aumento da temperatura do ar insuflado, reduzindo assim o gradiente de temperatura no interior do ambiente e resultando em maior uniformidade se comparado aos sistemas de ventilação por deslocamento.

$\mathrm{Na}$ camada superior, próxima ao teto, o comportamento do escoamento do ar é similar ao dos sistemas de ventilação por deslocamento.

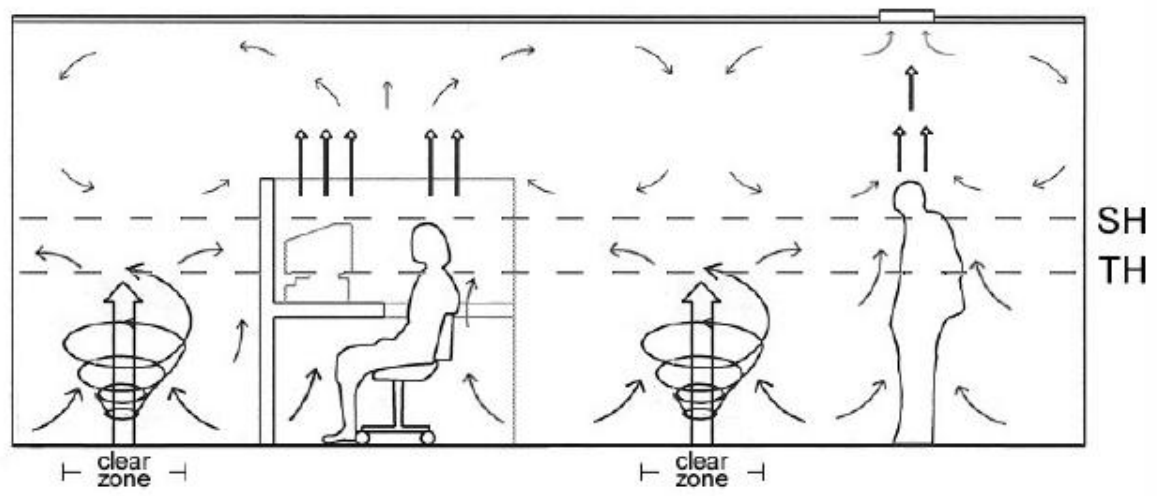

Figura 2.7 - Esquema do escoamento do ar no interior de um ambiente com o sistema de distribuição de ar pelo piso (FONTE: BAUMAN, 2003) 
A figura 2.7 é um esquema do escoamento do ar em ambientes com o sistema de distribuição de ar pelo piso. A figura mostra as três zonas que se formam no interior dos ambientes. A camada inferior vai do piso até à zona de influência superior do jato de ar que sai do difusor (Throw Height - TH). Esta camada caracteriza-se pela mistura do ar insuflado com o ar ambiente, e sua altura varia de acordo com o momento do jato de ar que sai do difusor, com a vazão de ar e com a carga térmica interna.

A camada intermediária é a transição entre as zonas inferior e superior. $O$ movimento do ar nessa zona depende das flutuações térmicas devido às fontes de calor. A zona intermediária só ocorre quando a altura do jato está abaixo da altura de estratificação.

A camada superior vai da altura de estratificação (Stratification Height $-\mathrm{SH}$ ) até o teto, e é similar aos sistemas de ventilação por deslocamento. Embora dentro desta camada a velocidade do ar seja baixa há mistura de ar resultante do momento das plumas térmicas que penetra nessa zona. A altura da linha de estratificação (SH) varia de acordo com a carga térmica interna e a vazão de ar.

Nos sistemas de distribuição de ar pelo piso, a região próxima aos difusores de ar é denominada zona livre (clear zone) dentro da qual a permanência não é recomendada devido ao excesso de correntes de ar e às temperaturas mais baixas.

Em situações nas quais os jatos de ar que saem dos difusores ultrapassarem a altura de estratificação, a camada intermediária deixa de existir, como pode ser observado na figura 2.8.

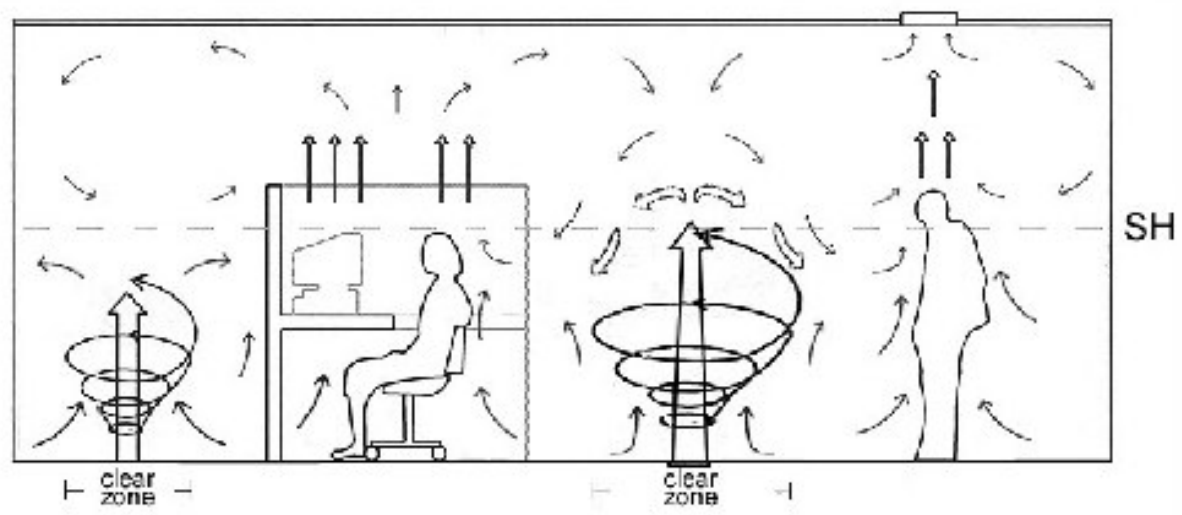

Figura 2.8 - Esquema do escoamento do ar em sistemas UFAD operando com velocidade do jato de ar elevada (FONTE: BAUMAN, 2003) 


\section{OBJETO DE ESTUDO}

São apresentadas, a seguir, as características da câmara de testes desenvolvida por Leite (2003), na qual foram realizadas as medições experimentais que serviram de referência para o presente estudo.

Trata-se de um escritório nos moldes do que existe nos edifícios brasileiros contemporâneos, ilustrado na Figura 3.1. É uma câmara de testes com $34,8 \mathrm{~m}^{2}$ de área, com possibilidades de distribuição de ar pelo piso e pelo teto. É um ambiente isolado com placas de poliuretano ${ }^{1}$ revestido com chapas de material melamínico. Contém um forro metálico modular de dimensões $120 \times 60 \mathrm{~cm}$, sem perfurações, onde se alojam oito luminárias para duas lâmpadas fluorescentes cada, formando um plenum superior para o retorno do ar e passagem de dutos para insuflação pelo teto.

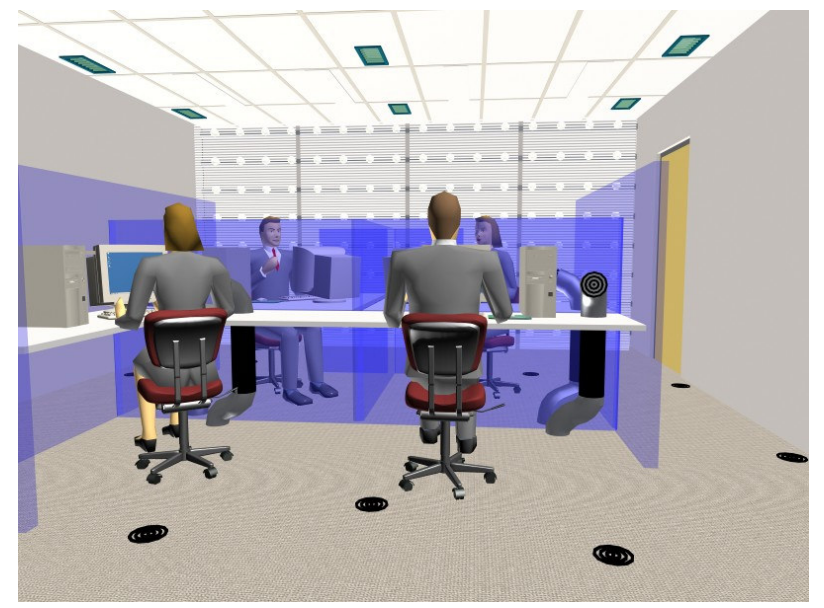

Figura 3.1 - Perspectiva da câmara de testes (FONTE: LEITE, 2003)

Em uma das paredes foi instalado um painel de lâmpadas para simular a radiação solar em superfície envidraçada (Figura 3.2). Para o dimensionamento da carga térmica equivalente, foi considerada a pior condição de insolação, resultando em um valor de 6.400 W. O painel de lâmpadas é constituído de oito fileiras, cada uma com 20 lâmpadas incandescentes de $40 \mathrm{~W}$ de potência nominal, distribuídas homogeneamente ao longo da extensão da parede.

${ }^{1} \mathrm{O}$ material isolante possui coeficiente de condutibilidade térmica médio de $0,0233 \mathrm{~W} / \mathrm{mK}$ $\left(0,02 \mathrm{kcal} / \mathrm{h} \mathrm{m}^{\circ} \mathrm{C}\right)$, com faixa de temperatura de trabalho de $-200^{\circ} \mathrm{C}$ a $+120^{\circ} \mathrm{C}$, segundo dados de ensaio fornecidos pelo fabricante, de acordo com a norma PN-0.01.5.001, da ABNT. 
Do lado interno da câmara e paralelamente ao painel de lâmpadas, foram colocadas persianas ajustáveis, com lâminas horizontais para variação do efeito da radiação no interior da câmara. Essas persianas cobrem toda a área da superfície envidraçada imaginária.

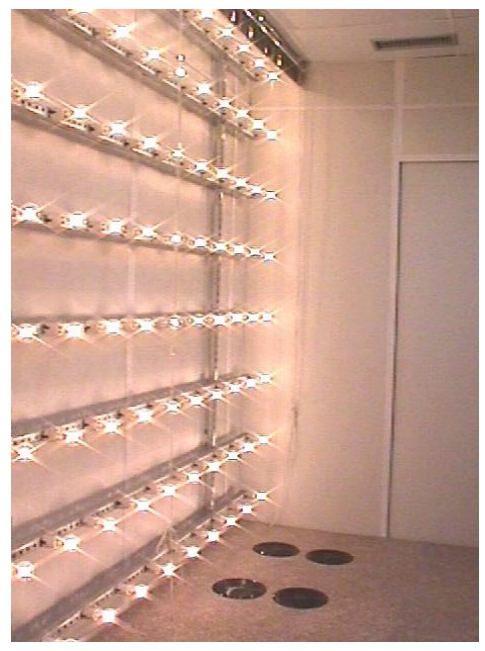

Figura 3.2 - Painel de lâmpadas (FONTE: LEITE, 2003)

Para representar o layout de escritórios, foi projetado e construído o mobiliário para compor três estações de trabalho, sendo duas adequadas para uma pessoa (com $8,7 \mathrm{~m}^{2}$ cada) e uma para duas pessoas $\left(17,4 \mathrm{~m}^{2}\right)$. Suas características e dimensões são bastante utilizadas nos edifícios da atualidade. São estações separadas por divisórias de 1,20 e 1,60 m de altura, revestidas por tecido que se aproxima razoavelmente daqueles mais utilizados nos escritórios. Sobre as mesas estão posicionados os equipamentos: micro computadores e impressoras.

Nas quatro estações de trabalho, foram colocados cilindros negros (simuladores) que dissipam calor equivalente a uma pessoa sentada (Figura 3.3). Esses simuladores foram confeccionados de acordo com a norma DIN 4715 1/1995 (DIN, 1995).

O piso da câmara de testes - piso elevado - é composto por placas metálicas moduladas e intercambiáveis, apoiadas em pedestais metálicos e revestidas com carpete em placas. Essas placas formam, com a laje de piso, o plenum inferior para o ar frio distribuído no ambiente, por meio de difusores instalados em posições previamente definidas. 


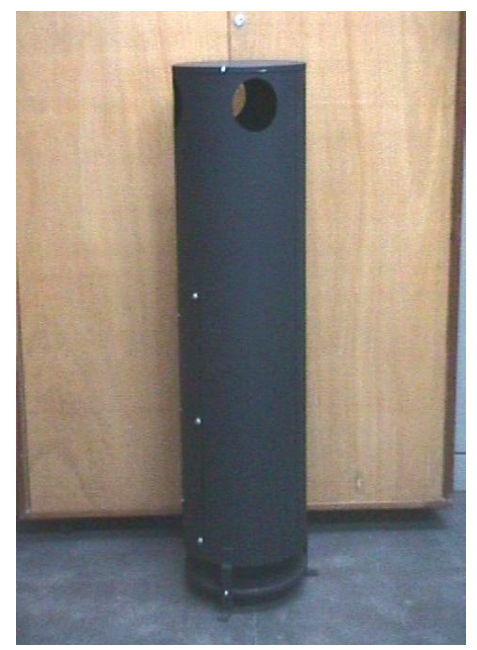

Figura 3.3 - Simulador (FONTE: LEITE, 2003)

Quanto aos difusores, foi feito um pré-dimensionamento para cargas térmicas máximas, tanto na zona periférica quanto nas demais de circulação e ocupação (internas), sendo a área periférica aquela próxima ao painel de lâmpadas. Para a distribuição de ar no piso, foram determinados 18 difusores circulares de Ø200 mm junto ao painel de lâmpadas e para a zona interna, 19 difusores circulares de $\varnothing 150 \mathrm{~mm}$, sendo 14 localizados no piso e cinco nas mesas, sendo que cada estação de trabalho conta com, no mínimo, um difusor (Figura 3.4).

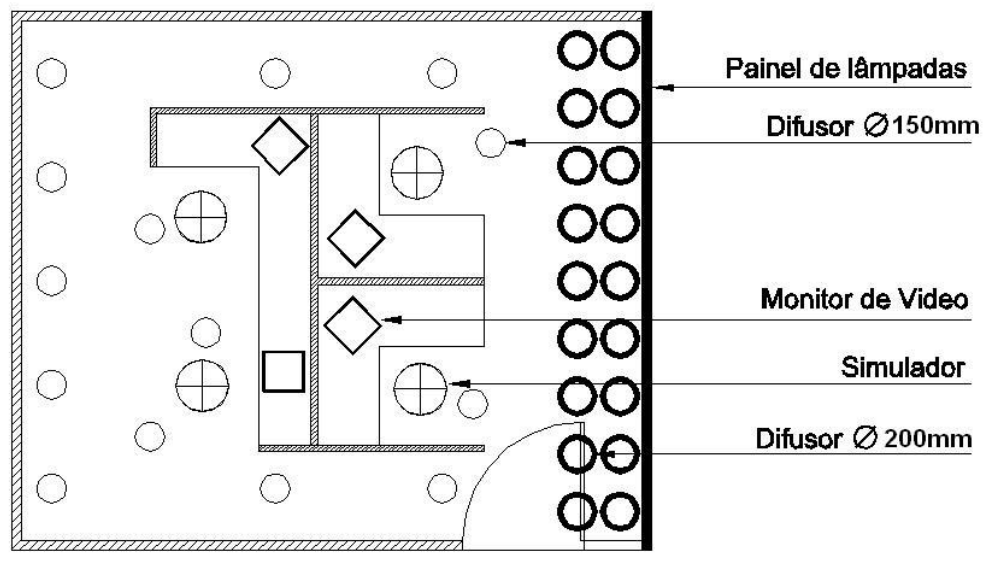

Figura 3.4 - Distribuição dos difusores de ar no piso.

Foram consideradas também, as características dos difusores escolhidos, cujas vazões máximas são: para $\varnothing 150 \mathrm{~mm}$, até $20 \mathrm{l} / \mathrm{s}$ e $\varnothing 200 \mathrm{~mm}$, até $40 \mathrm{l} / \mathrm{s}$, conforme dados fornecidos pelo fabricante (Trox Technik), com jatos do tipo espiralado (swir). 


\subsection{DESCRIÇÃO DO EXPERIMENTO}

O experimento descrito a seguir será utilizado como base para a verificação da adequação da estratégia proposta.

Trata-se de teste realizado por Leite (2004) na câmara de testes descrita acima, com o objetivo de verificar a perda de carga em um único difusor de ar. Para a realização do teste, somente um difusor de ar foi mantido aberto possibilitando a medição precisa dos campos de velocidade e temperatura do ar insuflado sem a influência dos fluxos adjacentes, provenientes dos demais difusores.

O difusor utilizado no teste (difusor do tipo "swirl") é bastante comum em ambientes com o sistema de distribuição de ar pelo piso, e se caracteriza pelo jato de ar espiralado. Este jato proporciona a mistura rápida do ar frio, insuflado no ambiente, com o ar existente no interior do ambiente.

Para a realização do teste, foi mantido aberto apenas um difusor de $\varnothing 200$ $\mathrm{mm}$, na posição indicada na figura 3.5.

Durante o teste, o painel de lâmpadas foi mantido desligado, assim como os simuladores. Somente os microcomputadores 1 e 3 (indicados na figura 3.6 foram mantidos ligados), com potência dissipada de 97,6W cada. As duas saídas de ar (retornos) mais próximas ao local onde foram realizadas as medições também foram vedadas.

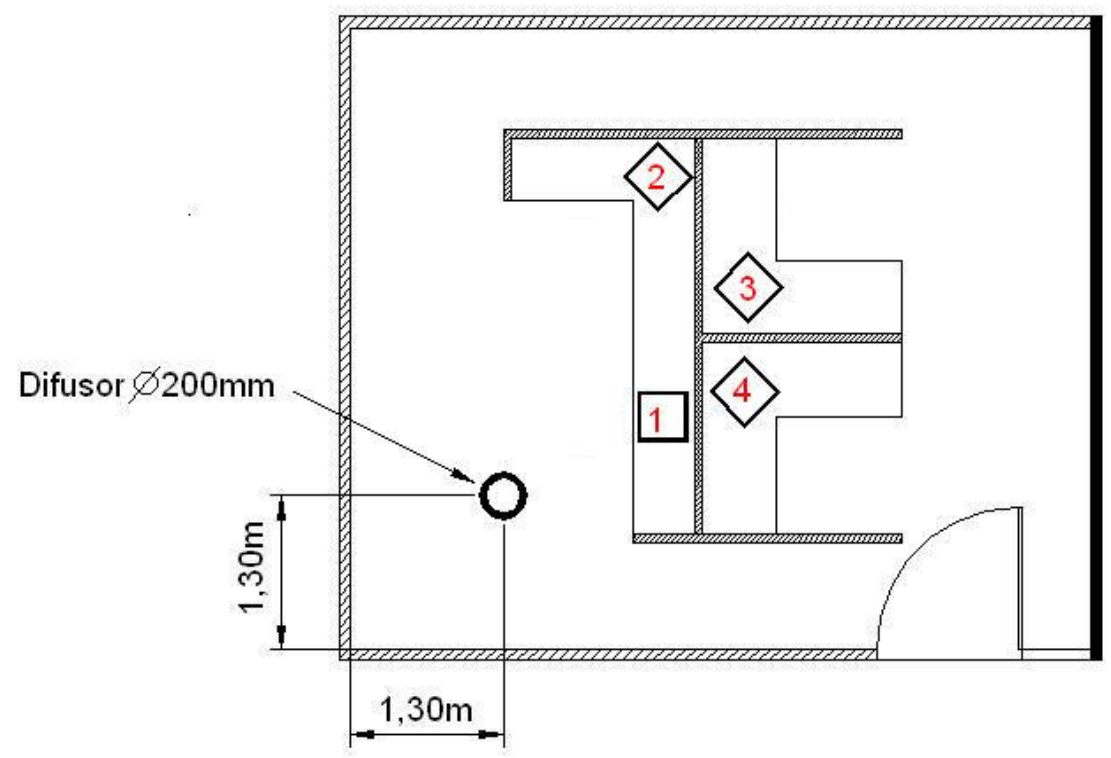

Figura 3.5 - Indicação do difusor de ar escolhido para as medições do teste 
Os testes foram realizados na condição de regime permanente, onde o diferencial de pressão estática do plenum para o ambiente foi mantido constante em $25 \mathrm{~Pa}$.

Segundo Leite (2004), foram determinados 12 perfis de temperatura e velocidade do ar, com base nos dados de medições simultâneas de seis termômetros do tipo PT100 e seis anemômetros do tipo "esfera quente" (cuja faixa de medição é de 0,03 a 3,0m/s, com incerteza de $0,03 \mathrm{~m} / \mathrm{s}$ ), posicionados nas alturas: 0,10m;0,60m;1,10m;1,70m;2,00m;2,35m. As 12 baterias de medições foram feitas, segundo um plano horizontal, nos seguintes pontos: centro do difusor (C), a $5 \mathrm{~cm}$ do centro (G), na borda do difusor (B), a 10, 20, 30, 40, 50, 60, 70, 80, $90 \mathrm{~cm}$ da borda do difusor (Figuras 3.6 e 3.7).

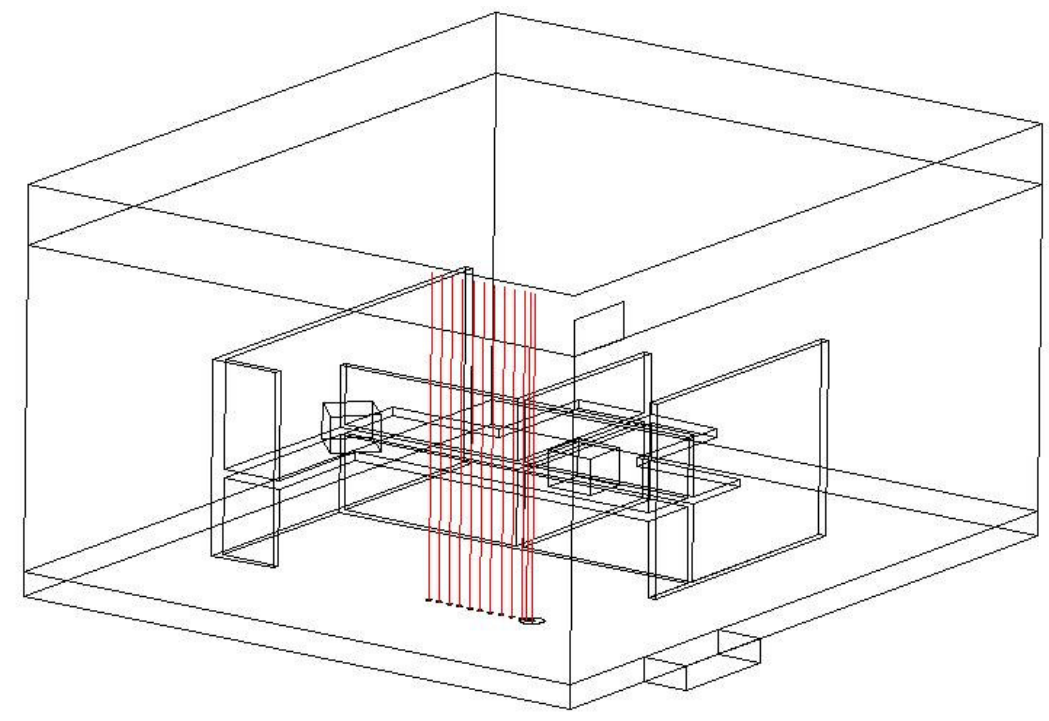

Figura 3.6 - Indicação dos pontos de medição (ao longo das linhas verticais)

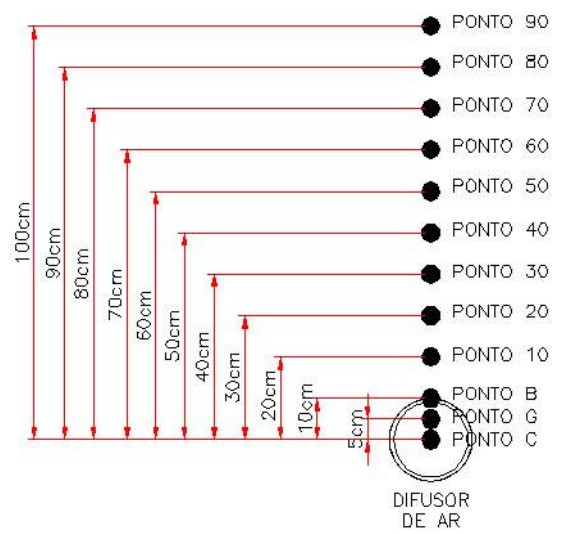

Figura 3.7 - Indicação das distâncias dos pontos de medição com relação ao centro do difusor 
Os resultados das medições para a temperatura e velocidade do ar podem ser visualizados nas figuras 3.8 e 3.9 .

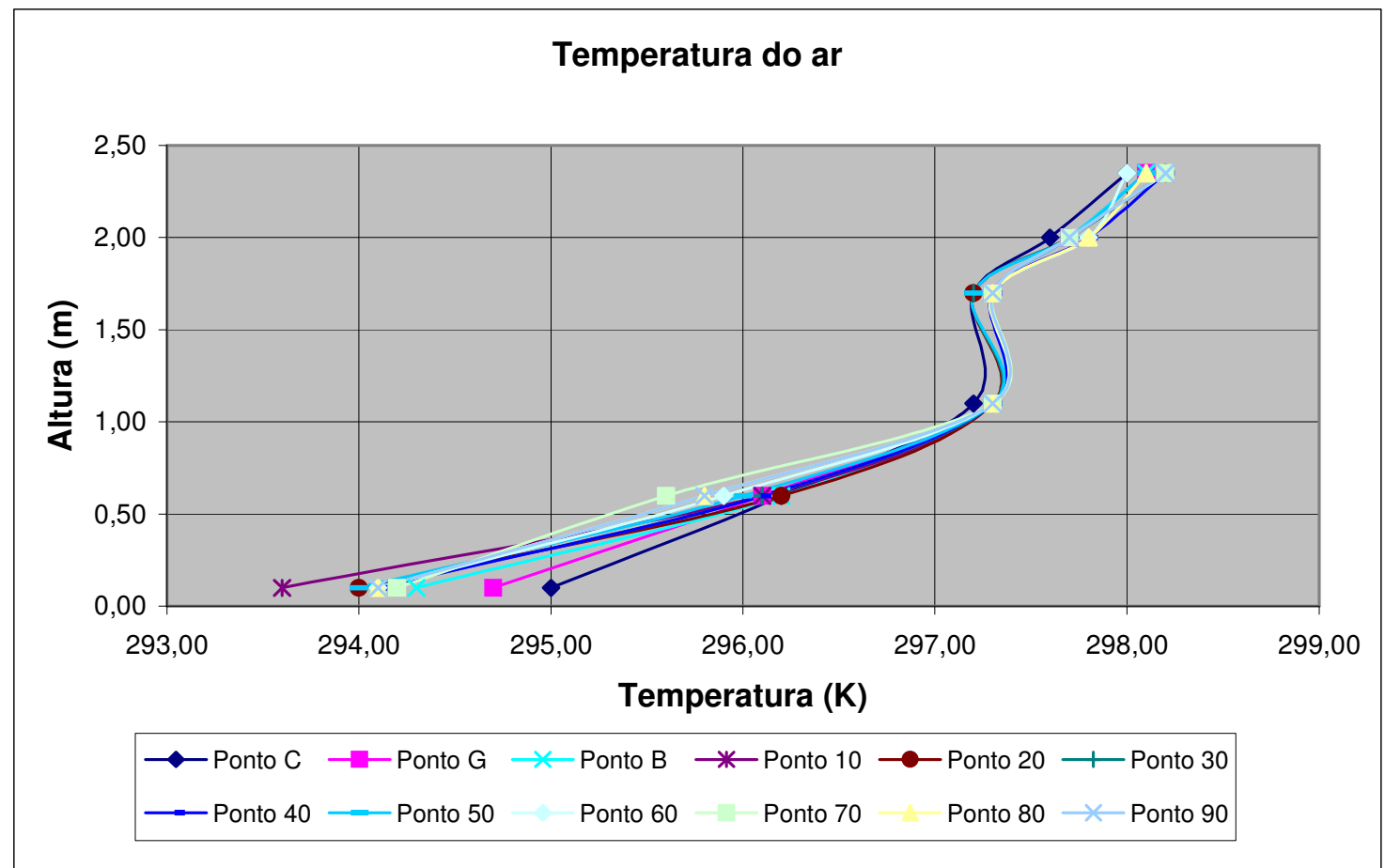

Figura 3.8 - Curvas resultantes das medições da temperatura do ar (FONTE: LEITE, 2004)

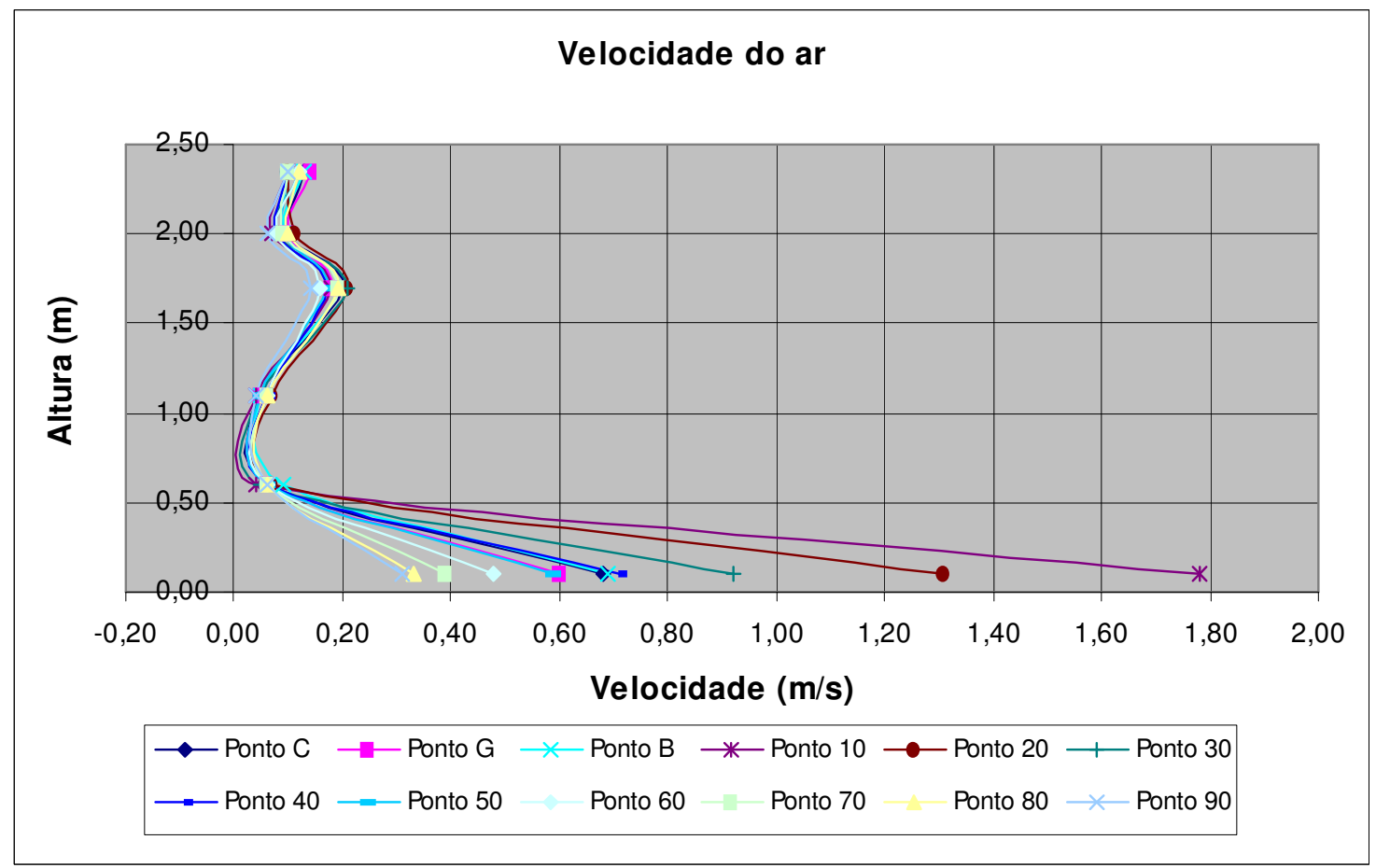

Figura 3.9 - Curvas resultantes das medições da velocidade do ar (FONTE: LEITE, 2004) 


\section{SIMULAÇÕES NUMÉRICAS}

Para o estudo do escoamento do ar no interior de ambientes, duas técnicas podem ser empregadas: a investigação experimental e a simulação numérica. A realização de medições experimentais fornece valores confiáveis para os gradientes de temperatura e velocidade do ar, porém, os experimentos geralmente têm custos elevados e consomem muito tempo.

Já a realização de simulações computacionais é menos custosa e pode ser utilizada como uma ferramenta de projeto (NIELSEN, 2004), principalmente com o avanço da capacidade computacional, como observaram Chen e Xu (1998), Luo e Roux (2004) e Djunaedy et al. (2003). As simulações com ferramentas de dinâmica dos fluidos computacionais (Computational Fluid Dynamics - CFD) envolvem a solução numérica de uma série de equações diferenciais não lineares, baseadas nas leis fundamentais do movimento de fluidos (leis fundamentais de conservação de massa, momento e energia). A solução dessas equações fornece informações detalhadas de velocidade do ar insuflado, intensidade de turbulência, distribuição de temperaturas e contaminantes, etc., em pontos ou regiões dentro de zonas particulares, possibilitando a visualização dos perfis de escoamento de ar, estudos de dispersão de poluentes e disponibilização dos dados necessários à análise das condições de conforto térmico em um determinado ambiente (BEAUSOLEILMORRISON, 2001; LUO e ROUX, 2004).

A Dinâmica dos Fluidos Computacional (Computational Fluid Dynamics CFD) é a análise dos sistemas envolvendo o escoamento de fluidos, transferência de calor e fenômenos associados, como, por exemplo, reações químicas, por meio de simulação computacional (VERSTEEG e MALALASEKERA, 1995).

As simulações computacionais, por sua vez, envolvem a solução numérica de uma série de equações diferenciais não lineares, baseadas nas leis fundamentais do movimento de fluidos (leis fundamentais de conservação de massa, momento, energia e transporte, em alguns casos).

A solução dessas equações fornece informações detalhadas de velocidade do ar insuflado, intensidade de turbulência, distribuição de temperaturas e contaminantes, etc., em pontos ou regiões dentro de zonas particulares, possibilitando a visualização dos perfis de escoamento de ar, estudos de dispersão 
de poluentes e disponibilização dos dados necessários à análise das condições de conforto térmico em um determinado ambiente (BEAUSOLEIL-MORRISON 2001; LUO e ROUX, 2004).

Segundo Nielsen (2004), os recursos de CFD têm sido usados por muitos anos como ferramentas de projeto de sistemas de ventilação em edificações. Esses recursos também têm sido empregados para avaliar o escoamento do ar em sistemas de distribuição de ar pelo piso, já que permitem a simulação de diferentes parâmetros de ventilação e de configurações do ambiente (taxa de ventilação, número, posição e tipo de difusor de ar, layout da sala, etc.).

\subsection{ETAPAS DA SIMULAÇÃO NUMÉRICA}

A primeira etapa da solução numérica envolve a modelagem da geometria do problema e a geração da malha, que podem responder por mais da metade do tempo total gasto com a simulação. Isto se deve ao fato de que os problemas tridimensionais que envolvem a modelagem de ambientes de geometrias complexas, considerando também os fatores que influenciam o escoamento do ar, como o número de ocupantes e sua posição, a distribuição do mobiliário e a localização dos difusores de ar em uma sala ventilada, tornam o processo de geração da malha mais complicado, resultando em mais tempo computacional e na necessidade de um computador de grande capacidade (ABANTO et al., 2004; DJUNAEDY et al. 1999; TEODOSIU et al., 2003; VERSTEEG e MALALASEKERA, 1995).

Após a definição da geometria, procede-se à geração da malha, que é a divisão do domínio em volumes de controle menores (subdomínios), nos quais serão discretizadas as equações governantes. A construção da malha é um dos principais fatores de sucesso ou fracasso da simulação numérica, já que a distribuição dos elementos da malha é fundamental para a correta predição do fluxo no domínio computacional.

As malhas podem ser classificadas como estruturadas, não-estruturadas ou híbridas. As malhas estruturadas caracterizam-se por elementos retangulares em 2D e hexaédricos em 3D; as malhas não-estruturadas possuem elementos triangulares em 2D e tetraédricos em 3D; finalmente, as malhas híbridas envolvem uma combinação das malhas as estruturadas e não-estruturadas. 
Considera-se a malha ideal, aquela que resolve toda a física relevante do escoamento, minimiza os erros que podem ser induzidos pela malha e usa o menor número possível de células para obter eficiência computacional (POTTER, 2004).

Após a geração da malha, são definidas as condições de contorno do modelo. As condições de contorno especificam o fluxo e as variáveis térmicas nas fronteiras do modelo físico. As condições de contorno, juntamente com as condições iniciais, as propriedades físicas do fluido e os parâmetros do escoamento especificam o problema a ser tratado. Assim, a especificação apropriada das condições de contorno do modelo é essencial para a correta predição da distribuição de ar em uma sala ventilada.

Além das condições de contorno, também o tratamento do fluxo de ar próximo às paredes é essencial para a correta predição do escoamento de um fluido. Os modelos de turbulência empregados geralmente são válidos somente para escoamentos distantes das paredes (números de Reynolds elevados) e, para reduzir esse efeito, as simulações devem contar com funções de parede, modelos de turbulência com baixos números de Reynolds ou modelos de duas camadas (TEODOSIU et al., 2003).

A seguir, são definidas as condições iniciais, as propriedades físicas do fluido e os parâmetros do escoamento. As equações são, então, resolvidas com os respectivos termos escritos em função dos valores das incógnitas em pontos discretos adjacentes, resultando num conjunto de equações algébricas, geralmente lineares, que fornecem a solução do problema.

Contudo, resultados numéricos fornecidos pelo computador devem ser sempre analisados em relação à física do problema. Isso porque erros de programação ou de definição das condições de contorno podem fazer uma simulação fornecer resultados visualmente plausíveis, mas fisicamente incompatíveis com o problema tratado.

\subsection{SIMULAÇÃO NUMÉRICA NO INTERIOR DE AMBIENTES COM O SISTEMA DE DISTRIBUIÇÃO DE AR PELO PISO}

O escoamento de ar no interior desses ambientes é caracterizado como sendo não-isotérmico, turbulento, tri-dimensional e transiente (LOOMANS, 1998). Além disso, em virtude do grande número de variáveis que interferem no perfil do 
escoamento do ar no interior de um ambiente, como quantidade de ocupantes, distribuição do mobiliário, dissipadores de calor, quantidade e posição dos difusores de ar, velocidade e temperatura do ar insuflado, taxa de renovação de ar, etc., a estimativa das condições ambientais resultantes neste ambiente é bastante complexa.

A velocidade de processamento cada vez maior e a memória disponível nos microcomputadores atuais tornam mais acessível o uso de ferramentas de CFD para a resolução de problemas de escoamento de ar em ambientes.

Da mesma maneira que os recursos de dinâmica dos fluidos computacional têm sido empregados no estudo de sistemas de ventilação mecânica, eles também têm sido empregados para avaliar o escoamento do ar em sistemas de distribuição de ar pelo piso, já que permitem a simulação de diferentes parâmetros de ventilação e de configurações do ambiente (taxa de ventilação, número, posição e tipo de difusor de ar, layout da sala, etc.).

\subsubsection{EQUAÇÕES GOVERNANTES}

Para a análise do escoamento do ar no interior de um ambiente com fontes de calor internas, assumindo a hipótese de fluido incompressível para o ar, as equações de conservação de massa, quantidade de movimento e energia (eq. 4.1 a 4.5) devem ser resolvidas pela ferramenta computacional.

a) Conservação da massa:

$$
\frac{\partial u}{\partial x}+\frac{\partial v}{\partial y}+\frac{\partial w}{\partial z}=0
$$

onde, $u, v$ e $w$ correspondem às velocidades nas direções $x, y$ e $z$, respectivamente.

b) Conservação da quantidade de movimento:

$$
\frac{\partial u}{\partial t}+\frac{\partial u^{2}}{\partial x}+\frac{\partial(u v)}{\partial y}+\frac{\partial(u w)}{\partial z}=-\frac{1}{\rho} \frac{\partial p}{\partial x}+v\left(\frac{\partial^{2} u}{\partial x^{2}}+\frac{\partial^{2} u}{\partial y^{2}}+\frac{\partial^{2} u}{\partial z^{2}}\right)
$$




$$
\begin{gathered}
\frac{\partial v}{\partial t}+\frac{\partial(u v)}{\partial x}+\frac{\partial v^{2}}{\partial y}+\frac{\partial(v w)}{\partial z}=-\frac{1}{\rho} \frac{\partial p}{\partial y}+v\left(\frac{\partial^{2} v}{\partial x^{2}}+\frac{\partial^{2} v}{\partial y^{2}}+\frac{\partial^{2} v}{\partial z^{2}}\right) \\
\frac{\partial w}{\partial t}+\frac{\partial(w u)}{\partial x}+\frac{\partial(w v)}{\partial y}+\frac{\partial\left(w^{2}\right)}{\partial z}=-\frac{1}{\rho} \frac{\partial p}{\partial z}+v\left(\frac{\partial^{2} w}{\partial x^{2}}+\frac{\partial^{2} w}{\partial y^{2}}+\frac{\partial^{2} w}{\partial z^{2}}\right)+F
\end{gathered}
$$

onde, $u, v$ e $w$ correspondem às velocidades nas direções $x, y$ e $z$, respectivamente. $t$ corresponde ao tempo, $p$ à pressão e $\rho$ à densidade.

O primeiro termo à esquerda das equações 4.2, 4.3 e 4.4 representa a taxa de aumento da quantidade de movimento no tempo; o segundo, o terceiro e o quarto correspondem à taxa de ganho de quantidade de movimento por convecção. $O$ primeiro termo à direita das equações corresponde à força da pressão. $\mathrm{O}$ último termo nas equações 4.2 e 4.3, e o penúltimo na equação 3.4 corresponde à taxa de ganho de quantidade de movimento pela transferência viscosa.

$\mathrm{Na}$ equação 4.4, $F$ corresponde ao termo de empuxo, dado por $F=-\left[1-\beta\left(T-T_{0}\right)\right] g$, onde $\beta$ é o coeficiente de expansão térmica, $T$ a temperatura do fluido, $T_{0}$ a temperatura de referência e $g$ é a aceleração da gravidade.

Se o efeito da gravidade for desprezível, considera-se $F=0$. Caso contrário, $F=-g$, para $T=T_{0}$.

c) Conservação de energia:

$$
\frac{\partial T}{\partial t}+\frac{\partial(u T)}{\partial x}+\frac{\partial(v T)}{\partial y}+\frac{\partial(w T)}{\partial z}=\alpha\left(\frac{\partial^{2} T}{\partial x^{2}}+\frac{\partial^{2} T}{\partial y^{2}}+\frac{\partial^{2} T}{\partial z^{2}}\right) .
$$

O primeiro termo à esquerda da equação 4.5 representa a taxa de aumento de energia no tempo; o segundo, o terceiro e o quarto representam o aumento de energia por convecção. O termo à direita da equação corresponde à transferência de energia por difusão, sendo que $\alpha$ é o coeficiente de difusividade térmica do fluido, dado por $\alpha=\frac{k_{t}}{\rho c_{p}}$, onde $k_{t}$ é a condutividade térmica, e $c_{p}$ o calor específico à pressão constante. 


\subsubsection{MODELAGEM DA TURBULÊNCIA}

O escoamento no interior de ambientes geralmente é turbulento, sendo que os fluxos turbulentos são caracterizados pela flutuação dos campos de velocidade. Como essas flutuações podem ser de pequena escala e alta freqüência, elas consomem elevado custo computacional. Assim, as equações governantes podem ser simplificadas, para tornar o processo de cálculo mais rápido, através do emprego de modelos de turbulência.

Segundo Nielsen (1998) a seleção do modelo de turbulência é fundamental para a correta predição do escoamento de ar em uma sala. A escolha do modelo de turbulência depende de considerações sobre a física do problema, a prática estabelecida para uma determinada classe de problemas, o nível de precisão desejado, os recursos computacionais disponíveis e a quantidade de tempo disponível para a simulação (FLUENT INC.; 2003b).

São apresentados abaixo os dois modelos de turbulência empregados nas simulações realizadas no presente estudo. O modelo $k-\varepsilon$ padrão, embora válido somente para escoamentos totalmente turbulentos, é o mais comumente empregado para a simulação do escoamento de ar no interior de ambientes mecanicamente ventilados (ZHAO et al., 2003) por ser econômico e relativamente preciso (PUSTELNIK, 2005).

Segundo Nielsen (2004), o modelo de turbulência $k$ - $\varepsilon$ padrão é aceitável em diversas situações de movimento de ar no interior de ambientes, mas em modelos tri-dimensionais pode-se optar pelo modelo RSM (Reynolds Stress Model), que garante resultados mais precisos, embora consuma 50\% mais tempo de cálculo.

\subsubsection{Modelo $k$ - $\varepsilon$ padrão}

O modelo de turbulência $k$ - $\varepsilon$ padrão é um modelo semi-empírico baseado no modelo das equações de transporte de energia cinética turbulenta $(k)$ e sua taxa de dissipação $(\varepsilon)$. Na derivação do modelo $k-\varepsilon$ assumiu-se que o fluxo é totalmente turbulento e os efeitos da viscosidade molecular são negligenciáveis (FLUENT INC., 2003b). 
A energia cinética turbulenta, $k$, e sua taxa de dissipação, $\varepsilon$, são obtidas a partir das seguintes equações de transporte:

$$
\begin{gathered}
\frac{\partial}{\partial t}(\rho k)+\frac{\partial}{\partial x_{i}}\left(\rho k u_{i}\right)=\frac{\partial}{\partial x_{j}}\left[\left(\mu+\frac{\mu_{t}}{\sigma_{k}}\right) \frac{\partial k}{\partial x_{j}}\right]+G_{k}+G_{b}-\rho \varepsilon-Y_{M}+S_{k} \\
\mathrm{e} \\
\frac{\partial}{\partial t}(\rho \varepsilon)+\frac{\partial}{\partial x_{i}}\left(\rho \varepsilon u_{i}\right)=\frac{\partial}{\partial x_{j}}\left[\left(\mu+\frac{\mu_{t}}{\sigma_{\varepsilon}}\right) \frac{\partial \varepsilon}{\partial x_{j}}\right]+C_{1 \varepsilon} \frac{\varepsilon}{k}\left(G_{k}+C_{3 \varepsilon} G_{b}\right)-C_{2 \varepsilon} \rho \frac{\varepsilon^{2}}{k}+S_{\varepsilon},
\end{gathered}
$$

Onde, $\mu_{t}$ representa a viscosidade turbulenta; $G_{k}$ representa a geração de energia cinética turbulenta devido ao gradiente de velocidade média; $G_{b}$ representa a geração de energia cinética turbulenta devido aos efeitos da flutuabilidade da temperatura; $Y_{M}$ corresponde à dissipação da dilatação em escoamento compressíveis; $C_{1 \varepsilon}, C_{2 \varepsilon}$ e $C_{3 \varepsilon}$ são constantes; $\sigma_{k}$ e $\sigma_{\varepsilon}$ são os número de Prandtl para as taxas de turbulência $k$ e $\varepsilon$, respectivamente; $S_{k}$ e $S_{\varepsilon}$ são os termos fonte definidos pelo usuário.

A viscosidade turbulenta, $\mu_{t}$, é computada pela combinação de $k$ e $\varepsilon$, tal que:

$$
\mu_{t}=\rho C_{\mu} \frac{k^{2}}{\varepsilon}
$$

As constantes $C_{1 \varepsilon}, C_{2 \varepsilon}, C_{\mu}$ e $\sigma_{\varepsilon}$ do modelo têm os seguintes valores, determinados experimentalmente:

$$
\begin{aligned}
& C_{1 \varepsilon}=1.44 \\
& C_{2 \varepsilon}=1.92 \\
& C_{\mu}=0.09 \\
& \sigma_{\varepsilon}=1.3
\end{aligned}
$$

O termo $G_{k}$, que representa a produção de energia cinética turbulenta, é definido por:

$$
G_{k}=-\overline{\rho u_{i}^{\prime} u_{j}^{\prime}} \frac{\partial u_{j}}{\partial x_{i}}
$$

O termo $G_{b}$, que representa a geração de energia cinética turbulenta devida aos efeitos da flutuação da temperatura. É empregado quando o campo gravitacional não é nulo e há gradiente de temperatura. É definido por:

$$
G_{b}=\beta g_{i} \frac{\mu_{t}}{\operatorname{Pr}_{t}} \frac{\partial T}{\partial x_{i}}
$$


onde $\beta$ é o coeficiente de expansão térmica, $P r_{t}$ é o número de Prandtl turbulento, $T$ a temperatura do fluido e $g$ é a aceleração da gravidade.

O coeficiente de expansão térmica $\beta$ é definido por:

$$
\beta=-\frac{1}{\rho}\left(\frac{\partial \rho}{\partial T}\right)_{p}
$$

onde $p$ é um dado valor de pressão.

\subsubsection{Modelo Reynolds Stress Model (RSM)}

O modelo de turbulência RSM resolve as equações de transporte das equações governantes pela solução das equações de transporte das tensões de Reynolds junto com uma equação para a taxa de dissipação. Isto implica em sete equações de transporte adicionais a serem resolvidas em problemas tridimensionais, aumentando consideravelmente o tempo de simulação. A vantagem da adoção deste modelo é o potencial para se atingir um resultado mais preciso, principalmente em fluxos turbulentos. Comparado ao modelo $k$ - $\varepsilon$ padrão, o modelo $\mathrm{RSM}$ requer 50 a $60 \%$ mais tempo de cálculo e 15 a 20\% mais memória computacional (FLUENT INC., 2003b).

As equações de transporte para o transporte das tensões de Reynolds são dadas por:

$$
\begin{aligned}
& \underbrace{\frac{\partial}{\partial t}\left(\rho \overline{u_{i}^{\prime} u_{j}^{\prime}}\right)}_{\text {Derivada_tempo_local }}+\underbrace{\frac{\partial}{\partial x_{k}}\left(\rho u_{k} \overline{u_{i}^{\prime} u_{j}^{\prime}}\right)}_{C_{i j}=\text { Convecção }}=\underbrace{-\frac{\partial}{\partial x_{k}}\left[\rho \overline{u_{i}^{\prime} u_{j}^{\prime} u_{k}^{\prime}}+\overline{p\left(\delta_{k j} u_{i}^{\prime}+\delta_{i k} u_{j}^{\prime}\right)}\right]}_{D_{T, i j} \equiv \text { Difusão_de_turbulência }}
\end{aligned}
$$

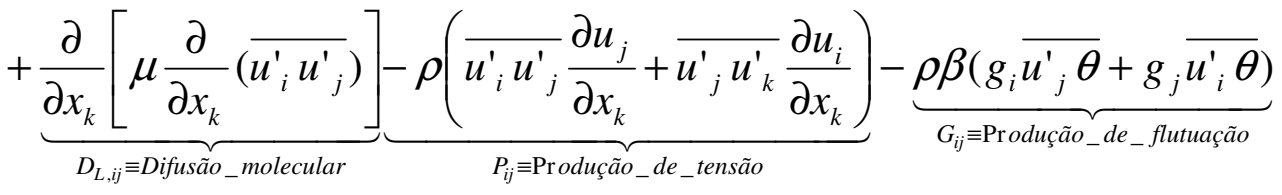

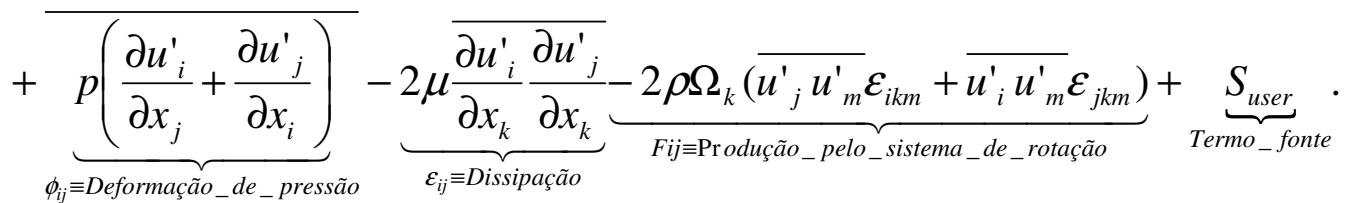

Os termos $C_{i j}, D_{i j}, P_{i j}$ e $F_{i j}$ não requerem modelagem. Contudo, $D_{T, i j}, G_{i j}, \phi_{i j}$ e $\varepsilon_{i j}$ precisam ser modelados para fechar a série de equações.

O termo $D_{T, i j}$ representa o transporte difusivo turbulento e é expresso por: 


$$
D_{T, i j}=\frac{\partial}{\partial x_{k}}\left(\frac{\mu_{t}}{\sigma_{k}} \frac{\partial \overline{u_{i}^{\prime} u_{j}^{\prime}}}{\partial x_{k}}\right)
$$

onde $\sigma_{k}=0.82$.

O termo $\phi_{i j}$ representa a deformação devido à pressão e é expresso por:

$$
\phi_{i j}=\phi_{i j, 1}+\phi_{i j, 2}+\phi i_{j, w} \text {. }
$$

O termo $\phi_{i j, 1}$ representa a deformação lenta devido à pressão, também conhecido como termo de retorno à isotropia, e é expresso por:

$$
\phi_{i j, 1} \equiv-C_{1} \rho \frac{\varepsilon}{k}\left[\overline{u_{i}^{\prime} u_{j}^{\prime}}-\frac{2}{3} \delta_{i j} k\right]
$$

com $C_{1}=1.8$.

O termo $\phi_{i j, 2}$ representa a deformação rápida devido à pressão e é expresso por:

$$
\phi_{i j, 2} \equiv-C_{2}\left[\left(P_{i j}+F_{i j}+G_{i j}-C_{i j}\right)-\frac{2}{3} \delta_{i j}(P+G-C)\right] \text {, }
$$

com $C_{2}=0.6, P=\frac{1}{2} P_{k k}, G=\frac{1}{2} G_{k k}$ e $C=\frac{1}{2} C_{k k}$.

O termo $\phi_{i j, w}$ representa o termo de reflexão da parede é expresso por:

$$
\begin{aligned}
& \phi_{i j, w} \equiv C_{1}^{\prime} \frac{\varepsilon}{k}\left(\overline{u_{k}^{\prime} u_{m}^{\prime}} n_{k} n_{m} \delta_{i j}-\frac{3}{2} \overline{u_{i}^{\prime} u_{k}^{\prime}} n_{j} n_{k}-\frac{3}{2} \overline{u_{j}^{\prime} u_{k}^{\prime}} n_{i} n_{k}\right) \frac{k^{3 / 2}}{C_{l} \varepsilon d} \\
& +C_{2}^{\prime}\left(\phi_{k m, 2} n_{k} n_{m} \delta_{i j}-\frac{3}{2} \phi_{i k, 2} n_{j} n_{k}-\frac{3}{2} \phi_{j k, 2} n_{i} n_{k}\right) \frac{k^{3 / 2}}{C_{l} \varepsilon d},
\end{aligned}
$$

com $C_{1}^{\prime}=0.5, C_{2}^{\prime}=0.3, n_{k}$ é o componente $x_{k}$ da unidade normal à parede, $d$ é a distância normal à parede e $C_{1}=\frac{C_{\mu}^{3 / 4}}{k}$, com $C_{\mu}=0.09$ e $k=0.4187$.

O termo $G_{i j}$ representa a flutuação dos gradientes de temperatura e é expresso por:

$$
G_{i j}=\beta \frac{\mu_{t}}{\operatorname{Pr}_{t}}\left(g_{i} \frac{\partial T}{\partial x_{j}}+g_{j} \frac{\partial T}{\partial x_{i}}\right),
$$

onde $P r_{t}$ é o número de Prandtl turbulento para energia, com valor de 0.85 . O termo $\varepsilon_{i j}$ representa a taxa de dissipação e é expresso por:

$$
\varepsilon_{i j}=\frac{2}{3} \delta_{i j}\left(\rho \varepsilon+Y_{M}\right),
$$


onde $Y_{M}=2 \rho \varepsilon M_{t}^{2}$ e representa um termo adicional da dilatação da dissipação. O número de Mach $\left(M_{t}\right)$ é definido por:

$$
M_{t}=\sqrt{\frac{k}{a^{2}}},
$$

onde $a$ representa a velocidade do som.

A taxa de dissipação escalar, $\varepsilon$, é computada com uma equação de transporte similar àquela usada em modelos $k-\varepsilon$ padrão:

$$
\frac{\partial}{\partial t}(\rho \varepsilon)+\frac{\partial}{\partial x_{i}}\left(\rho \varepsilon u_{i}\right)=\frac{\partial}{\partial x_{j}}\left[\left(\mu+\frac{\mu_{t}}{\sigma_{\varepsilon}}\right) \frac{\partial \varepsilon}{\partial x_{j}}\right] C_{\varepsilon 1} \frac{1}{2}\left[P_{i i}+C_{\varepsilon 3} G_{i i}\right] \frac{\varepsilon}{k}-C_{\varepsilon 2} \rho \frac{\varepsilon^{2}}{k}+S_{\varepsilon},
$$

onde $\sigma_{\varepsilon}=1.0, C_{\varepsilon 1}=1.44, C_{\varepsilon 2}=1.92, C_{\varepsilon 3}$ é avaliado como uma função da direção do fluxo local com relação ao vetor gravitacional, e $S_{\varepsilon}$ é o termo fonte definido pelo usuário.

Quando a energia cinética turbulenta é necessária para a modelagem de um termo específico, ela pode ser obtida pela equação:

$$
k=\frac{1}{2} \overline{u_{i}^{\prime} u_{i}^{\prime}} .
$$

A modelagem da viscosidade turbulenta é similar à do modelo $k$ - $\varepsilon$ padrão:

$$
\mu_{t}=\rho C_{\mu} \frac{k^{2}}{\varepsilon}
$$

onde $C_{\mu}=0.09$.

\subsubsection{TRATAMENTO DO FLUXO PRÓXIMO À PAREDE}

Os modelos de turbulência empregados geralmente são válidos somente para escoamentos distantes das paredes e, para reduzir esse efeito, as simulações devem contar com funções de parede, modelos de turbulência com baixos números de Reynolds ou modelos de duas camadas (TEODOSIU et al., 2003).

No caso do emprego de funções de parede, adotadas no presente estudo, a simulação correta de fluxos turbulentos requer que alguns cuidados sejam tomados durante a geração da malha, que deve ter mais pontos próximos à parede. $\mathrm{A}$ distância da parede das células adjacentes à parede deve ser determinada 
considerando-se a taxa sobre a qual a lei logarítmica é válida. Essa distância é normalmente medida na unidade $\mathrm{y}^{+}$.

$$
y^{+}=\frac{y \sqrt{\tau_{0} / \rho}}{v}
$$

Onde, $y$ é a distância da parede, $\rho$ é a densidade, $v$ a viscosidade cinemática e $\tau_{0}$ a tensão de cisalhamento na parede.

A lei logarítmica é válida para $y^{+}>30$ até 60 , com um valor desejável de $y^{+} \approx 30$. Quando $y^{+}<11.225$ o FLUENT aplica a lei linear (laminar).

\subsubsection{PARÂMETROS CARACTERÍSTICOS}

O escoamento do ar em ambientes com o sistema de distribuição de ar frio pelo piso é bastante característico, cujo comportamento foi descrito no capítulo 2 . Para a compreensão do fenômeno físico desse sistema, Lin e Linden (2005) apresentaram o modelo descrito a seguir. Para a elaboração do modelo, os autores consideraram um ambiente com uma fonte de calor, um difusor de ar no piso e uma saída de ar no teto.

Em seu estudo, as seguintes considerações foram apresentadas:

- A fonte de calor no interior do ambiente aquece o ar de seu entorno. O ar quente sobe em direção ao teto, por convecção natural, formando uma camada de ar mais quente do que o ar insuflado no interior do ambiente através dos difusores de ar existentes no piso, resultando na estratificação térmica do ar em duas camadas: a camada superior, mais quente, e a camada inferior, mais fria;

- Quando a velocidade do jato de ar que atravessa o difusor é baixa, de tal modo que o ar insuflado no ambiente não penetra na camada superior (ar quente), ocorre o sistema de ventilação por deslocamento puro. Neste caso, somente o fluxo flutuante da fonte de calor (B) e a vazão de ar do difusor (Q) são parâmetros relevantes;

- Por outro lado, quando a velocidade de insuflação é tal que, o jato de ar ultrapassa a altura de estratificação e entra na camada superior, ocorre um sistema de ventilação híbrido entre mistura e deslocamento. 
Os autores concluíram que o comportamento do escoamento de ar é definido, principalmente, pelas plumas térmicas resultantes do fluxo flutuante da fonte de calor (B), pela vazão do ar insuflado (Q) e pelo momento vertical do fluxo de ar insuflado (M). Do modelo desenvolvido por Lin e Linden (2005) são apresentados, a seguir, os principais parâmetros que caracterizam o movimento do ar em sistemas de ventilação por deslocamento e em sistemas de distribuição de ar pelo piso.

\subsubsection{Sistema de ventilação por deslocamento}

No caso do sistema de ventilação por deslocamento (Figura 4.1), a estratificação térmica em duas camadas é estabelecida devido às diferenças de densidade produzidas pelas fontes de calor. A camada superior é formada pelo ar quente da pluma térmica, e a camada inferior pelo ar frio insuflado através do difusor de piso. $\mathrm{O}$ ar na camada superior sai do ambiente através das aberturas do teto na taxa $Q$ dada pela vazão de ar do difusor de piso, que é igual ao fluxo de ar $Q_{p}$ da pluma térmica na altura $h$ (altura de estratificação térmica).

$$
Q=Q_{p}=Q_{\text {out }},
$$

onde $Q_{\text {out }}$ é o fluxo de ar que sai do ambiente.

A força de flutuação é descrita em termos de uma gravidade reduzida:

$$
g^{\prime}=\frac{\rho_{r}-\rho}{\rho_{r}} g
$$

onde $\rho$ é a densidade do ar, $\rho_{r}$ é a densidade de referência e $g$ a aceleração da gravidade. A aproximação de Boussinesq foi aplicada para que a diferença das densidades $\Delta \rho=\rho_{r}-\rho$ seja considerada muito menor do que a densidade de referência, $\Delta \rho<<\rho_{r}$. 


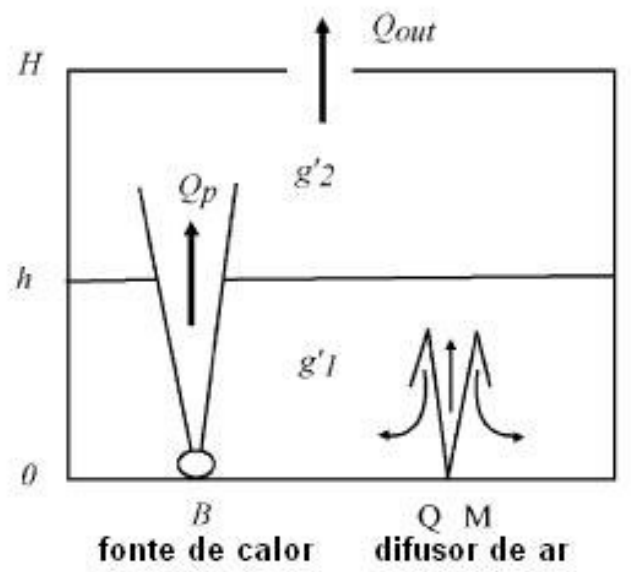

Figura 4.1 - Sistema de ventilação por deslocamento (FONTE: LIN e LINDEN, 2005)

A gravidade reduzida $g_{1}^{\prime}$ na camada inferior é a mesma que a do fluxo de ar do difusor, já que no sistema de ventilação por deslocamento, não há mistura:

$$
g_{1}^{\prime}=g_{f}^{\prime}=0 .
$$

Após a formação e estabilização das duas camadas, superior e inferior (considerando-se o regime permanente), a densidade do ar na camada superior é a mesma que a da pluma térmica na altura de estratificação.

A gravidade reduzida $g_{2}^{\prime}$ na camada superior é determinada pelo fluxo flutuante da fonte de calor (B) e pela distância vertical $h$ da altura de estratificação até a origem da pluma térmica (fonte de calor). Também pode ser determinada por:

$$
g_{2}^{\prime}=\frac{B}{Q_{\text {out }}}
$$

já que o fluxo flutuante $g_{2}^{\prime} Q_{\text {out }}$ que sai do ambiente é igual ao fluxo flutuante da fonte de calor $B$.

Nos sistemas de ventilação por deslocamento, o aumento da vazão de ar através do difusor causa a elevação da altura da linha de estratificação e a diminuição da temperatura na camada superior.

\subsubsection{Sistemas UFAD}

Quando o fluxo vertical tem momento $(M)$ suficiente para atravessar a altura de estratificação $h$, a mistura do ar insuflado com o ar aquecido da camada superior interfere no perfil do escoamento do ar. Com maior velocidade de insuflação, o ar 
que sai do difusor de ar é forçado para cima e a atravessa a altura de estratificação térmica. Como a temperatura do ar insuflado é mais baixa que a temperatura ambiente, o ar volta a cair em direção ao piso, carregando consigo uma parcela do ar que estava na camada superior, como pode ser observado na figura 4.2.

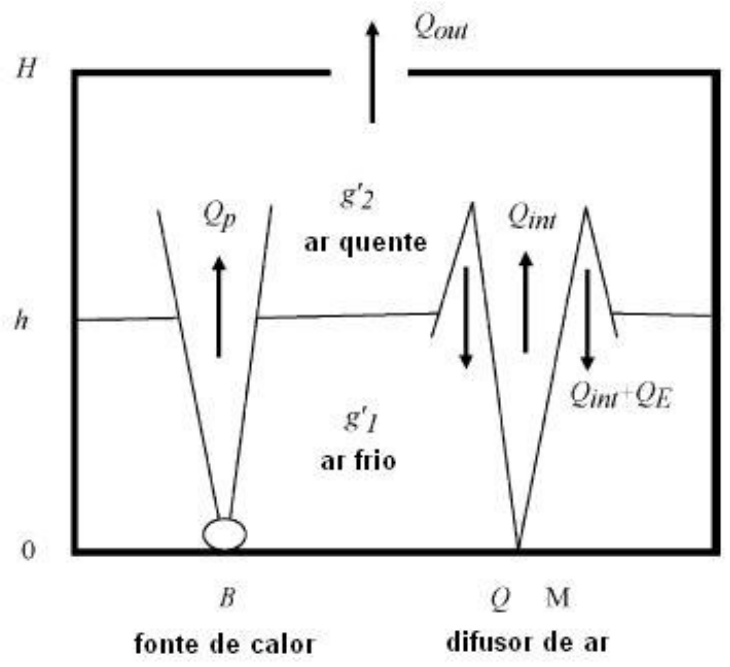

Figura 4.2 - Sistema de distribuição de ar pelo piso (FONTE: LIN e LINDEN, 2005)

Tem-se:

$$
Q=Q_{\text {out }} \text {. }
$$

Quando o momento vertical $M$ de uma fonte turbulenta é grande o suficiente para causar re-entrada do volume de ar da camada superior dentro da camada inferior, o fluxo de ar insuflado na camada superior pela pluma térmica aumenta:

$$
Q_{p}=Q_{\text {out }}+Q_{E},
$$

onde $Q_{E}$ representa o fluxo de entrada do ar da camada superior para a camada inferior. Comparações do sistema de distribuição de ar pelo piso com o sistema de ventilação por deslocamento mostram que, com a mesma fonte de calor e mesma vazão, a altura de estratificação $h$ aumenta, nos sistemas de distribuição de ar pelo piso, como conseqüência do volume de ar da camada superior que entra na camada inferior.

Similarmente ao sistema de ventilação por deslocamento, o fluxo flutuante $g_{2}^{\prime} Q_{\text {out }}$ que sai do ambiente é igual ao fluxo flutuante da fonte de calor $(B)$. Contudo, devido à re-entrada de ar da camada superior na camada inferior, a gravidade $g_{1}^{\prime}$ da camada inferior não é mais a mesma que a do fluxo de ar do difusor, já que há 
mistura. Neste caso, $g_{1}^{\prime}$ tem um valor intermediário entre a camada superior e a do fluxo de ar do difusor.

Em contraste com o sistema de ventilação por deslocamento, no qual a camada inferior depende da temperatura de insuflação, a temperatura da camada inferior dos sistemas de distribuição de ar pelo piso depende da mistura do ar quente da camada superior do ambiente.

O fluido entra na camada superior e circula de volta para a camada inferior, trazendo consigo um ganho de calor $g_{2}^{\prime} Q_{E}$. Assim, a flutuação na camada inferior é expressa por:

$$
g_{1}^{\prime}=\frac{g_{2}^{\prime} Q_{E}}{Q_{E}+Q}
$$

Quando a vazão do difusor aumenta (momento vertical do fluxo de ar), o fluxo de ar $Q_{E}$ que retorna à camada inferior aumenta. A gravidade reduzida $g_{1}^{\prime}$ da camada inferior se aproxima da gravidade reduzida $g_{2}^{\prime}$ da camada superior à medida que momento vertical do fluxo aumenta. Se $g_{1}^{\prime} \approx g_{2}^{\prime}$, considera-se que há mistura total.

\subsubsection{PROPRIEDADES FÍSICAS DO FLUIDO}

Do exposto no item 4.2.4, verifica-se que a densidade tem papel fundamental no escoamento do ar no interior de ambientes com o sistema de distribuição de ar pelo piso. A ferramenta de simulação empregada (FLUENT) no presente estudo disponibiliza o uso de alguns modelos de densidade do ar em problemas de escoamentos incompressíveis. No presente estudo, serão abordados os seguintes modelos: Modelo de Boussinesq, Lei do Gás Ideal Incompressível e Densidade em Função da Temperatura.

\subsubsection{Modelo de Boussinesq}

Quando há fontes de calor no interior de um ambiente, a densidade do fluido varia com a temperatura. Neste caso, o escoamento pode sofrer a influência da força da gravidade que age nas variações da densidade do fluido. Uma convergência mais 
rápida pode ser obtida, adotando-se o modelo de Boussinesq para a densidade do ar.

O modelo de Boussinesq trata a densidade como um valor constante nas equações resolvidas, exceto para o termo flutuante na equação de momento, que varia em função da temperatura:

$$
\left(\rho-\rho_{0}\right) g \approx-\rho_{0} \beta\left(T-T_{0}\right) g,
$$

onde $\rho_{0}$ é a densidade (constante) do fluxo, $T_{0}$ é a temperatura operativa e $\beta$ é o coeficiente de expansão térmica do fluido, dado por:

$$
\beta=-\frac{1}{\rho}\left(\frac{\partial \rho}{\partial T}\right)_{p} .
$$

A equação 3.32 é obtida usando-se a aproximação de Boussinesq, onde $\rho=-\rho_{0}(1-\beta \Delta T)$ para eliminar $\rho$ do termo flutuante. Essa aproximação é precisa somente para pequenas mudanças na densidade, onde $\beta\left(T-T_{0}\right)<<1$.

\subsubsection{Lei do gás ideal incompressível}

Este modelo é usado quando as variações de pressão são tão pequenas que o fluido pode ser considerado totalmente incompressível, mas deseja-se usar a lei do gás ideal para expressar a relação entre a densidade e temperatura. A densidade é definida por:

$$
\rho=\frac{p_{o p}}{\frac{R}{M_{w}} T},
$$

onde $R$ é a constante universal dos gases, $M_{w}$ é o peso molecular do gás, e $p_{o p}$ é a pressão operativa. Desta forma, a densidade depende somente da pressão operativa e não do campo da pressão relativa local.

\subsubsection{Densidade em função da temperatura (piecewise-linear function):}

Este modelo é usado quando a densidade é função somente da temperatura. Os pares de dados (temperatura e densidade) devem ser inseridos pelo operador, para relacionar as duas variáveis, tal que: 


$$
\rho(T)=\rho_{n}+\frac{\rho_{n+1}-\rho_{n}}{T_{n+1}-T_{n}}\left(T-T_{n}\right),
$$

onde $1 \leq n \leq N$ e $N$ é o número de segmentos.

\subsection{APLICATIVOS UTILIZADOS NA SIMULAÇÃO}

Para realizar as simulações, serão utilizados os seguintes aplicativos:

- GAMBIT 2.1 (FLUENT INC., 2003c, 2003d, 2003e), aplicativo para modelar geometrias e gerar malhas;

- FLUENT 6.1.22 (FLUENT INC., 2003a, 2003b), código numérico para realização dos cálculos propriamente ditos.

\subsubsection{GAMBIT}

O GAMBIT é um código específico para a realização da etapa de préprocessamento, que consiste na preparação de dados de entrada de um problema de escoamento em um programa de CFD. Nele, são realizadas as etapas de modelagem da geometria, geração da malha e caracterização dos contornos do modelo (parede, entrada de ar, saída de ar, meio poroso, etc.).

\subsubsection{FLUENT}

O FLUENT é um código comercial de CFD (Dinâmica dos Fluidos Computacional), no qual é possível simular, em regime permanente ou transiente, diversos tipos de escoamentos (incompressíveis ou compressíveis, invíscidos, laminares ou turbulentos) por meio da seleção de parâmetros e condições de contorno adequadas. O programa também possibilita a abordagem de problemas que envolvem transferência de calor, reações químicas e trajetória de partículas em suspensão.

No FLUENT podem ser modeladas condições de contorno para entrada e saída de fluxo, paredes, condições de simetria e periodicidade, zonas internas (fluido, sólido, meio poroso) e condições de superfícies internas (fan, meio poroso, radiador). 
Fluent usa o método dos volumes finitos para converter as equações governantes em equações algébricas que podem ser resolvidas numericamente. Este método consiste na integração das equações governantes sobre cada volume de controle, resultando em equações discretas que conservam cada quantidade com base no volume de controle. O processo consiste na:

- Divisão do domínio em volumes de controle discreto usando uma malha computacional;

- Integração das equações dos fluxos de massa, quantidade de movimento, energia, etc., nos contornos dos volumes de controle para construir equações algébricas para as variáveis discretas dependentes (desconhecidas) tais como velocidades, pressão e temperatura;

- Linearização das equações discretizadas e solução do sistema de equações lineares resultantes fornecendo valores atualizados das variáveis dependentes (velocidade, temperatura, etc.).

A discretização das equações governantes pode ser ilustrada considerandose a equação de conservação de transporte da quantidade escalar $\phi$, escrita na forma integral para um volume de controle arbitrário $V$ :

$$
\oint \rho \phi \vec{v} \cdot d \vec{A}=\oint \Gamma_{\phi} \nabla \phi \cdot d \vec{A}+\int_{V} S_{\phi} d V
$$

onde $\rho$ é a densidade; $\vec{v}$ a velocidade vetorial; $\vec{A}$ o vetor da área da superfície; $\Gamma_{\phi}$ o coeficiente de difusão para $\phi ; \nabla \phi$ o gradiente de $\phi ; S_{\phi}$, o termo fonte de $\phi$ por unidade de volume.

A equação acima é aplicada para cada volume de controle, ou célula, no domínio computacional. A discretização da equação acima numa dada célula resulta em:

$$
\sum_{f}^{N_{\text {faces }}} \rho_{f} \vec{v}_{f} \phi_{f} \cdot \vec{A}_{f}=\sum_{f}^{N_{\text {faces }}} \Gamma_{\phi}(\nabla \phi)_{n} \cdot \vec{A}_{f}+S_{\phi} V,
$$

onde, $N_{\text {faces }}$ é o número de faces da célula; $\phi_{f}$ o valor de $\phi$ na face $f$; $\rho_{f} \vec{v}_{f} \cdot \vec{A}_{f}$ o fluxo de massa através da face; $\vec{A}_{f}$ a área da face $f,|A| ;(\nabla \phi)_{n}$ a magnitude de $\nabla \phi$ normal à face $f ; V$ o volume da célula. 


\subsection{DESENVOLVIMENTO DAS SIMULAÇÕES NUMÉRICAS}

Como não se pode garantir que o simulador forneça resultados representativos para qualquer combinação de parâmetros que envolvem os fenômenos de escoamento dos fluidos, sendo necessário realizar os processos de verificação e validação para garantir que, a partir dos testes realizados, resultados compatíveis com o fenômeno físico real sejam encontrados. O objetivo das etapas de verificação e validação não é responder se o simulador "funciona" ou não, mas quão bem ele trata os diversos fenômenos físicos relevantes à sua aplicação como ferramenta de previsão.

A etapa de verificação determina se a implementação do modelo corresponde à sua descrição conceitual. Essa etapa tem o objetivo de estimar a confiabilidade do processo de resolução do problema. Os resultados numéricos fornecidos pela implementação do modelo são assim comparados a outras soluções, consideradas "de referência".

$\mathrm{Na}$ etapa de validação a representatividade do modelo em relação ao fenômeno físico real é testada, por meio de comparações com dados experimentais representativos do fenômeno em estudo.

No presente estudo, assume-se que essas etapas já foram desenvolvidas no trabalho de Pustelnik (2005). Em seu estudo, Pustelnik (2005) realizou a simulação numérica de um experimento também realizado na câmara experimental descrita no capítulo 3, utilizando, para tanto, a mesma ferramenta computacional que a empregada neste trabalho (FLUENT). Para a realização das simulações, Pustelnik (2005) empregou os seguintes modelos de turbulência disponíveis na ferramenta computacional utilizada: Spalart Allmaras, $k-\varepsilon$ padrão, $k-\varepsilon$ RNG, $k-\varepsilon$ realizável, $k-\omega$ padrão, $k$ - $\omega$ SST e RSM. Embora a análise dos perfis de velocidade do ar tenha sido considerada insatisfatória, devido à elevada incerteza das medições, na análise dos perfis de temperatura, o autor afirma que boa concordância foi verificada na utilização dos modelos $k$ - $\mathcal{E}$. Contudo, o modelo que melhor representa os dados experimentais, segundo Pustelnik (2005) é o RSM.

Sendo assim, para o presente estudo, admite-se que as equações diferenciais são corretamente resolvidas no Fluent e o modelo de turbulência $k-\mathcal{E}$ padrão representa com boa aproximação o fenômeno físico a ser estudado. 


\subsubsection{HIPÓTESES E SIMPLIFICAÇÕES ADOTADAS}

Para a realização das simulações no presente estudo foram respeitadas as mesmas hipóteses e simplificações adotadas para a simulação do escoamento do ar em sistemas de distribuição de ar pelo piso, que aquelas estabelecidas no trabalho de Pustelnik (2005).

As seguintes hipóteses foram adotadas para a realização das simulações:

- Escoamento turbulento em regime permanente. O sistema de distribuição de ar pelo piso apresenta um comportamento do escoamento do ar bastante característico, com uma região de mistura do ar na zona ocupada e uma região de estratificação do ar, acima da zona ocupada (deslocamento do ar na direção do teto). Como a zona ocupada é a região de maior interesse, para estudos de conforto térmico, adotou-se como hipótese o escoamento turbulento para todo o domínio computacional;

- Fluxo incompressível, ou seja, a densidade do elemento do fluido (ar) não muda durante seu movimento;

- Fluxo de calor constante e uniformemente distribuído nos monitores de vídeo;

- A umidade relativa do ar não foi levada em consideração. Supõe-se que o ar insuflado no interior do ambiente tenha baixa umidade, não tendo participação significativa na transferência de calor;

- Paredes, divisórias, piso e teto considerados adiabáticos, ou seja, não possuem participação na transferência de calor;

- Difusores de ar e grelhas de retorno modelados como meios porosos, com a perda de carga (figura 4.6) imposta na direção normal à superfície de entrada de ar.

\subsubsection{MODELAGEM DA GEOMETRIA}

A geometria da câmara experimental, ilustrada nas figuras 4.3 a 4.5 , foi modelada no pré-processador GAMBIT, versão 2.1 (FLUENT INC., 2003c e 2003e). 


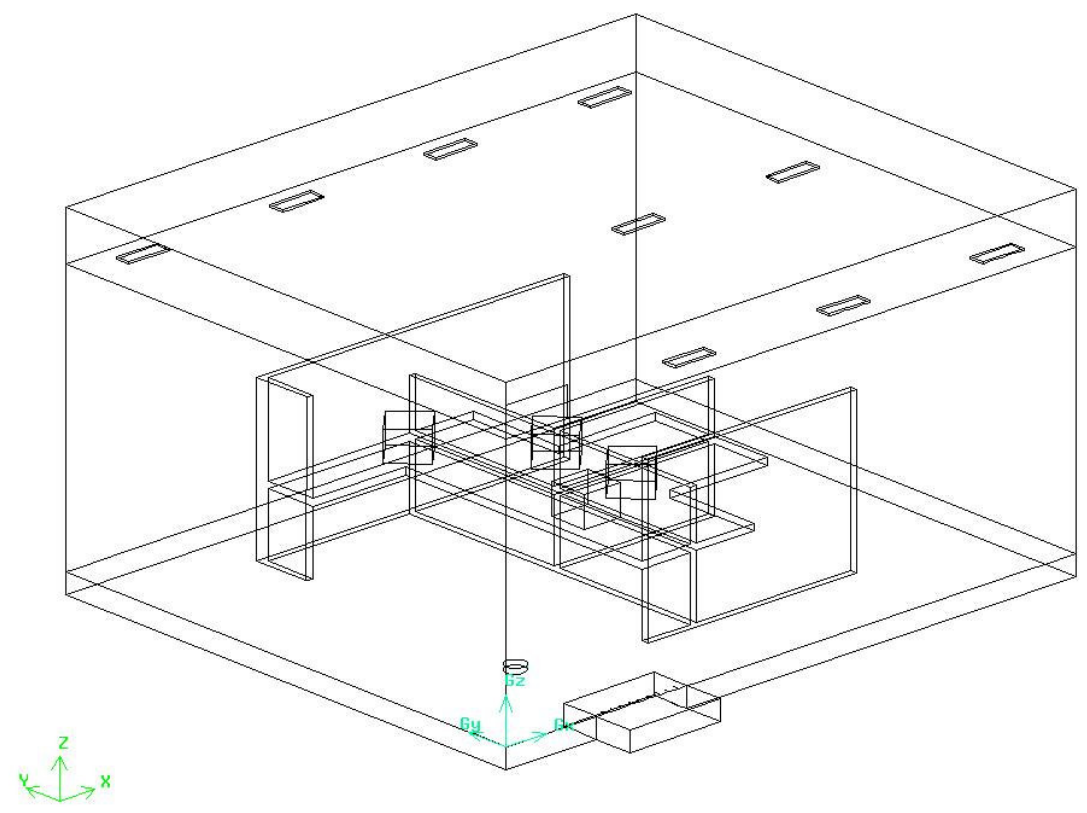

Figura 4.3 - Modelo geométrico da câmara de testes

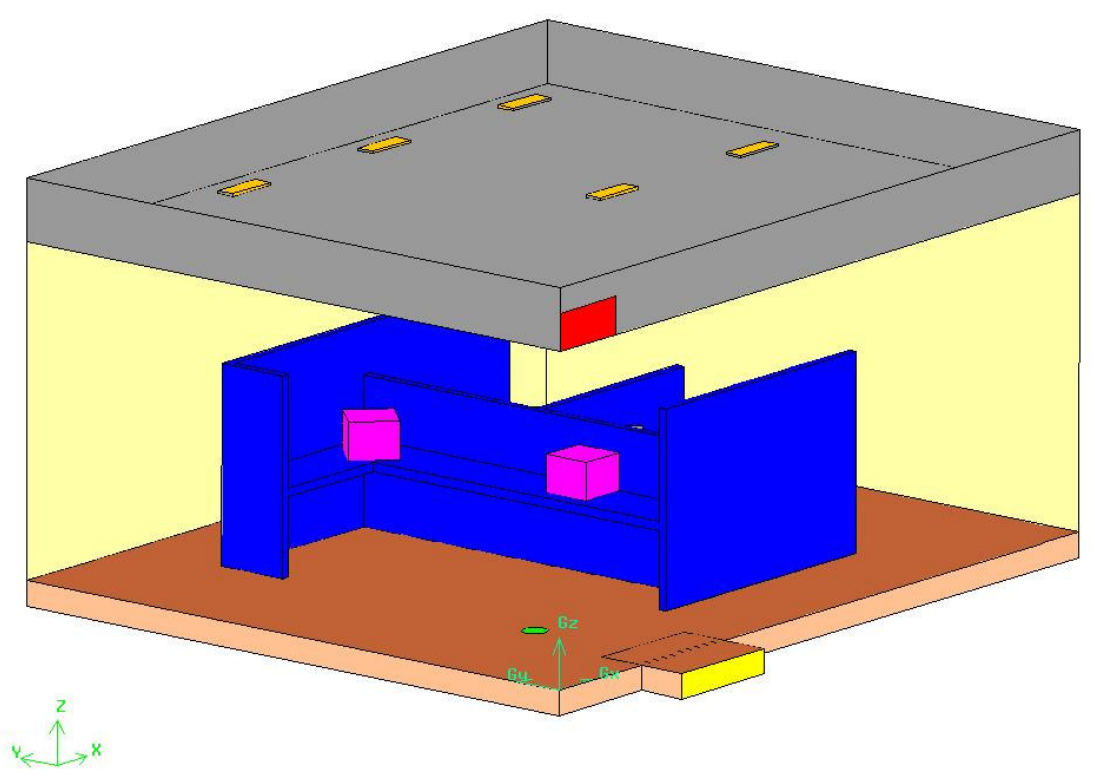

Figura 4.4 - Representação da câmara de testes 


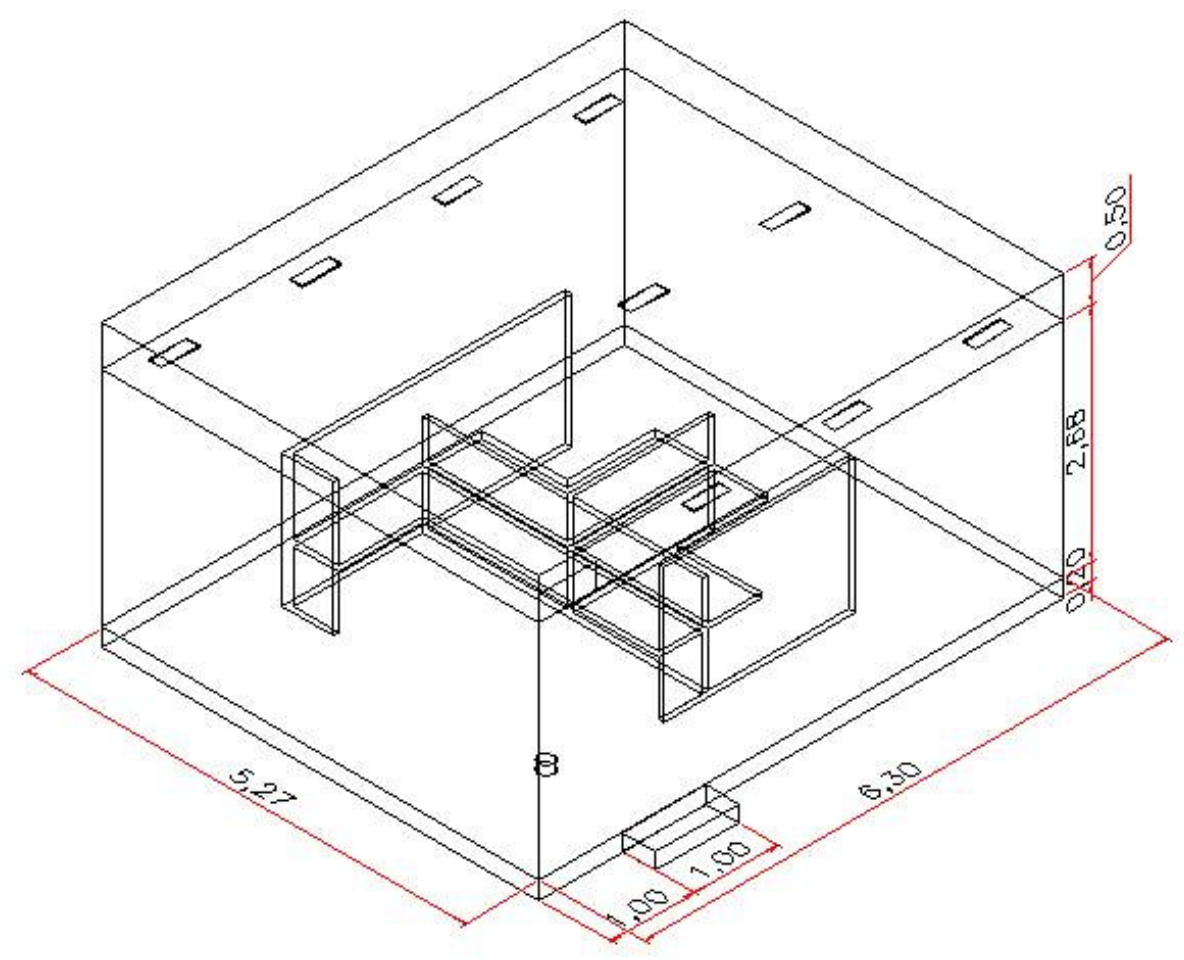

Figura 4.5 - Dimensões da câmara experimental

\subsubsection{GERAÇÃO DA MALHA}

A escolha do tipo de malha depende da complexidade geométrica e da física. Em uma sala vazia, por exemplo, a malha estruturada seria a escolha mais indicada para o fenômeno físico e para as camadas próximas às paredes, que são bem capturadas em elementos alinhados, contudo, quando há muitos objetos (mesas, cadeiras, manequins, etc.) a geração de uma malha não estruturada pode ser a mais indicada (ABANTO et al., 2004).

Segundo Abanto et al. (2004), Hu (2003) e Teodosiu et al. (2003) o emprego da malha não-estruturada é mais vantajoso:

- Para a discretização de domínios com geometrias complexas;

- Nos casos em que o fluxo não está alinhado com a malha;

- Para facilitar o refinamento da malha.

Além disso, a criação de malhas estruturadas ou blocos-estruturados (que consistem de elementos quadriláteros ou hexaédricos) em determinados problemas pode ser extremamente demorada, e, em alguns casos, até mesmo impossível (FLUENT INC.; 2003b). 
Para o presente estudo uma malha híbrida, composta por elementos tetraédricos e hexaédricos, foi gerada com 779.249 elementos. Malhas estruturadas foram empregadas na entrada de ar, nos monitores, nas grelhas de retorno e na saída de ar. Já o processo de construção da malha no interior do ambiente (fluido) baseia-se na divisão do domínio computacional em elementos tetraédricos. As figuras 4.6 a 4.9 ilustram a malha, gerada no pré-processador GAMBIT.

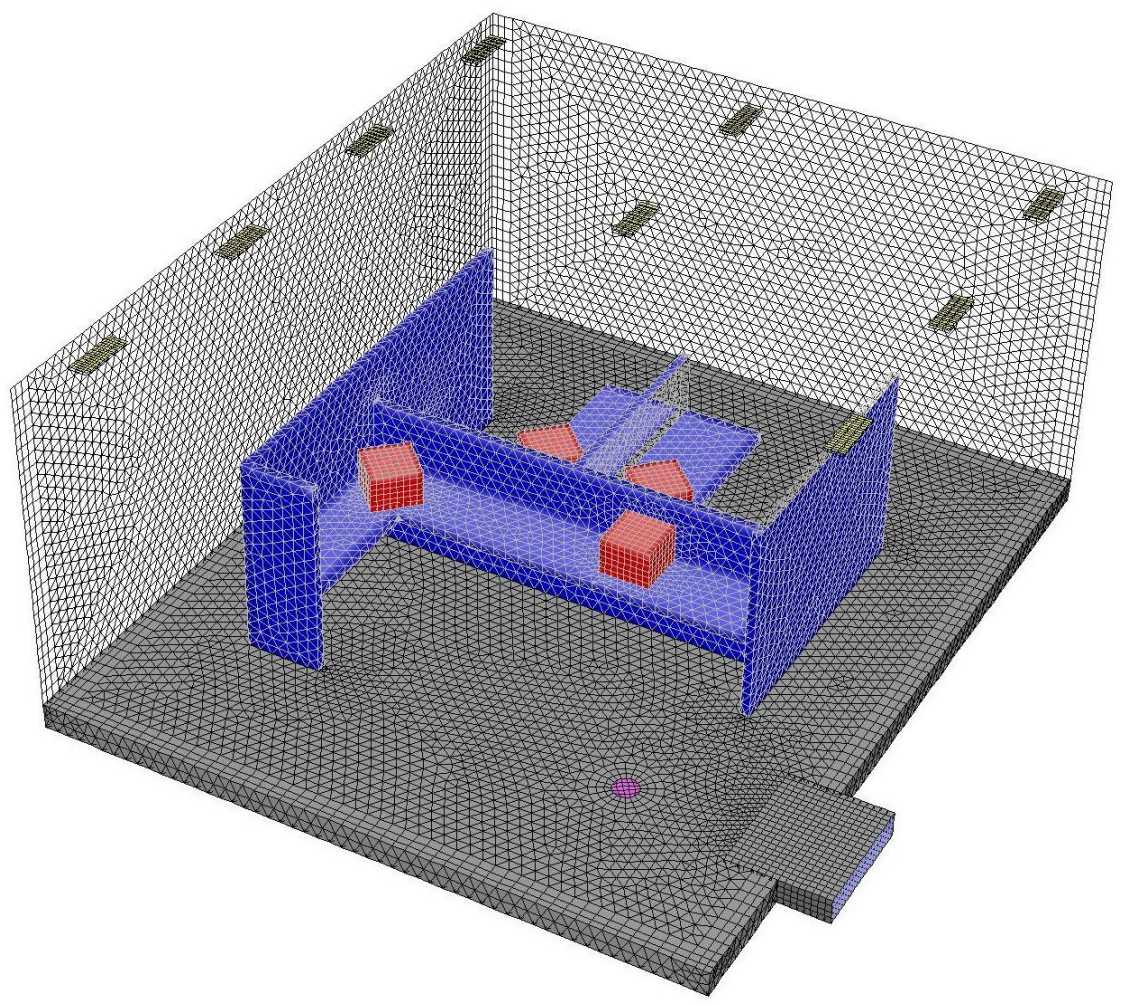

Figura 4.6 -Representação da malha 1 - Perspectiva 


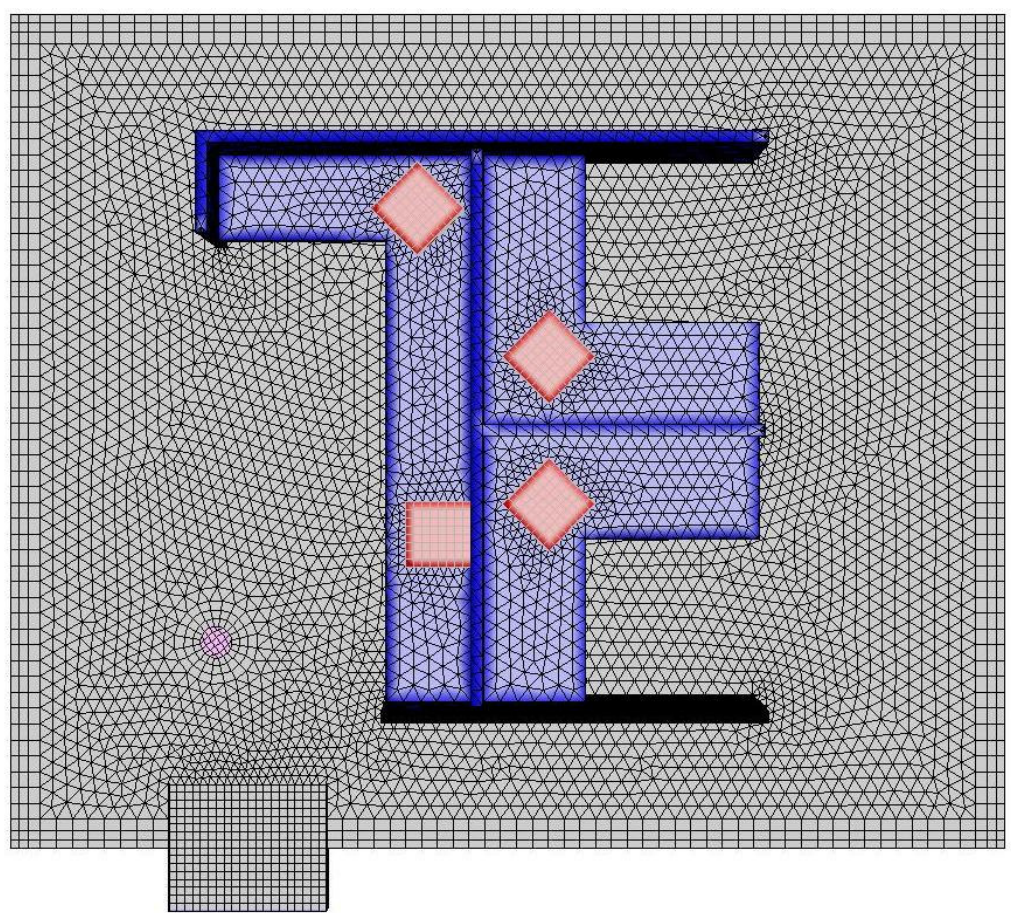

Figura 4.7 -Representação da malha 1 - Vista do piso

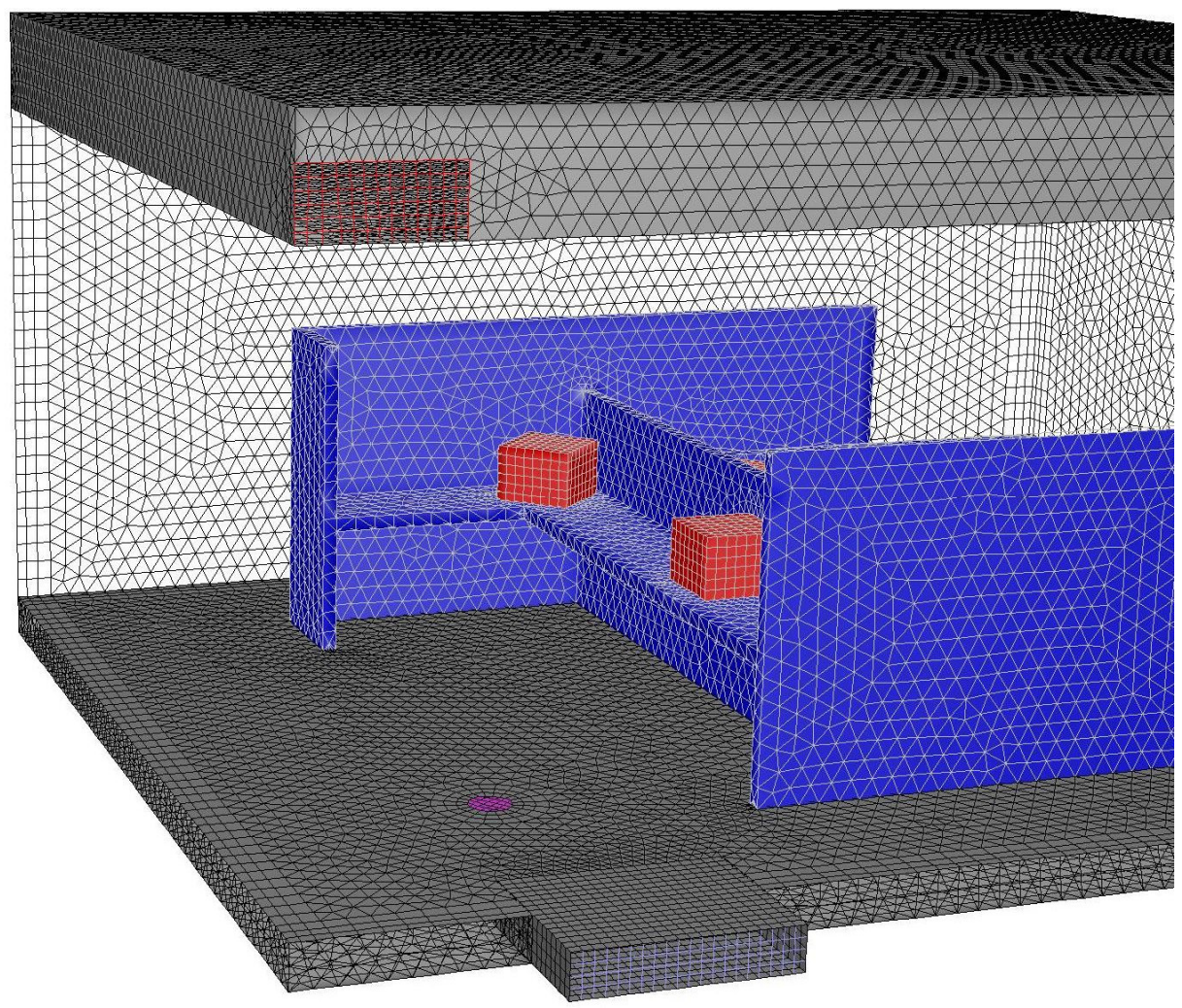

Figura 4.8 - Representação da malha 1 - Detalhe 1 


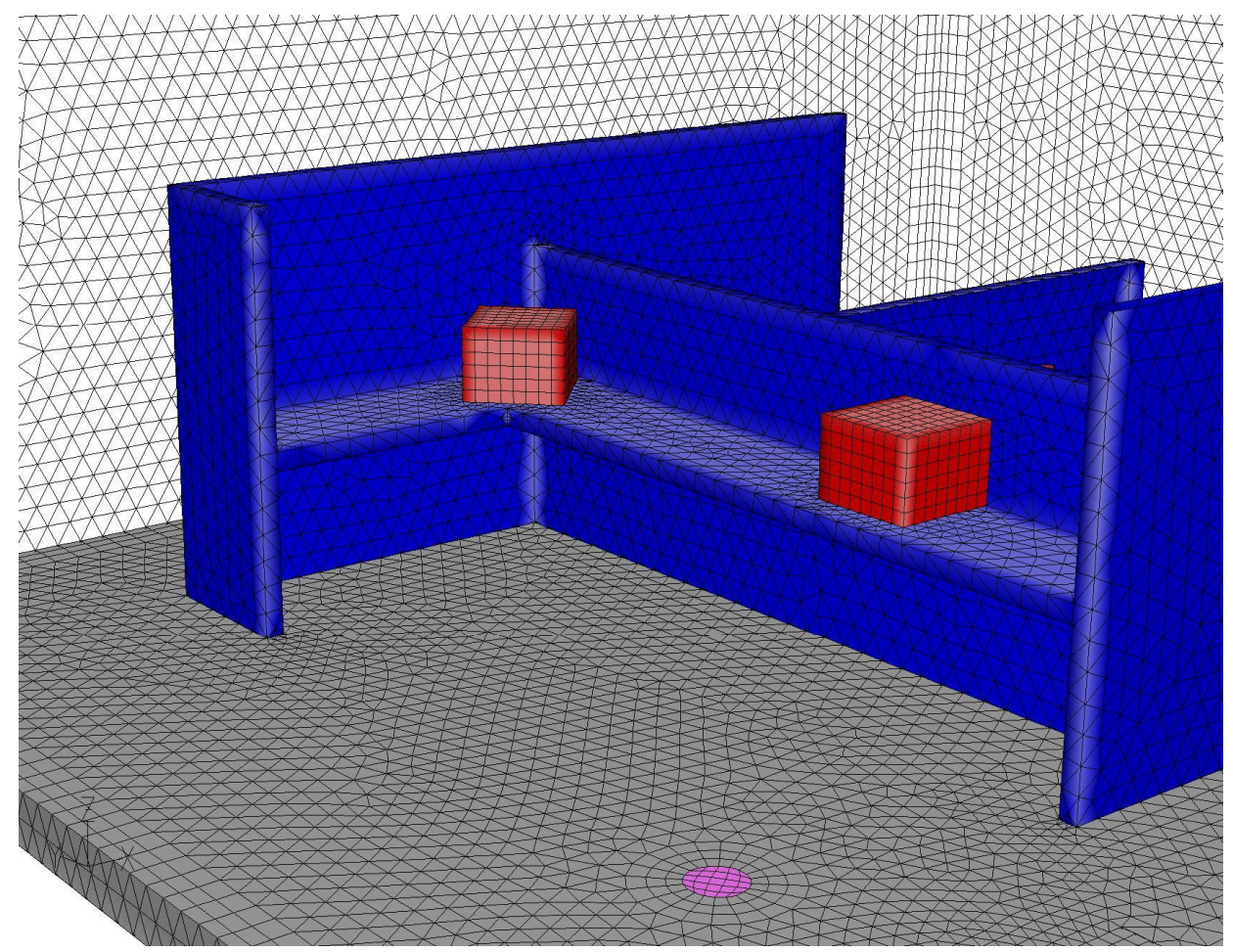

Figura 4.9 - Representação da malha 1 - Detalhe 2

\subsubsection{CONDIÇÕES DE CONTORNO}

As seguintes condições de contorno (ilustradas na figura 4.10) foram adotadas para o presente estudo:

- Entrada de ar: modelada com a condição Velocity inlet, usada para definir a velocidade e as propriedades escalares do fluxo, válida somente para fluxos incompressíveis. Para simulações numéricas utilizando os modelos $k-\varepsilon$, $k-\omega$ ou RSM, a solução é independente dos valores iniciais de $k$ e $\varepsilon$ (ou $k$ e $\omega$ ) (FLUENT INC., 2003b). Assim, foram mantidos os valores default préestabelecidos no FLUENT: $1 \mathrm{~m}^{2} / \mathrm{s}^{2}$ para $k$ e $1 \mathrm{~m}^{2} / \mathrm{s}^{3}$ para $\varepsilon$.

- Grelhas de retorno: modeladas com a condição de meio poroso, no qual foi imposta uma perda de carga extraída do gráfico da Figura 4.12;

- Saída de ar: modelada com a condição Pressure Outlet, usada para definir a pressão estática na saída de ar.

- Paredes, divisórias, piso e teto: modelados com a condição Wall, com fluxo de calor e de massa nulos. O conjunto foi considerado adiabático, ou seja, não troca calor com o meio; 
- Painel de lâmpadas: como o painel de lâmpadas foi mantido desligado no experimento, na simulação foi modelado com a condição Wall, com fluxo de calor e de massa nulos;

- Monitores de vídeo: Modeladas fontes de calor sólidas.

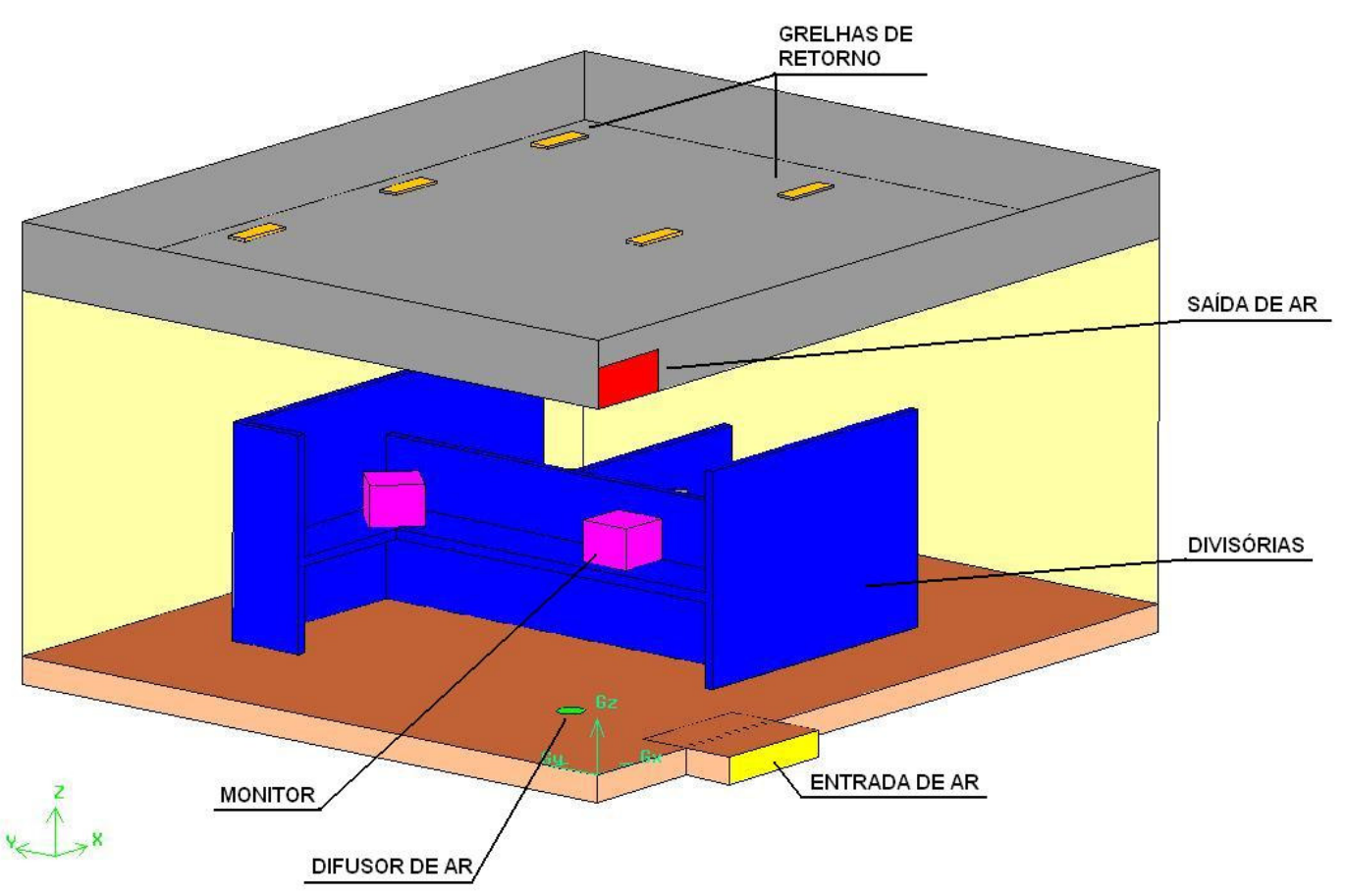

Figura 4.10 - Indicação dos principais elementos da câmara de testes

\subsubsection{Difusor de ar}

O tipo de difusor de ar e os parâmetros de insuflação geralmente determinam o escoamento do ar no interior do ambiente (HU, 2003). Assim, a correta caracterização dos difusores de ar no modelo computacional é fundamental para que os resultados das simulações numéricas sejam factíveis.

O difusor de ar geralmente apresenta uma estrutura bastante complexa que dificulta sua representação detalhada no domínio computacional. Mesmo que o método de predição numérica permita o emprego de dimensões que vão de milímetros (componentes dos difusores de ar) até diversos metros (paredes das salas) (NIELSEN, 2004; ZHAO et al., 2003), a modelagem detalhada de um difusor de ar aumenta significativamente o tempo de simulação e exige grande capacidade computacional, praticamente inviabilizando a realização das simulações numéricas. 
Assim, para o presente estudo, foram utilizadas as condições empregadas por Pustelnik (2005) para a definição do difusor de ar. Trata-se de um cilindro no qual foi imposta, em sua superfície superior (em contato com o ar do interior da sala), a condição de contorno fan. Esta condição foi empregada para impor uma velocidade tangencial (Figura 4.11) com o objetivo de reproduzir o perfil helicoidal de velocidades característico do fenômeno físico real. A velocidade tangencial imposta foi fixada em $0,4 \mathrm{~m} / \mathrm{s}$, para o eixo $Z$ negativo (considerou-se o eixo $Z$ normal ao piso, sendo que o $Z$ positivo aponta para cima do piso elevado e o $Z$ negativo aponta para baixo do piso elevado).

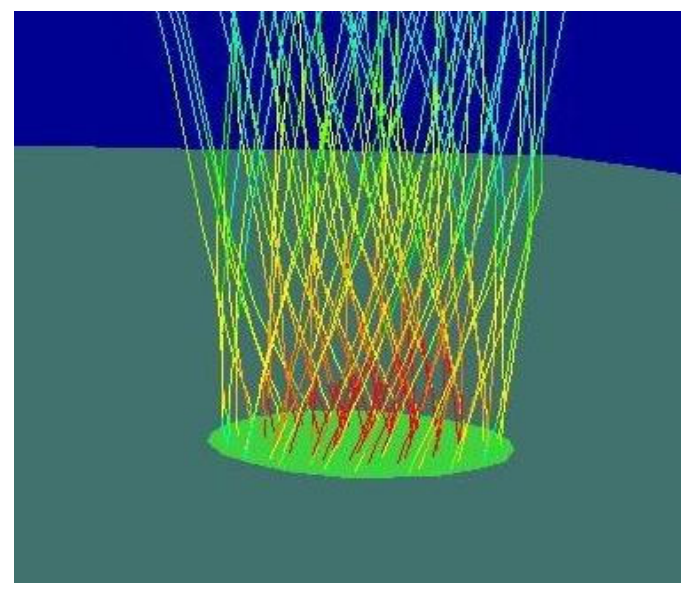

Figura 4.11 - Representação da velocidade tangencial imposta no difusor de ar

A região interna do cilindro foi caracterizada como um meio poroso, no qual foi imposta a perda de carga fornecida pelo fabricante do difusor (figura 4.12).

No caso dos difusores de ar de $\phi 200 \mathrm{~mm}$, a perda de carga é determinada pela "power law", que é uma relação entre as duas escalares perda de carga e velocidade, definida pela função $y=21,509 x^{2,0298}$. Os valores de $y$ correspondem à perda de carga e os valores de $x$ correspondem à velocidade do ar. Para as grelhas de retorno, a perda de carga é definida pela função $y=0,031 x^{2,0528}$. 


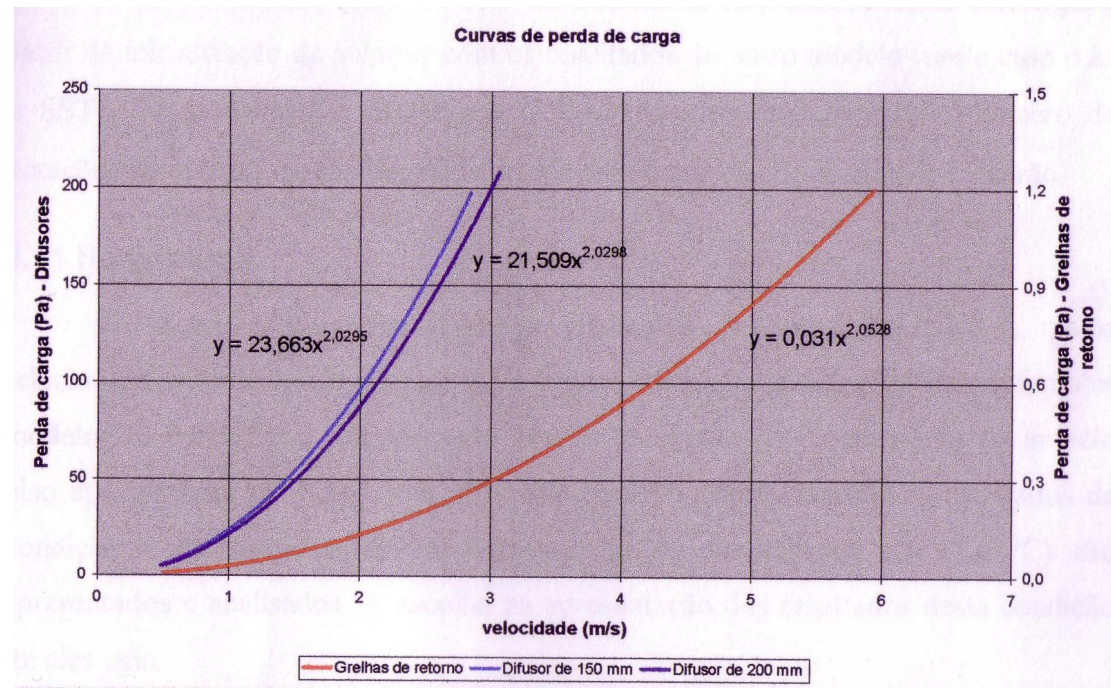

Figura 4.12 - Perda de carga nas grelhas de retorno e difusores de $150 \mathrm{~mm}$ e $200 \mathrm{~mm}$ (FONTE: PUSTELNIK, 2005)

\subsubsection{PROPRIEDADES FÍSICAS DO FLUIDO}

Após a definição das condições de contorno, foram definidas as propriedades físicas do fluido. O fluido empregado para a realização das simulações é o ar, com as seguintes propriedades:

- Viscosidade:

- Condutividade térmica:

- Calor específico:

- Peso molecular:
$1,7894 \times 10^{-5} \mathrm{~kg} / \mathrm{m} . \mathrm{s}$

$0,0242 \mathrm{~W} / \mathrm{m} . \mathrm{K}$

$1006,43 \mathrm{~J} / \mathrm{kg} . \mathrm{K}$

$28,966 \mathrm{~kg} / \mathrm{kgmol}$

Para a realização dos testes 1,2 e 3 , descritos no item 5.2, foi empregado o modelo de Boussinesq para a densidade do ar, com as seguintes propriedades:

- Densidade:

- Coeficiente de expansão térmica:
$1,225 \mathrm{~kg} / \mathrm{m}^{3}$

$$
3,43 \times 10^{-3} \cdot 1 / \mathrm{K}
$$

\subsubsection{MODELO DE TURBULÊNCIA}

O modelo de turbulência adotado foi o $k-\varepsilon$ padrão. Embora seja válido somente para turbulência totalmente desenvolvida (NIELSEN, 1998), o modelo $k-\varepsilon$ padrão é o mais utilizado nas simulações de escoamento do ar no interior de 
ambientes ventilados mecanicamente, por apresentar resultados satisfatórios e não consumir muito tempo de cálculo.

\subsubsection{CONDIÇÕES INICIAIS}

As condições iniciais impostas para todos os testes foram de velocidades nulas nas coordenadas $(x, y, z)$ e temperatura de $290 \mathrm{~K}\left(17^{\circ} \mathrm{C}\right)$. Por se tratar de um escoamento em regime permanente, os resultados dos perfis de temperatura e de velocidade independem das condições iniciais.

\subsubsection{MÉTODO DE SOLUÇÃO NUMÉRICA}

As simulações foram realizadas empregando-se a versão do solver que resolve problemas tridimensionais com cálculos de dupla precisão.

Para a formulação do solver foi empregado o método segregado implícito. Por segregado entende-se que o solver resolve as equações de continuidade, momento e energia seqüencialmente (segregadas umas das outras).

No método de solução segregado, as equações governantes não lineares são linearizadas para produzir um sistema de equações para as variáveis dependentes em cada célula computacional. O sistema linear resultante é então resolvido para fornecer uma solução de campo atualizada. A maneira com a qual as equações governantes são linearizadas toma uma forma implícita com relação à variável dependente, quando o valor desconhecido nas células é computado usando uma relação que inclui tanto os valores existentes quanto os valores desconhecidos das células vizinhas. Depois disso, cada variável desconhecida vai aparecer em mais de uma equação no sistema, e essas equações devem ser resolvidas simultaneamente para determinar as quantidades desconhecidas.

Em resumo, a aproximação segregada implícita resolve uma variável de campo considerando todas as células ao mesmo tempo. A seguir, ela resolve para a próxima variável de campo, e assim por diante. Tradicionalmente tem sido o método mais empregado para o estudo de fluidos incompressíveis ou medianamente compressíveis. 
Para a discretização das equações governantes foi empregado o esquema upwind de primeira ordem. Embora para malhas tetraédricas resultados mais precisos sejam obtidos usando-se o esquema upwind de segunda ordem, este não pode ser empregado para modelos que contenham meios porosos.

A discretização é a transformação das equações diferenciais contínuas em equações discretas, possibilitando o cálculo computacional. O método de discretização da ferramenta computacional empregada no presente estudo foi descrito no item 4.3.2.

O FLUENT armazena os valores discretos das escalares $\phi$ no centro das células. Contudo, valores das faces $\phi_{f}$ são requeridos para os termos convectivos e devem ser interpolados dos valores do centro das células. Isto é conseguido pelo esquema upwind.

No esquema upwind a aproximação da derivada espacial depende da direção de propagação das variáveis. Elas utilizam valores sempre à montante da posição na qual elas são aplicadas, já que o valor da variável em um dado ponto depende das propriedades transportadas, de pontos à montante de $\mathrm{P}$, e não das propriedades à jusante (direção para onde se propaga a variável).

\subsubsection{CRITÉRIO DE CONVERGÊNCIA}

Adotou-se como critério de convergência a estabilização do perfil da velocidade média medida ao longo de uma linha imaginária (do piso ao teto) localizada sobre o centro do difusor de ar.

\subsubsection{TESTE DE INDEPENDÊNCIA DE MALHA}

A simulação numérica de um determinado problema pode apresentar diferentes resultados dependendo da qualidade da malha empregada. Assim, é necessário realizar o teste de independência de malha, que se constitui em um refinamento sucessivo de uma malha, que a princípio pode ser grosseira, até que a solução não se altere, dentro de um critério de tolerância (FORTUNA, 2000; VERSTEEG e MALALASEKERA, 1995). 
O teste de independência de malha, teve início com a simulação do ambiente empregando-se a malha 1, ilustrada nas figuras 4.6 a 4.9, com 779.249 elementos. Para a simulação, foram adotados os seguintes valores para as condições de contorno:

- Entrada de ar: foi adotado um valor arbitrário de velocidade igual a 0,2 $\mathrm{m} / \mathrm{s}$, e a temperatura de $290 \mathrm{~K}\left(17^{\circ} \mathrm{C}\right)$, já que não havia dados disponíveis sobre o valor da velocidade e temperatura do ar insuflado no interior do plenum;

- Difusor de ar: velocidade tangencial de 0,3 m/s para reproduzir o perfil helicoidal característico dos difusores swirl. Foi imposta a condição de meio poroso sob o fan, no qual foi também imposta uma perda de carga extraída do gráfico da Figura 4.12;

- Paredes, divisórias, piso e teto: Considerados adiabáticos;

- Monitores de vídeo: Considerados adiabáticos;

- Grelhas de retorno: meio poroso, no qual foi imposta uma perda de carga extraída do gráfico da Figura 4.12;

- Saída de ar: estabeleceu-se uma pressão estática igual a zero, que reproduz a saída para o meio ambiente (PULSTELNIK, 2005).

Após a simulação numérica com o emprego da malha 1, outros dois testes foram realizados. No FLUENT, versão 6.1.22 (FLUENT INC., 2003a, 2003b), a malha 1 foi refinada, resultando na malha 2, com 1.066 .991 elementos. A malha 2 , por sua vez, foi novamente refinada, resultando na malha 3, com 1.593.120 elementos. Os refinamentos da malha 1 e 2, que resultaram na malha 2 e 3 , respectivamente, correspondem a uma adaptação da malha que divide os elementos em elementos menores, em regiões definidas pelo operador.

Esse processo se faz necessário porque, em geral, quanto maior o número de células, melhor a precisão da solução. Contudo, como o tempo de cálculo depende do refinamento da malha, malhas muito refinadas consomem muito tempo de simulação. Assim, malhas ótimas são freqüentemente não-uniformes, ou seja, mais refinadas nas áreas onde variações grandes ocorrem de ponto a ponto e mais grosseiras em regiões com relativamente pouca mudança (VERSTEEG e MALALASEKERA, 1995). O teste de independência de malhas é necessário para estabelecer a malha ideal, ou seja, aquela cujos resultados sejam precisos e não variem com refinamentos sucessivos, além de não consumir tempo de cálculo demasiado. 
A figura 4.13 mostra os resultados dos perfis da velocidade do ar para as três malhas construídas.

Para se concluir que a simulação é independente da malha, os perfis de velocidade do ar resultantes devem ser idênticos. Pequenas discrepâncias entre os perfis de velocidade do ar (Figura 4.13) podem ser resultados da existência de escoamentos localizados que não possuem características de regime permanente; algumas variáveis podem flutuar em torno de um valor médio, tendo o seu valor instantâneo dependendo do número de iterações (PUSTELNIK, 2005).

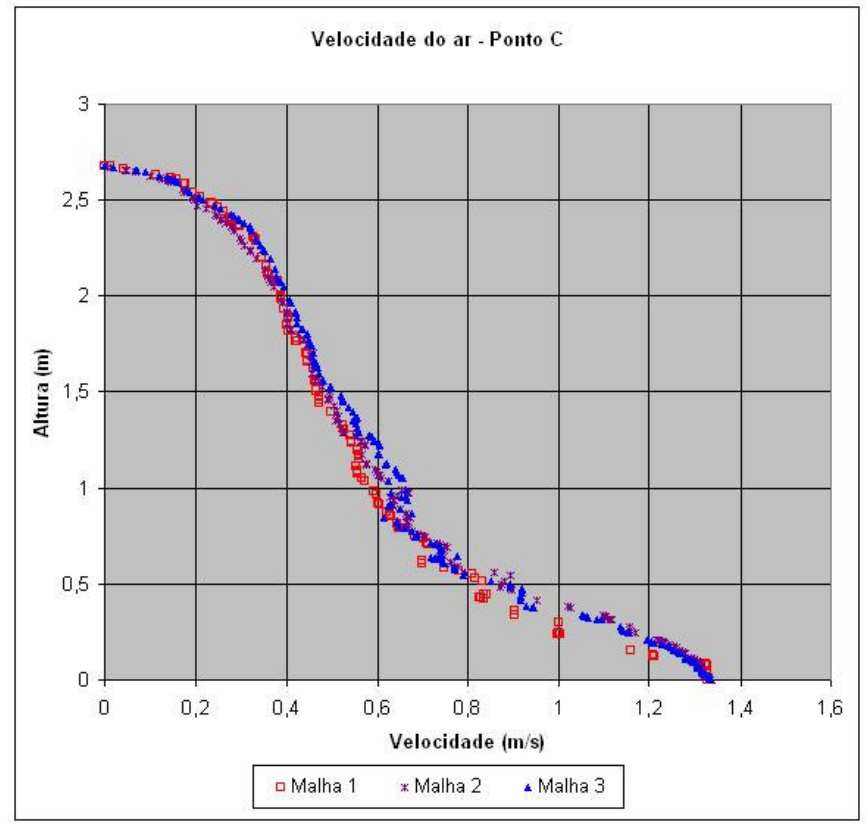

Figura 4.13 - Teste de independência de malha

Como os três perfis de velocidade do ar resultantes são bastante semelhantes, foi adotada a malha 1, com menor número de elementos, para dar prosseguimento à verificação das hipóteses adotadas para a simulação do experimento citado. 


\section{ESTRATÉGIA PROPOSTA}

O objetivo do presente estudo é desenvolver uma estratégia para a determinação dos parâmetros de operação de sistemas de distribuição de ar pelo piso. A estratégia baseia-se no estabelecimento de inter-relações dos parâmetros que definem o escoamento do ar em sistemas UFAD, por meio da utilização de uma ferramenta de dinâmica dos fluidos computacional e um método gráfico.

Assim, a primeira etapa consiste na realização de simulações numéricas do caso que se deseja estudar, por exemplo, a câmara experimental descrita no capítulo 3. Essas simulações são necessárias para fornecer os valores de variávies desconhecidas e possibilitar o estabelecimento de relações entre as variávies.

São necessárias no mínimo três simulações. Cada uma é realizada combinando-se diferentes valores para duas variáveis (dados de entrada, como a velocidade e a temperatura do ar insuflado, por exemplo). Os resultados dessas simulações fornecem os valores da terceira variável.

Os parâmetros empregados nas simulações, juntamente com os resultados obtidos, são transferidos para um gráfico tridimensional. Cada eixo do gráfico corresponde a um dos parâmetros. Assim, é possível determinar três pontos no espaço e, conseqüentemente, um plano que contém os resultados de todas as combinações possíveis entre os parâmetros considerados (figuras 5.1 e 5.2).

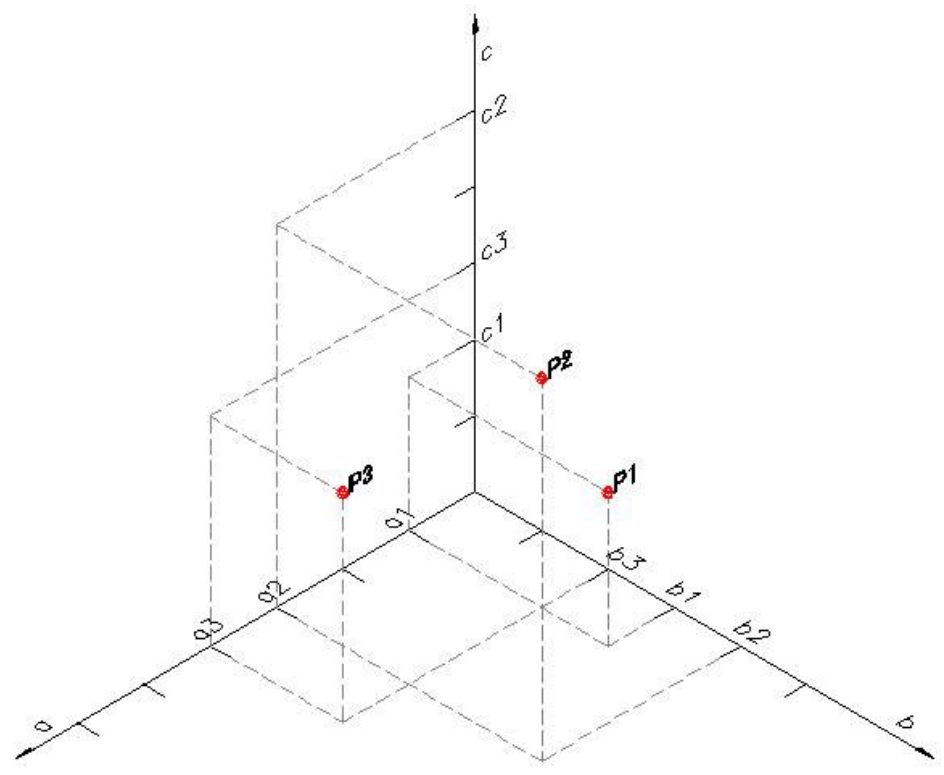

Figura 5.1 - Pontos P1, P2 e P3 representam a combinação dos valores das três variáveis para cada simulação 
Obtém-se desse modo, um sistema de inter-relações dos parâmetros estudados, facilitando o processo de tomada de decisão.

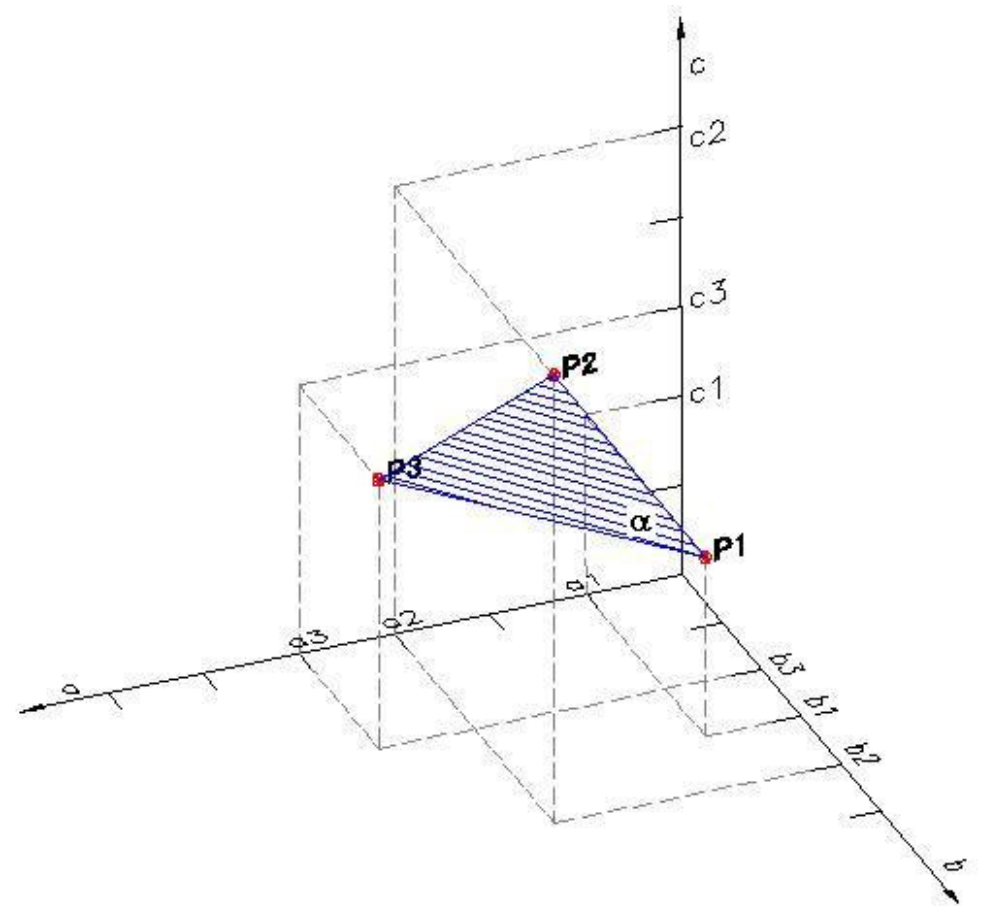

Figura 5.2 - Definição do plano $\alpha$ por meio da ligação entre os pontos

O plano a contém as combinações possíveis entre as três variáveis, a, b e c (Figura 5.3).

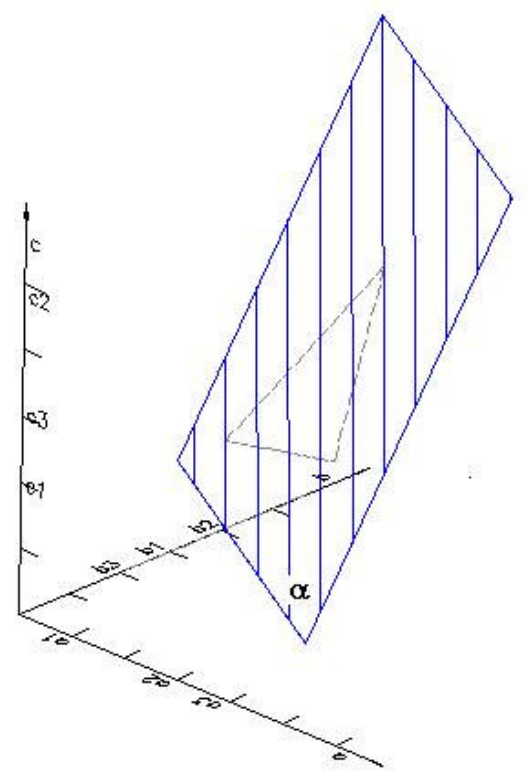

Figura 5.3 - Plano $\alpha$ 
Assim, supondo que o projetista do sistema de ventilação mecânica esteja interessado em manter um valor "c4" para a variável "c" no interior do ambiente, um valor "a4", determinado pelo projetista, é adotado, para a variável "a". Os dados das variáveis "a" e "c" são então plotados no gráfico, conforme ilustrado na figura 5.4.

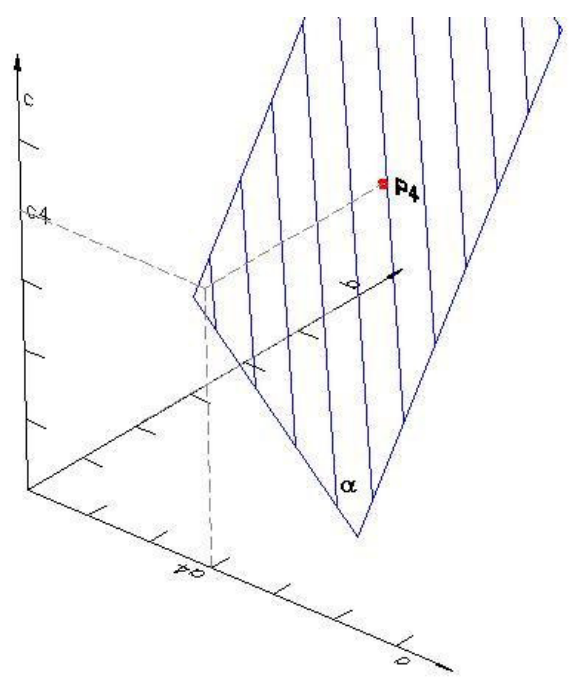

Figura 5.4 - Determinação do ponto P4

A projeção do ponto $\mathrm{P} 4$, ilustrada na figura 5.5, no plano das coordenadas "a" e "b" fornece o valor "b4" da variável "b", necessário para manter no ambiente o valor desejado para a variável "c".

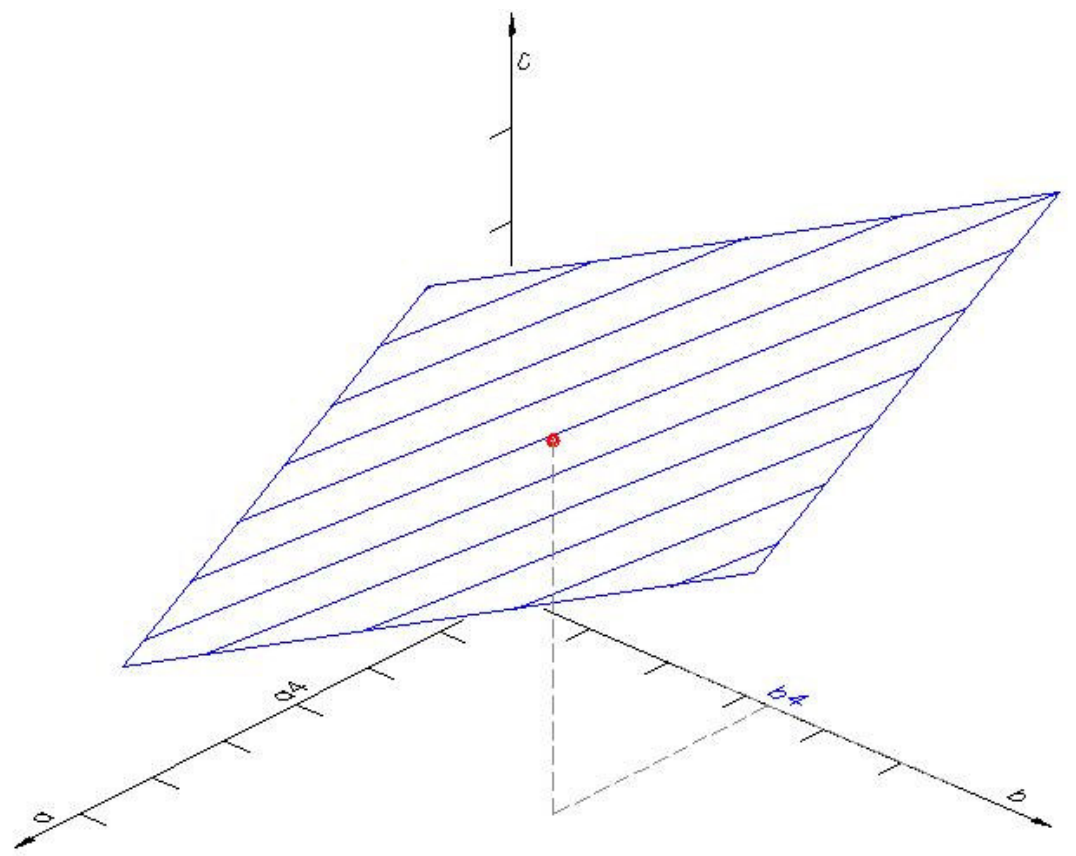

Figura 5.5 - Determinação do valor da variável "b" 
A estratégia estabelece as inter-relações entre as variáveis de operação do sistema de distribuição de ar frio pelo piso de maneira direta e bastante simplificada. Seu uso ultrapassa a barreira de aplicação em sistemas de distribuição de ar frio pelo piso, podendo ser utilizado também para o estabelecimento de inter-relações entre as variáveis dos sistemas de distribuição de ar frio convencionais.

No capítulo seguinte será apresentada a verificação da estratégia proposta com base em um teste experimental realizado por Leite (2004). 


\section{VERIFICAÇÃO DA ESTRATÉGIA PROPOSTA}

Para a verificação da estratégia proposta um teste foi realizado, com base no experimento descrito no item 3.1. O experimento fornece os dados de velocidade e temperatura do ar medidos próximos ao difusor de piso, bem como um diferencial de pressão entre o plenum do piso e o interior do ambiente. A condição interna do ambiente durante a realização do experimento será adotada como condição ideal, ou seja, aquela que se deseja manter.

A estratégia descrita no capítulo 5 possibilita que sejam estabelecidas combinações de valores de vazão e temperatura, que resultem na condição desejada (diferença de pressão entre o plenum do piso e o ambiente de 25Pa).

\subsection{SIMULAÇÕES NUMÉRICAS}

Foram simulados três casos tomando-se como base o experimento descrito no item 3.1 e adotando-es os procedimentos descritos no item 4.4

As simulações foram realizadas utilizando-se os seguintes valores para vazão e temperatura na entrada de ar:

- Teste 1: $30 \mathrm{~L} / \mathrm{s}$ e $290 \mathrm{~K}\left(17^{\circ} \mathrm{C}\right)$;

- Teste 2: $40 \mathrm{~L} / \mathrm{s}$ e $294 \mathrm{~K}\left(21^{\circ} \mathrm{C}\right)$;

- Teste 3: $32 \mathrm{~L} / \mathrm{s}$ e $294 \mathrm{~K}\left(21^{\circ} \mathrm{C}\right)$.

Os valores de pressão estática resultantes para as três simulações realizadas podem ser observados nas figuras 6.1 a 6.3. Dos resultados das três simulações realizadas foram extraídos os diferenciais de pressão indicados na tabela 6.1. 


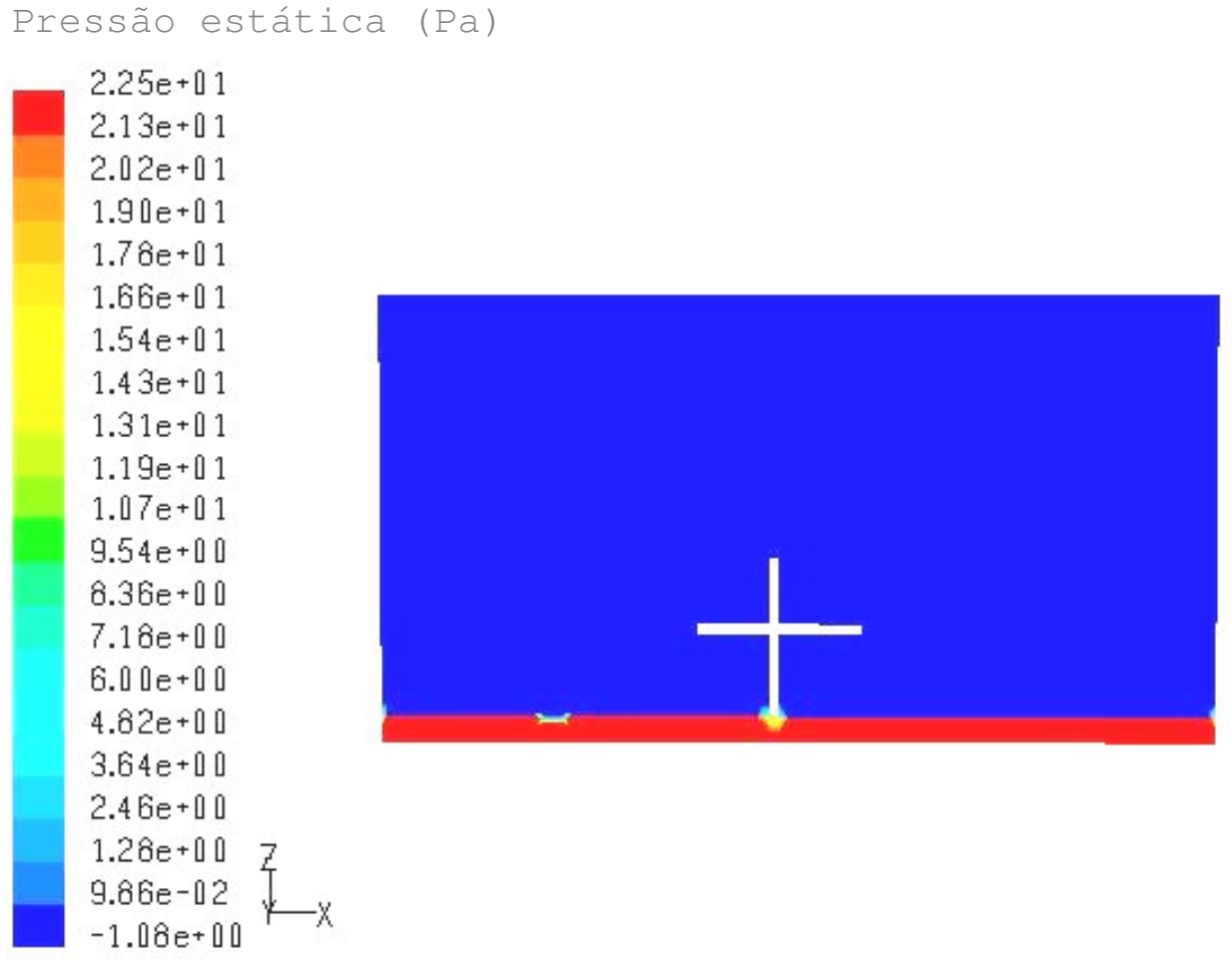

Figura 6.1 - Teste 1 - Pressão estática $(\mathrm{Pa})$

Pressão estática (Pa)

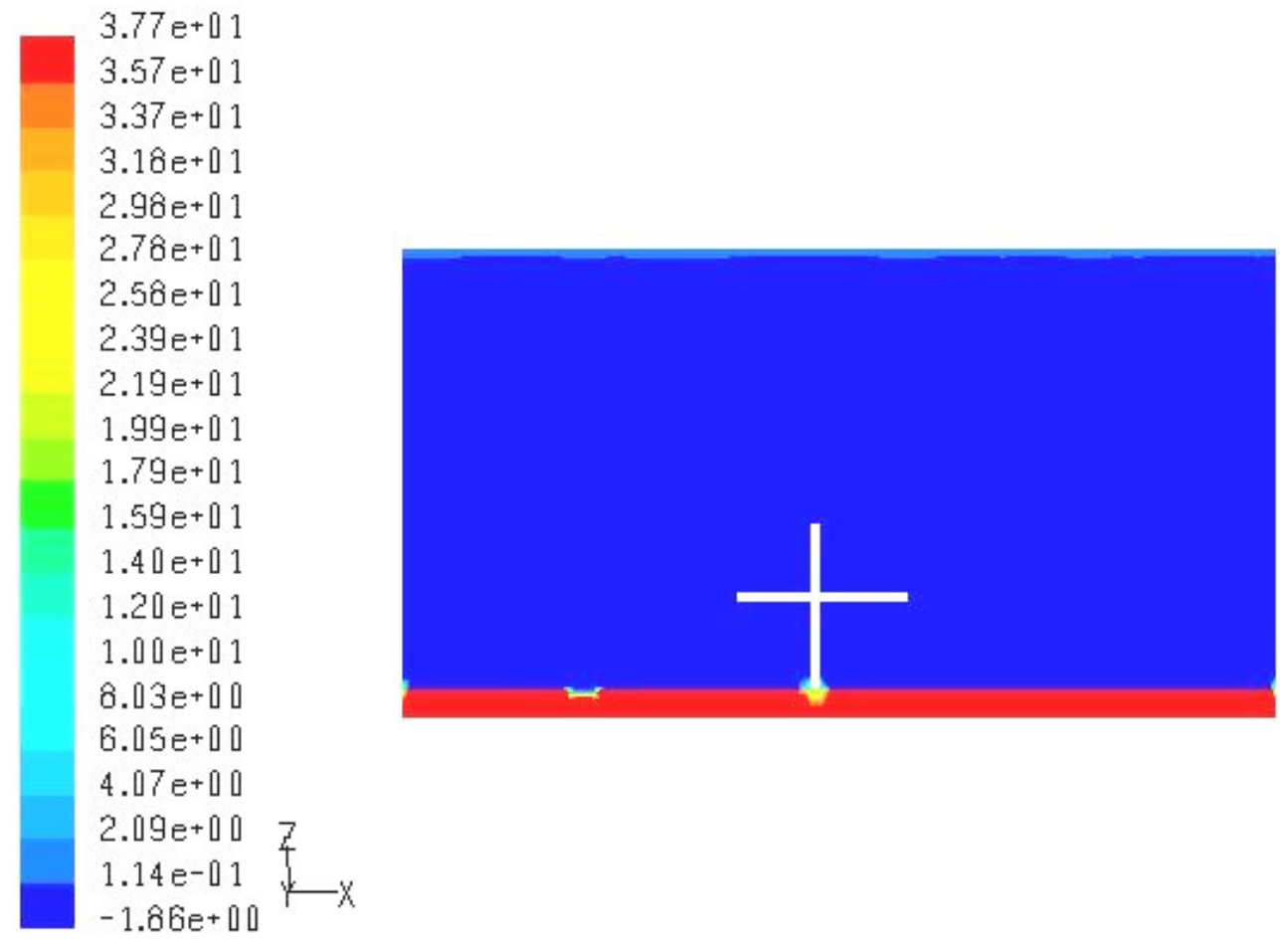

Figura 6.2 - Teste 2 - Pressão estática $(\mathrm{Pa})$ 


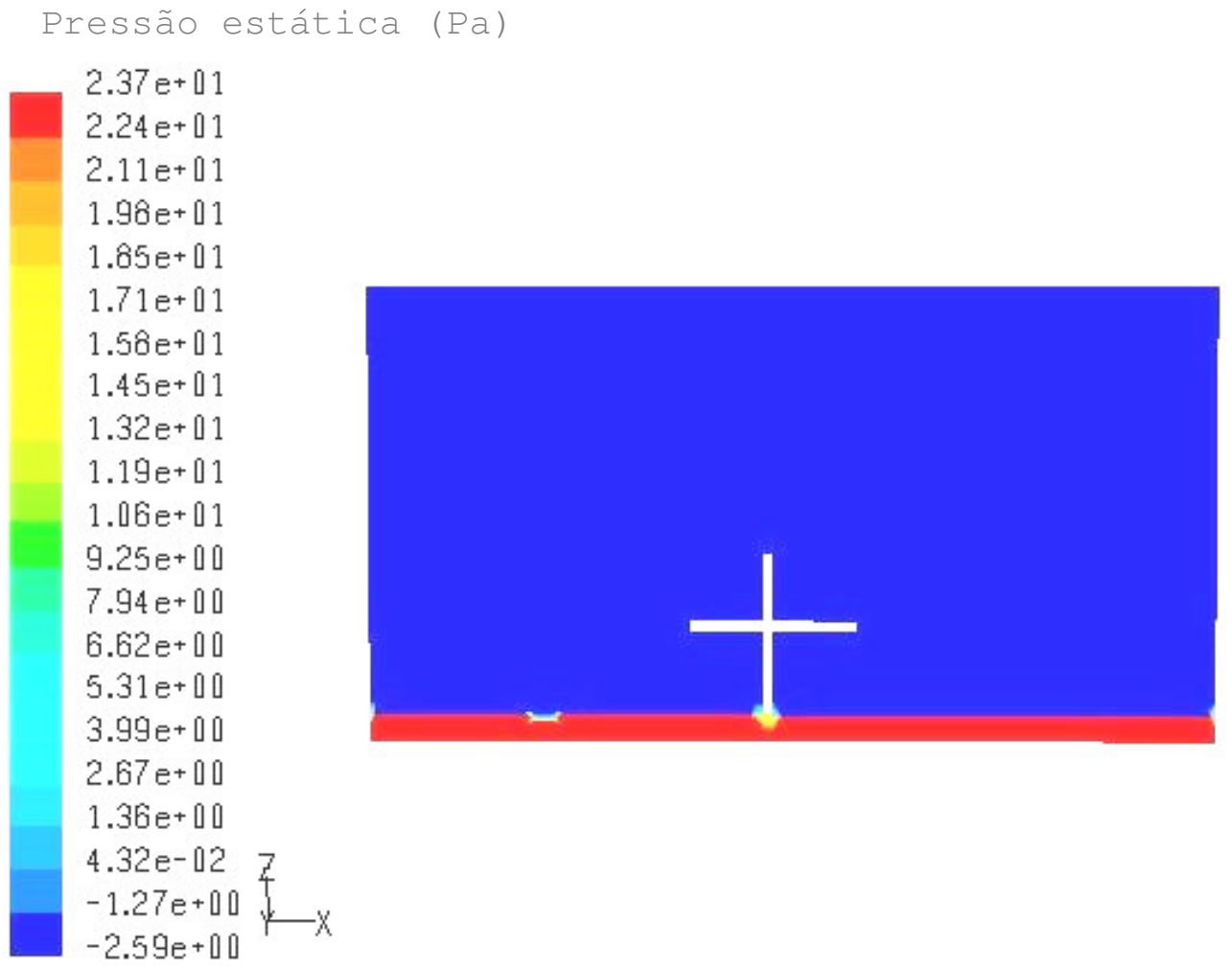

Figura 6.3 - Teste 3 - Pressão estática $(\mathrm{Pa})$

A tabela 6.1 apresenta os dados empregados para os parâmetros de operação (vazão e temperatura do ar) e os respectivos valores resultantes de diferença de pressão entre o plenum do piso e o ambiente.

Tabela 6.1 - Resultados dos testes

\begin{tabular}{|c|c|c|c|c|}
\hline Teste & Velocidade (m/s) & Vazão (L/s) & Temperatura (K) & $\Delta \mathbf{p ~ ( P a )}$ \\
\hline Teste 1 & 0,15 & 30,00 & 290,00 & 23,58 \\
\hline Teste 2 & 0,20 & 40,00 & 294,00 & 39,56 \\
\hline Teste 3 & 0,16 & 32,00 & 294,00 & 26,29 \\
\hline
\end{tabular}

\subsection{CONSTRUÇÃO DO GRÁFICO}

Os dados experimentais representam uma condição a qual se deseja atingir. Do experimento em estudo sabe-se que o diferencial de pressão entre o plenum do piso e o interior da sala é de 25Pa. Sabe-se também que esse diferencial de pressão pode ser resultado de uma série de combinações entre vazão e temperatura do ar.

Assim, foi estabelecida uma relação entre a vazão, a temperatura do ar e a diferença de pressão, por meio de um gráfico em três dimensões que relaciona os três parâmetros. 


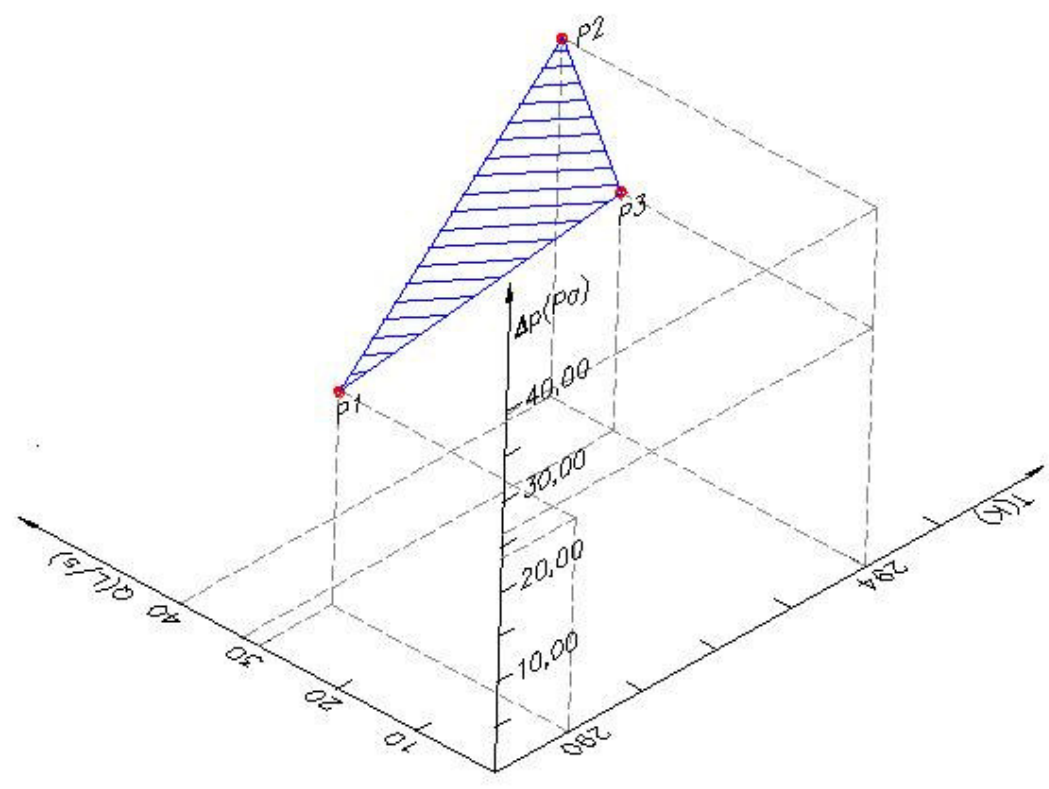

Figura 6.4 - Ligação entre os pontos resultantes

A ligação entre os pontos P1, P2 e P3 resultou em um plano, ilustrado na figura 6.4, que se constitui na primeira aproximação entre as três variáveis em estudo.

Assim, para uma determinada combinação entre vazão e temperatura, por exemplo, é possível obter o valor da diferença de pressão esperada, possibilitando ao projetista a determinação de diferentes combinações entre as variáveis, que resultem na condição desejada no interior do ambiente.

\subsection{VERIFICAÇÃO DO MÉTODO}

No item anterior foi apresentado o modo de construção do gráfico. Porém, é necessário verificar se o gráfico construído fornece, de fato, resultados confiáveis.

Para tanto, serão adotados valores para duas variáveis ( $T$ e $\Delta p)$. $O$ valor da variável desconhecida $(Q)$ será determinado graficamente. Posteriormente, será realizada uma simulação utilizando o valor da variável obtido graficamente $(Q)$, combinado com o valor de uma das variáveis, mantido constante $(T)$. Espera-se que o resultado da simulação coincida com o valor adotado para a terceira variável $(\Delta p)$. O processo de verificação será descrito, a seguir, com maiores detalhes.

Para a verificar a validade da hipótese de estabelecer relações entre as variáveis por um plano, foram utilizados os dados do experimento em estudo. Deseja-se manter uma diferença de pressão de $25 \mathrm{~Pa}$ entre o plenum do piso e o 
interior do ambiente. Assumindo-se que o ar seja insuflado a uma temperatura de 290K, é possível determinar, a partir do gráfico, o valor da vazão de ar necessário para que o valor de 25Pa seja estabelecido.

Para a verificação da estratégia uma nova simulação foi então realizada, com o valor de vazão de $31,00 \mathrm{~L} / \mathrm{s}$, obtido do gráfico da figura 6.4. Para a temperatura, o valor adotado foi de 290K. Assim, espera-se que a diferença de pressão entre o plenum do piso e interior do ambiente seja de 25Pa.

\subsubsection{RESULTADOS DA VERIFICAÇÃO}

Para a visualização dos resultados foi elaborado um esquema de representação, ilustrado nas figuras 6.5 e 6.6, descrito a seguir, que corresponde a dois planos verticais, construídos sobre o eixo do difusor de ar, paralelos aos eixos de coordenadas $\mathrm{X}$ e $\mathrm{Y}$. Além deles, um terceiro plano vertical foi construído "cortando" o monitor de vídeo (figuras 8.4 e 8.5).

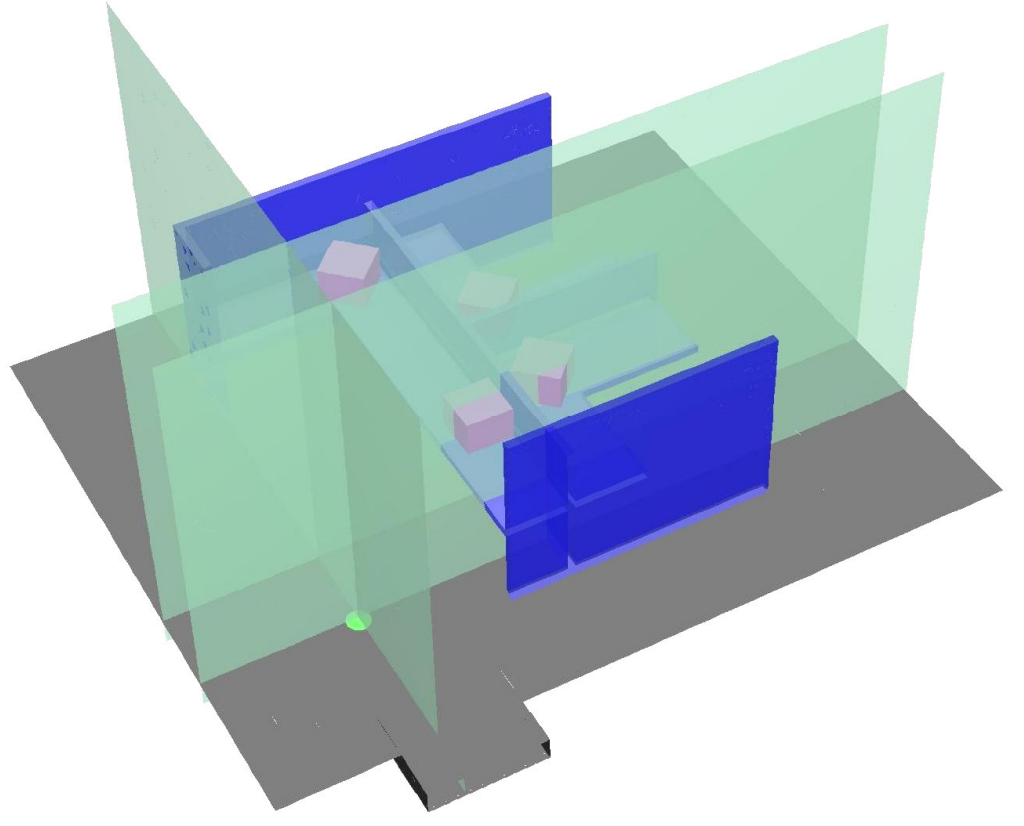

Figura 6.5 - Planos verticais de visualização 


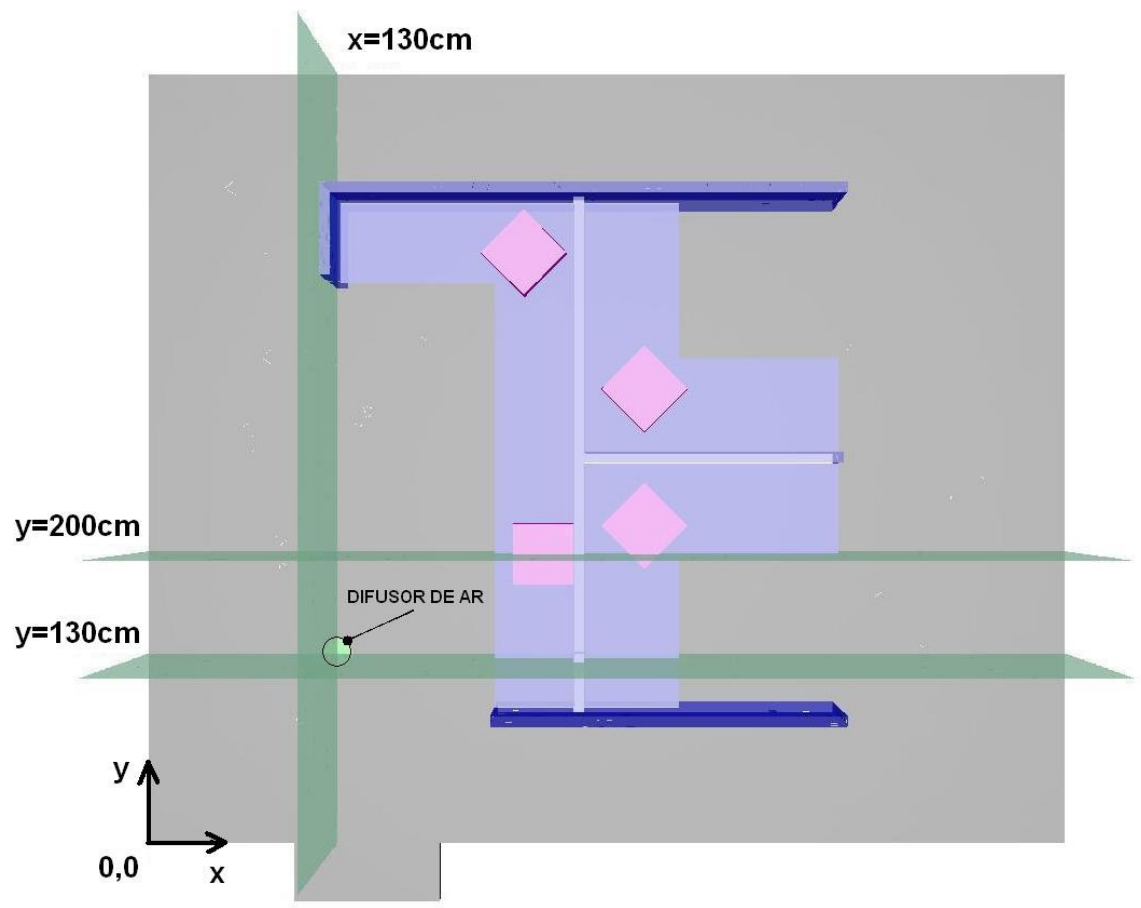

Figura 6.6 -Planos verticais de visualização - Vista superior

As figuras 6.7 e 6.8 ilustram o resultado da diferença de pressão no modelo.

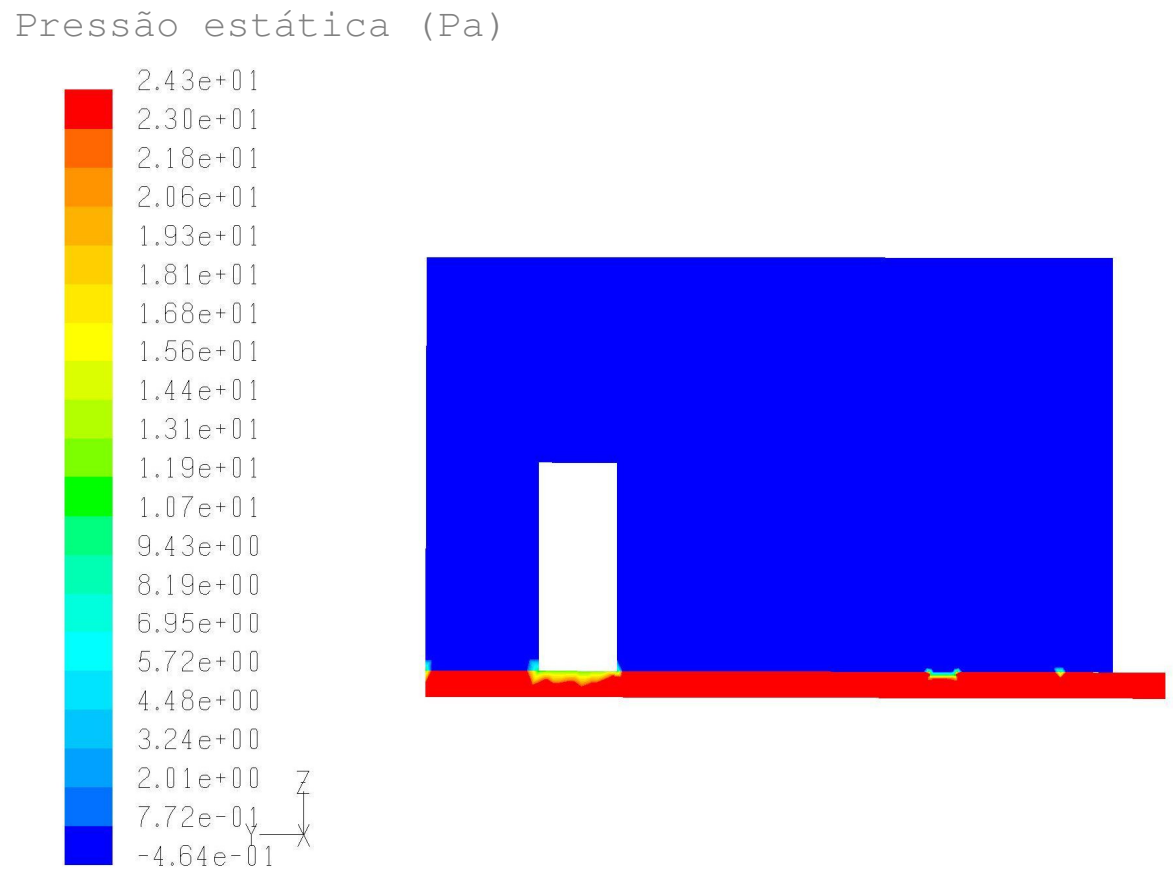

Figura 6.7 - Pressão estática $(\mathrm{Pa})$ para o plano $X=130 \mathrm{~cm}$. 


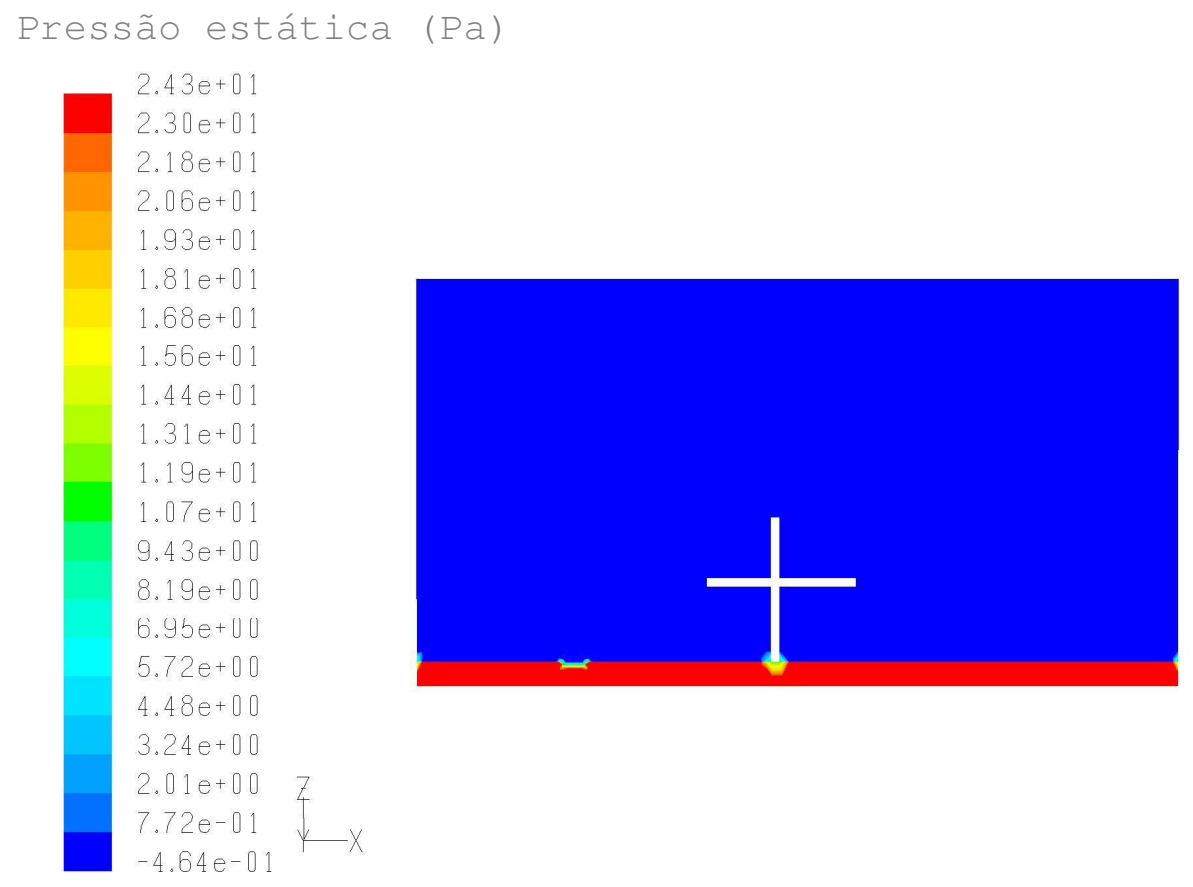

Figura 6.8 - Pressão estática $(\mathrm{Pa})$ para o plano $\mathrm{Y}=130 \mathrm{~cm}$

A diferença de pressão entre o plenum do piso e o ambiente é de $24,8 \mathrm{~Pa}$, bastante próximo do valor esperado de 25Pa, portanto, a aproximação é satisfatória indica que a estratégia proposta pode ser utilizada para a determinação de parâmetros de operação de sistema de distribuição de ar pelo piso. 


\section{ANÁLISE DOS RESULTADOS}

A simulação foi realizada adotando-se uma combinação entre valores de vazão e temperatura do ar que resultassem na diferença de pressão de $25 \mathrm{~Pa}$. Como não foram encontrados registros dos valores adotados para essas variáveis quando da realização do experimento, uma outra combinação pode ter sido adotada, resultando em uma condição interna diferente.

Durante o experimento, a temperatura do ar insuflado provavelmente não ultrapassou os $295 \mathrm{~K}\left(22^{\circ} \mathrm{C}\right)$, que foi o maior valor para a temperatura medida no centro do difusor, a $10 \mathrm{~cm}$ de altura do piso. A figura 7.1 apresenta a projeção do intervalo de temperatura de 290 a $295 \mathrm{~K}$ no plano $\beta$, para uma diferença de pressão de 25Pa.

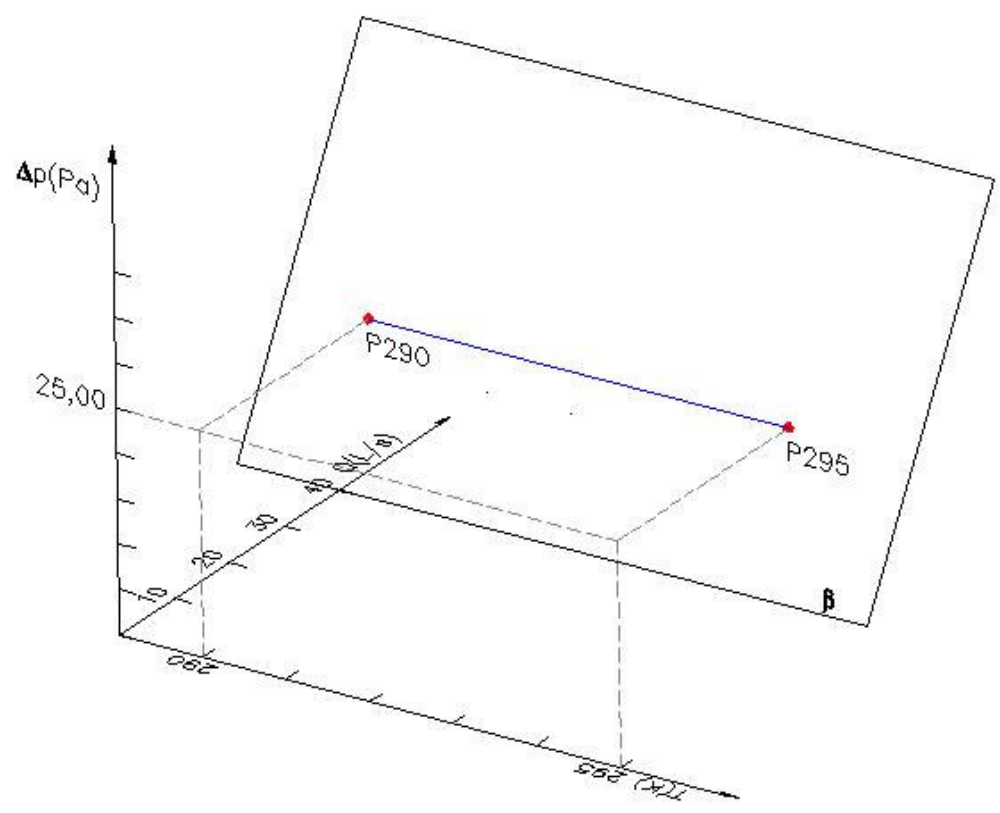

Figura 7.1 - Projeção do segmento de reta resultante do intervalo de temperaturas de 290 a $295 \mathrm{~K}$ para a diferença de pressão de $25 \mathrm{~Pa}$

Com base no gráfico, é possível extrair o intervalo correspondente às vazões que resultem na diferença de pressão de $25 \mathrm{~Pa}$, para o intervalo de temperaturas considerado.

A figura 7.2 mostra que, para o problema em questão, praticamente não há variação da vazão para o intervalo de temperatura considerado. A diferença é de apenas $0,05 \mathrm{~L} / \mathrm{s}$. Assim, pode-se concluir que o valor adotado para a vazão, na simulação, deve estar bastante próximo do real. 


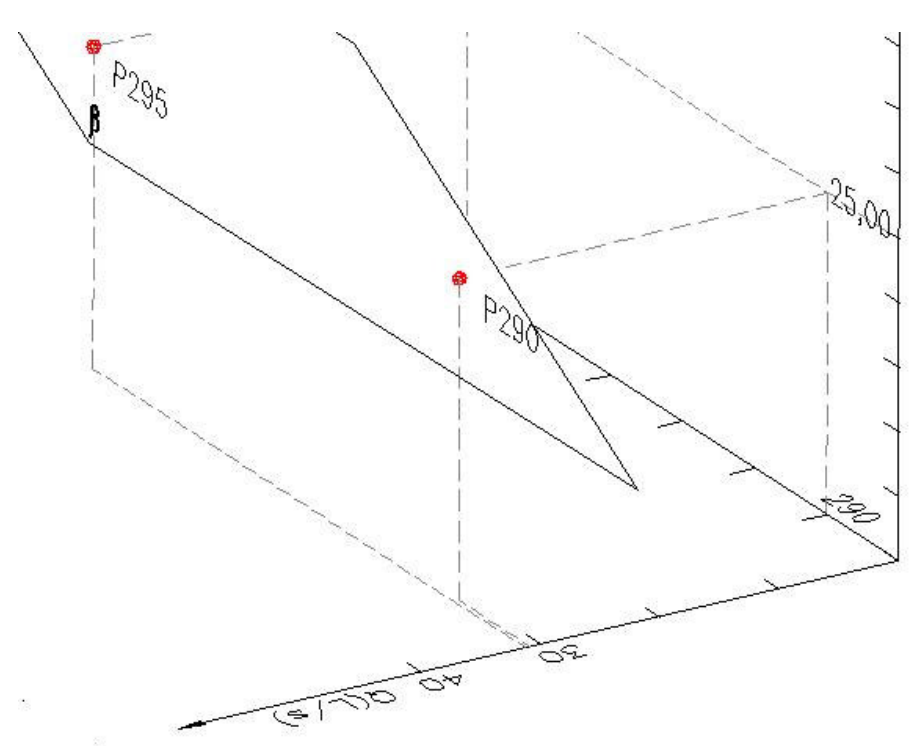

Figura 7.2 - Valores de vazão necessários para que, a uma dada temperatura, mantenha-se a diferença de pressão de $25 \mathrm{~Pa}$

A determinação do valor estimado da temperatura do ar insuflado foi feita com base no trabalho de Leite (2003), que verificou, por meio de medições experimentais, que a diferença de temperatura entre a do ar insuflado no plenum (medido exatamente na entrada de ar no plenum) e a do ar medido a $10 \mathrm{~cm}$ de altura do piso pode chegar até a $5^{\circ} \mathrm{C}$. Assim, para a simulação do presente estudo, foi adotado o valor de $17^{\circ} \mathrm{C}$ na entrada de ar, uma vez que o valor da temperatura medido a $10 \mathrm{~cm}$ do piso, no centro do difusor é de $22^{\circ} \mathrm{C}$.

Do exposto acima, pode-se supor que foi estabelecida uma boa aproximação entre os dados adotados nas simulações com os dados experimentais para a entrada de ar. Ainda que os valores adotados na simulação não sejam exatamente os mesmo que aqueles adotados no experimento, as diferenças resultariam em discrepâncias de ordem qualitativa, o que não impede a análise dos perfis de temperatura e velocidade resultantes das simulações.

\subsection{ANÁLISE DOS PERFIS DE VELOCIDADE E TEMPERATURA DO AR}

A seguir, são apresentadas algumas considerações acerca dos resultados de velocidade e temperatura do ar resultantes da simulação realizada para verificação da estratégia proposta. 
Para a análise dos resultados, foram construídas linhas verticais nos pontos de medição, como pode ser observado na figura 7.3. Os resultados das simulações foram plotados ao longo dessas linhas, sendo então tabulados na forma de gráficos.

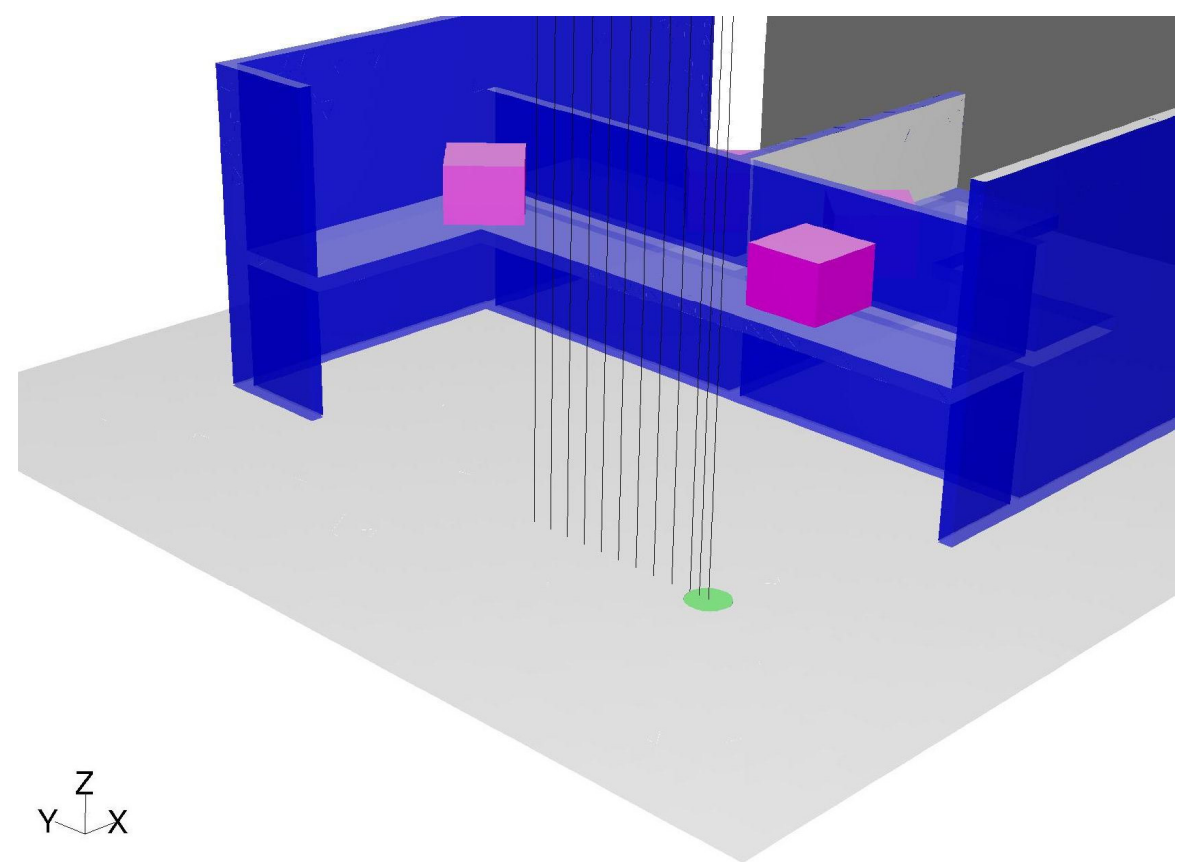

Figura 7.3 - Linhas verticais que representam os pontos de medição

Além das linhas e dos planos verticais (apresentados no item 6.3.1), foram construídos planos horizontais que possibilitam a visualização dos contornos de temperatura e velocidade. Os planos horizontais, ilustrados na figura 7.4, foram construídos nas alturas de medição (10, 60, 110, 170, 200 e $235 \mathrm{~cm}$ acima do piso).

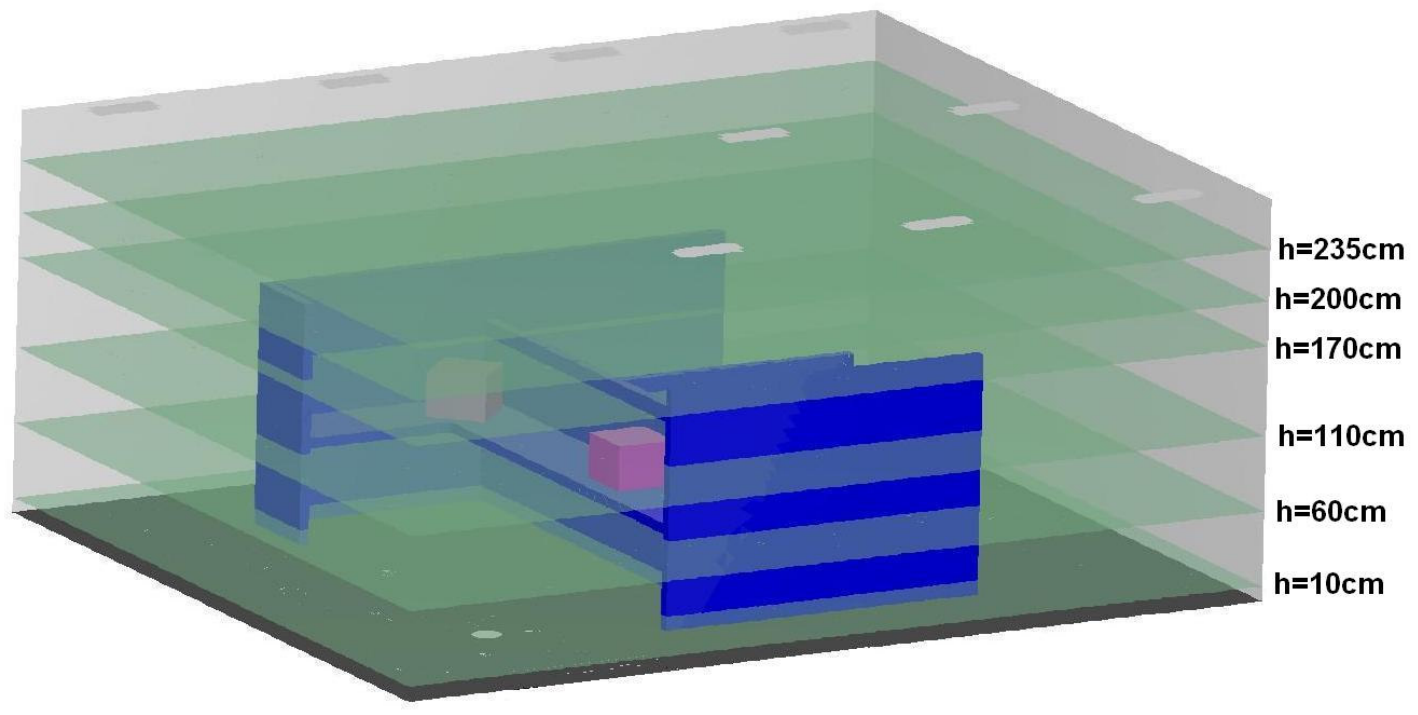

Figura 7.4 - Planos horizontais de visualização 


\subsubsection{TEMPERATURA DO AR}

As figuras 7.5 a 7.7 ilustram os valores da temperatura do ar nos planos verticais $x=130 \mathrm{~cm}, y=130 \mathrm{~cm}$ e $y=200 \mathrm{~cm}$.
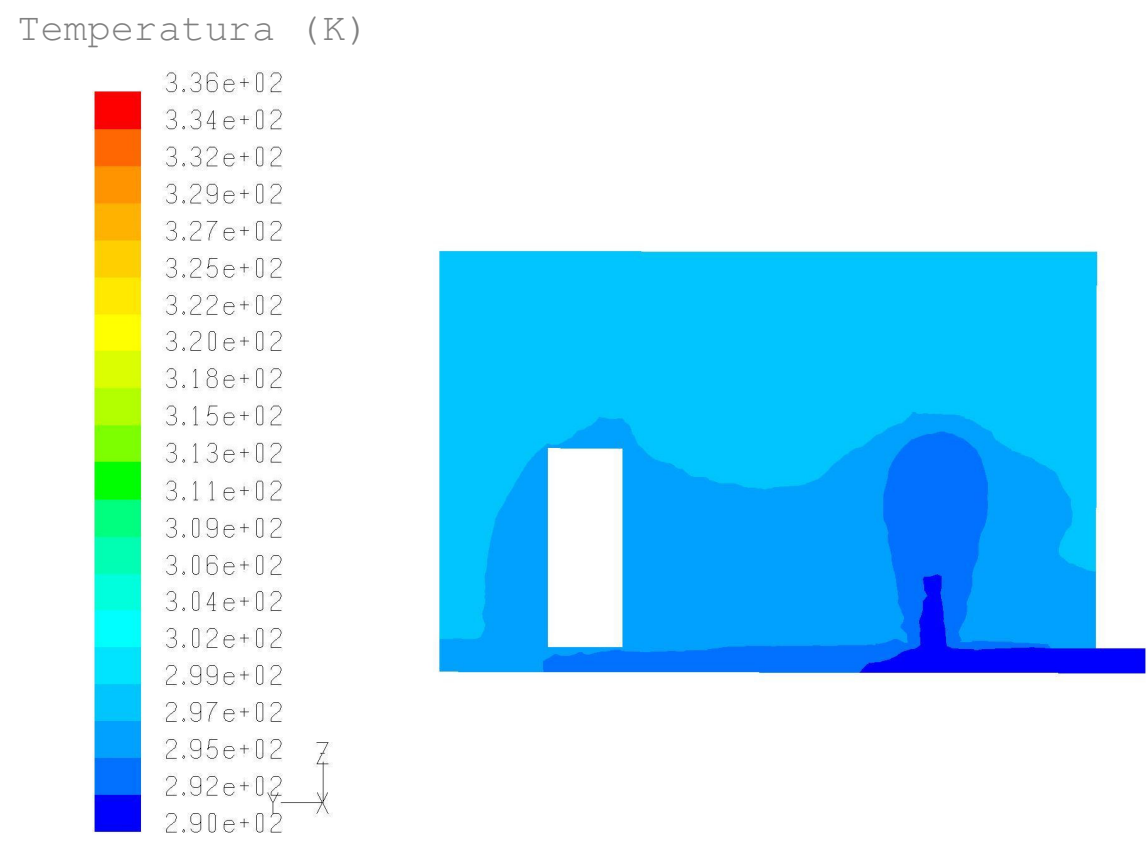

Figura 7.5 - Temperatura $(K)$ no plano $x=130 \mathrm{~cm}$

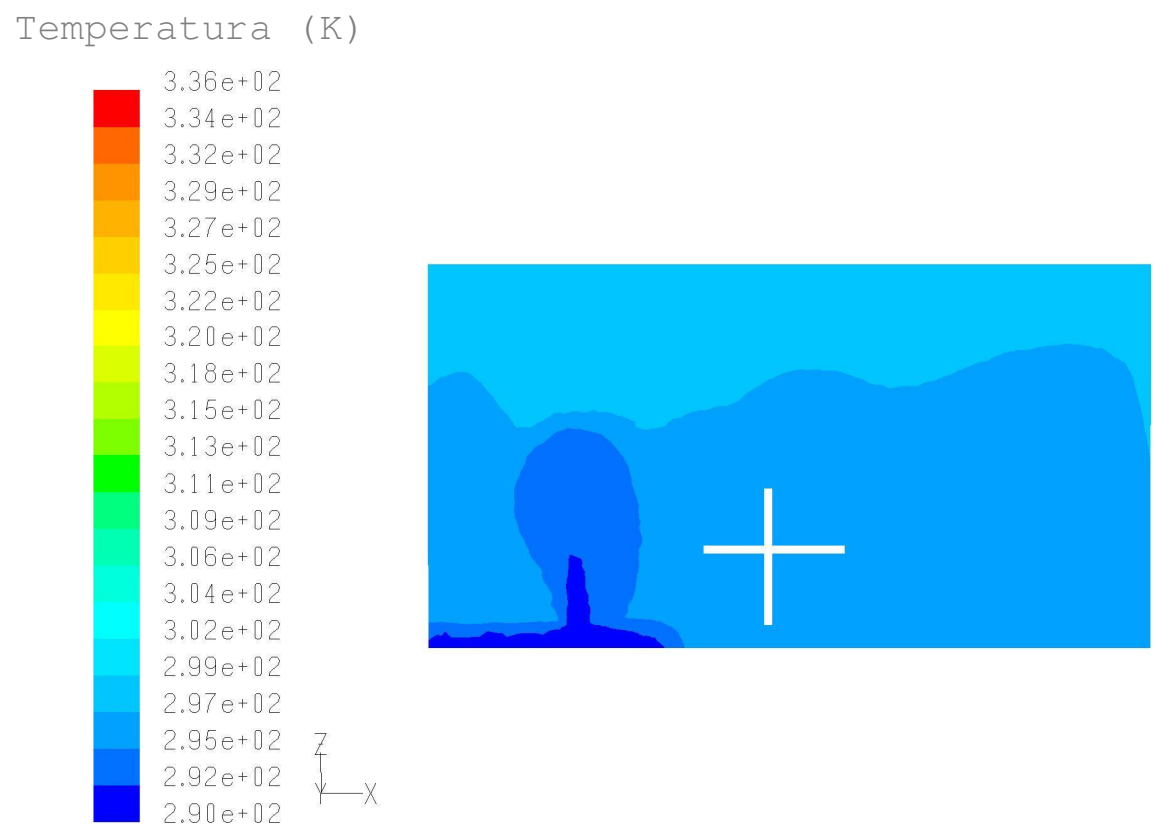

Figura 7.6 - Temperatura $(K)$ no plano $y=130 \mathrm{~cm}$ 

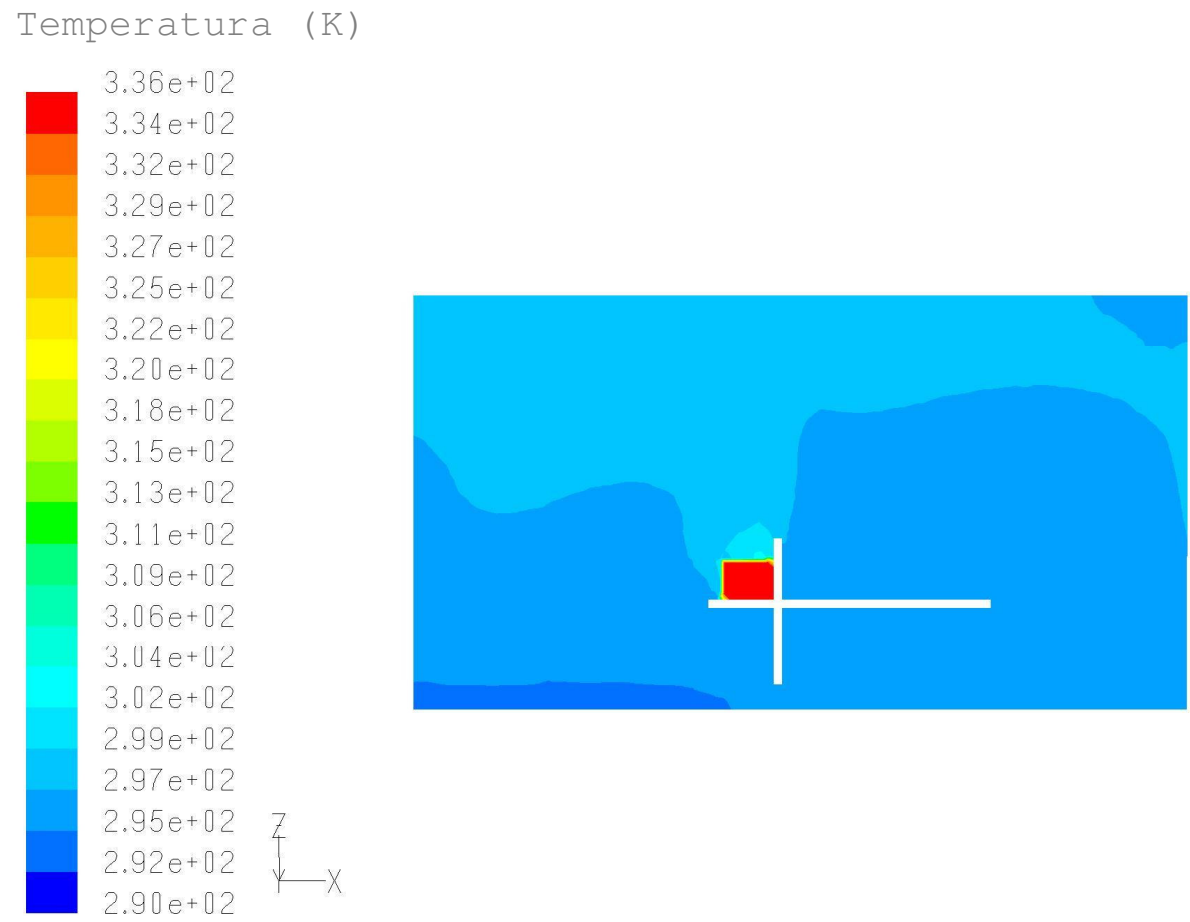

Figura 7.7 - Temperatura (K) no plano $y=200 \mathrm{~cm}$

As figuras 7.8 a 7.13 ilustram os valores da temperatura do ar nos planos horizontais $z=10 \mathrm{~cm}, z=60 \mathrm{~cm}, z=110 \mathrm{~cm}, z=170 \mathrm{~cm}, z=200 \mathrm{~cm}$ e $z=235 \mathrm{~cm}$.
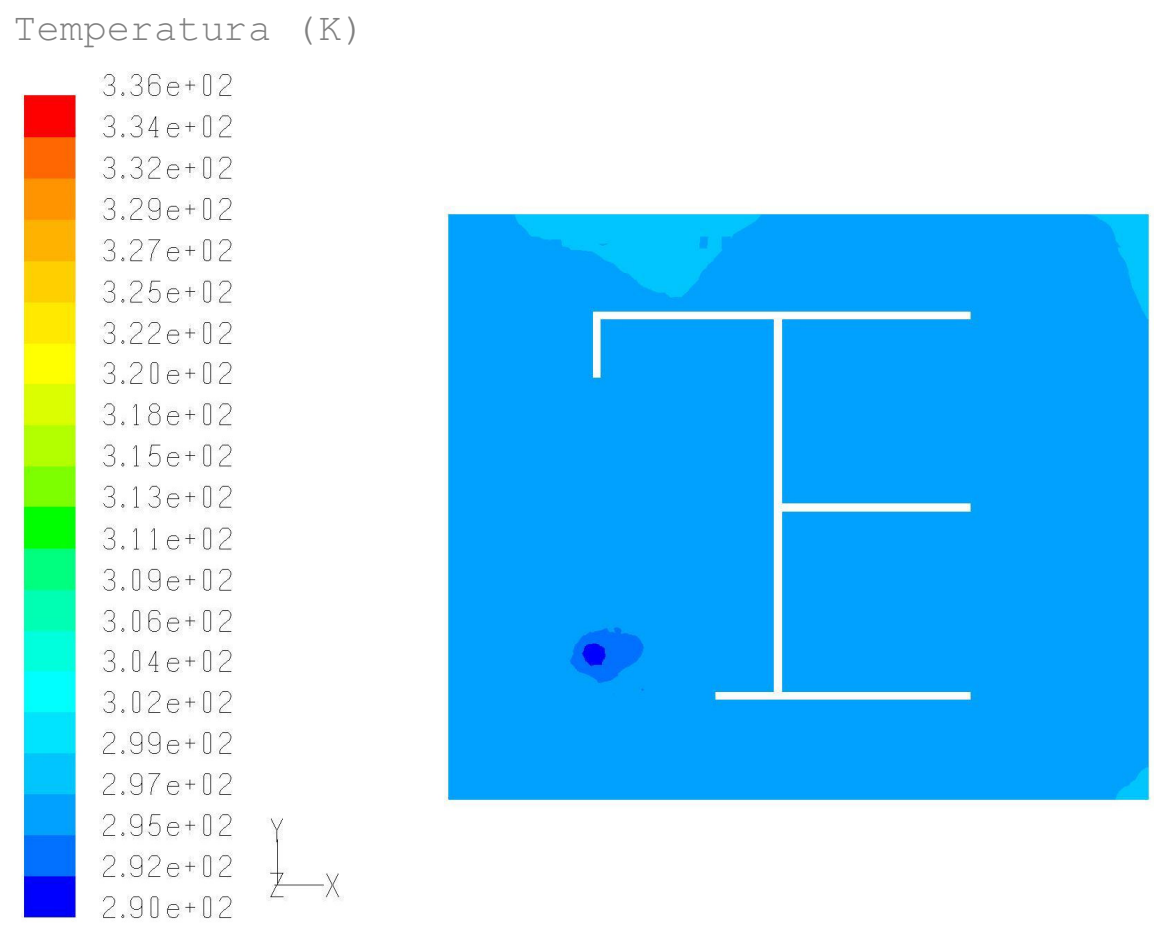

Figura 7.8 - Temperatura $(K)$ no plano $z=10 \mathrm{~cm}$ 
Temperatura (K)
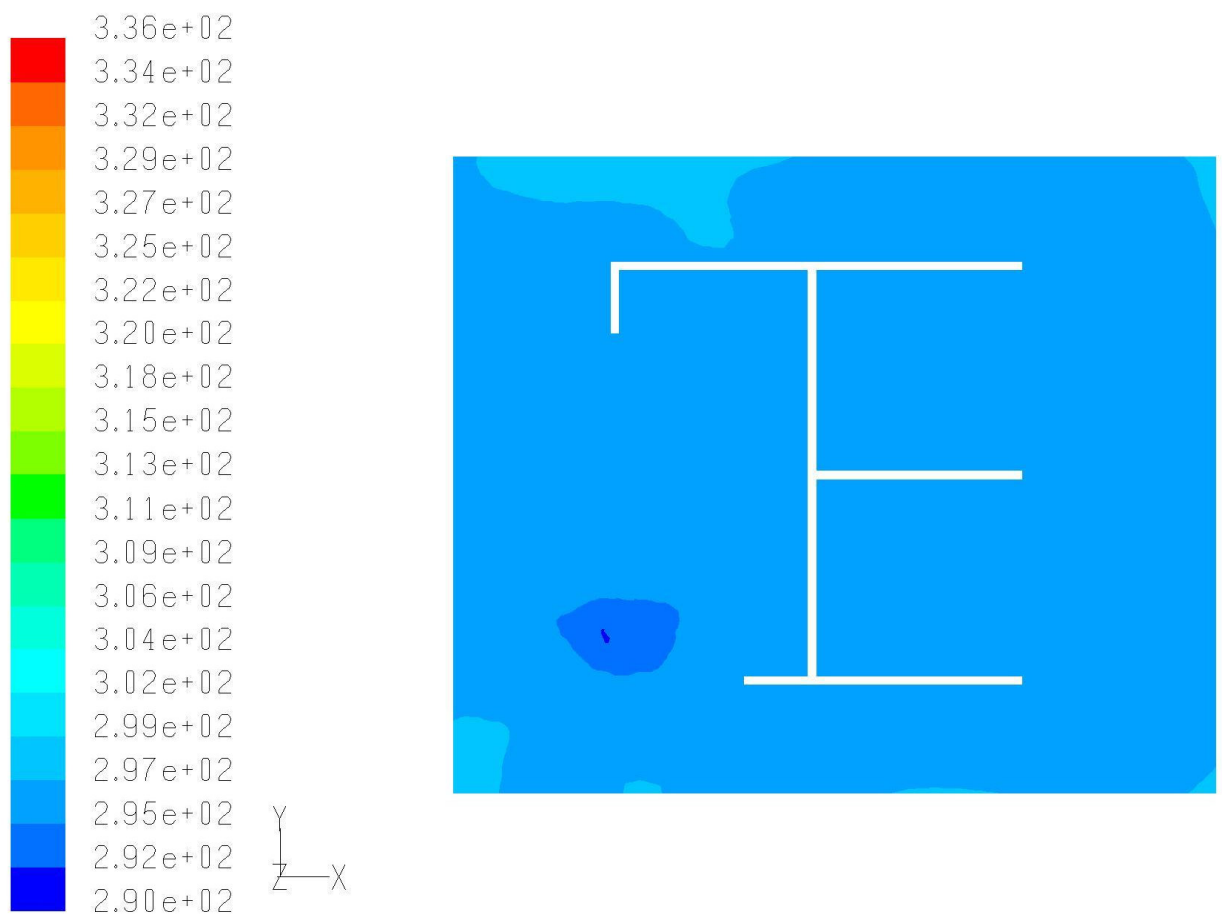

Figura $7.9-$ Temperatura $(K)$ no plano $\mathrm{z}=60 \mathrm{~cm}$

Temperatura (K)

$3.36 e+02$

$3.34 e+02$

$3.32 e+02$

$3.29 e+02$

$3.27 e+02$

$3.25 e+02$

$3.22 e+02$

$3.20 e+02$

$3.18 e+02$

$3.15 e+02$

$3.13 e+02$

$3.11 e+02$

$3.09 e+02$

$3.06 e+02$

$3.04 e+02$

$3.02 e+02$

$2.99 e+02$

$2.97 e+02$

$2.95 e+02$

$2.92 e+02$

$2.90 e+02$

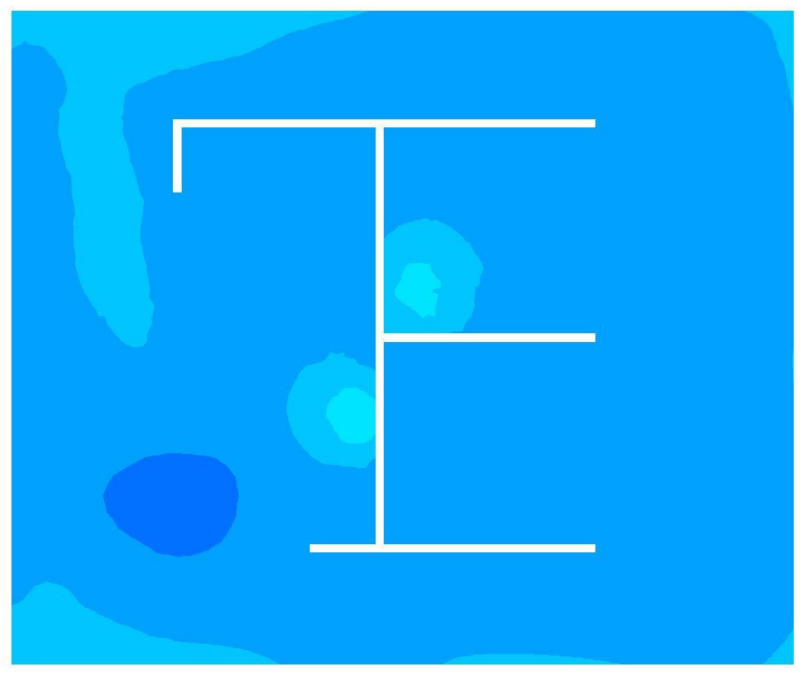

Figura 7.10 - Temperatura $(K)$ no plano $z=110 \mathrm{~cm}$ 
Temperatura (K)
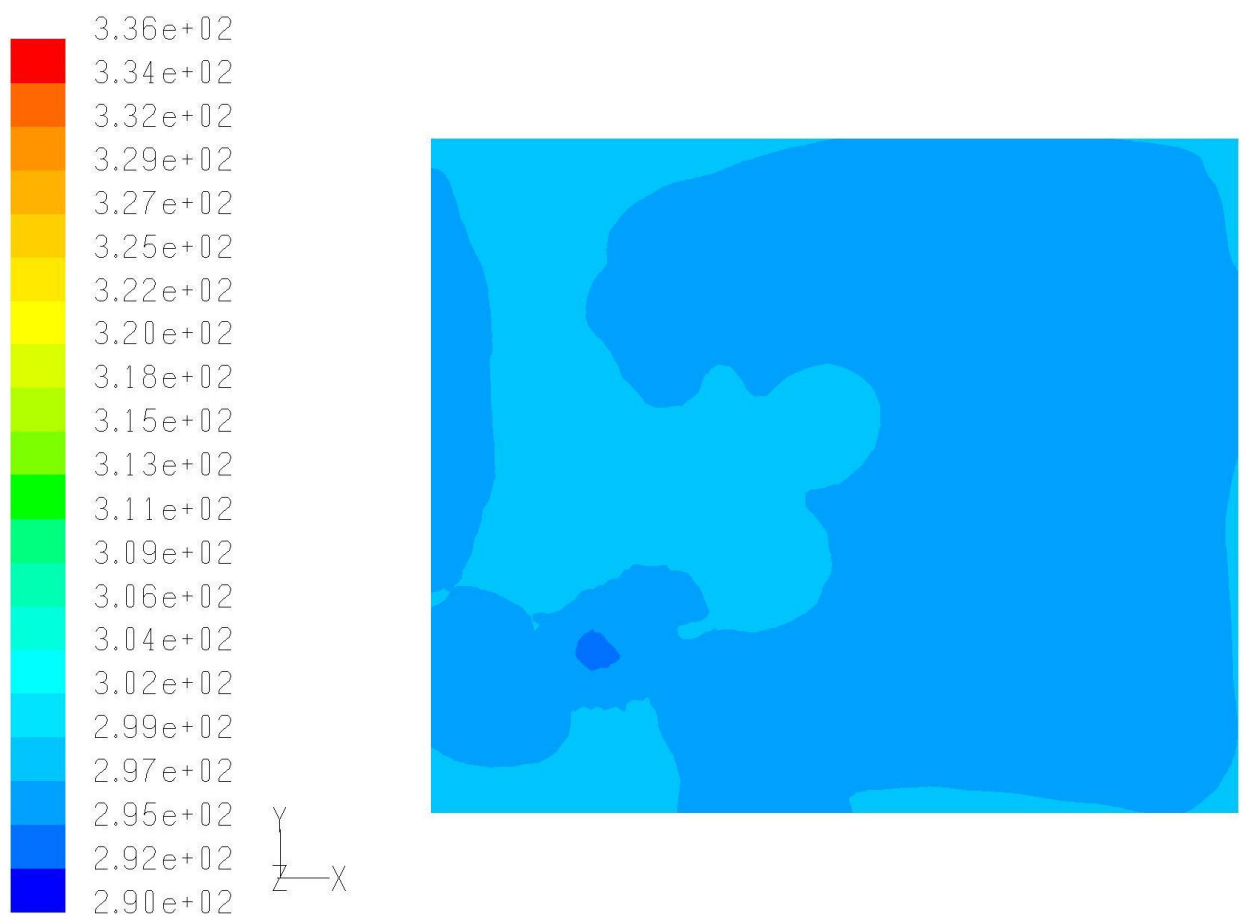

Figura 7.11 - Temperatura $(K)$ no plano $z=170 \mathrm{~cm}$

Temperatura ( $\mathrm{K})$
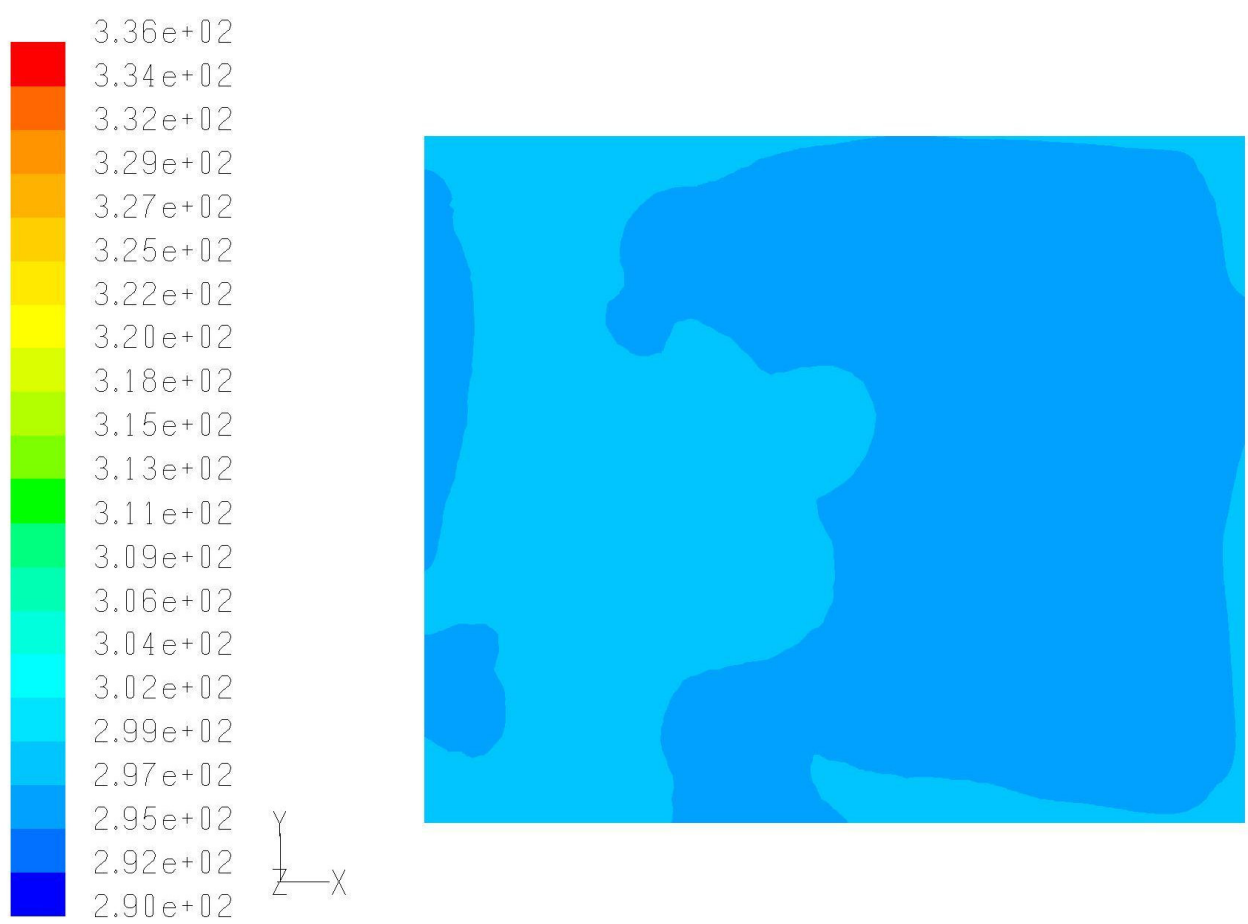

Figura 7.12 - Temperatura (K) no plano $z=200 \mathrm{~cm}$ 

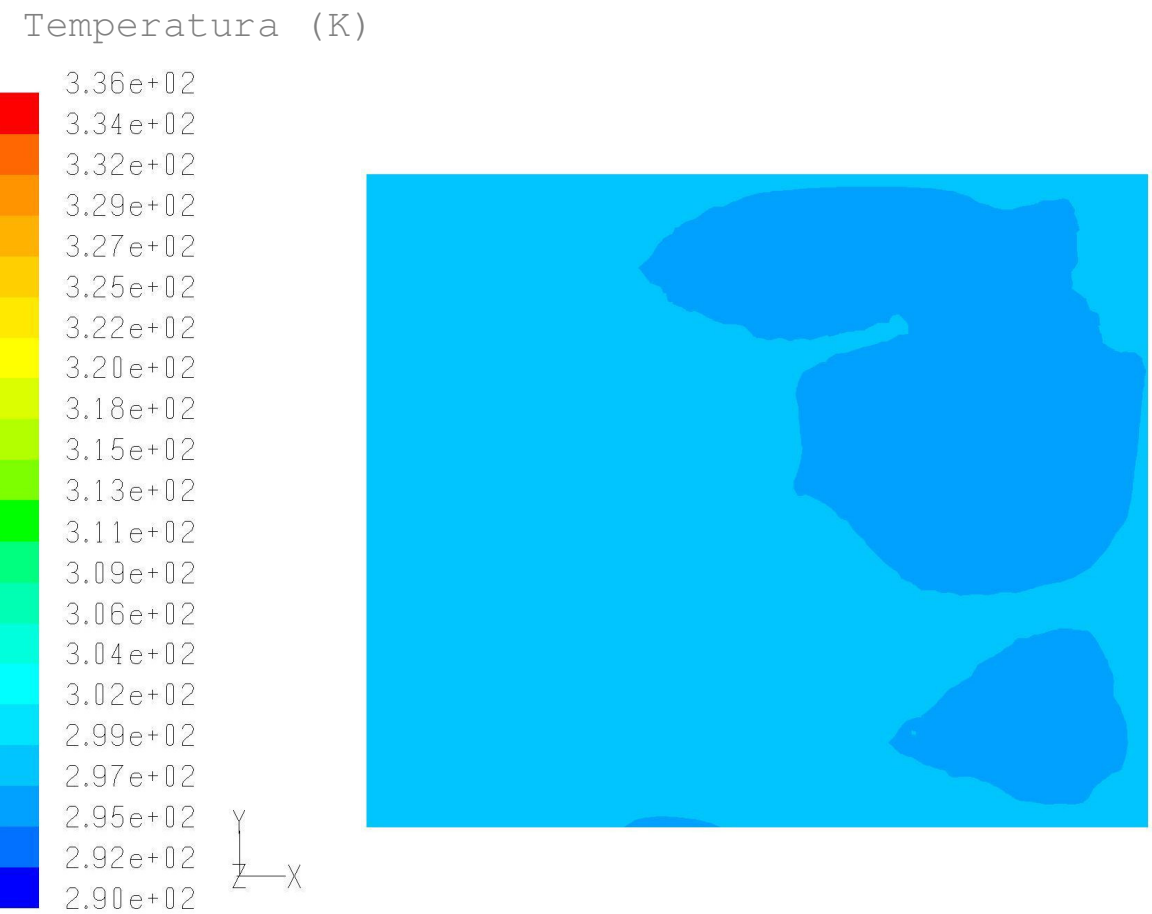

Figura $7.13-$ Temperatura $(K)$ no plano $z=235 \mathrm{~cm}$

As figuras 7.14 a 7.17 ilustram os resultados das simulações comparados com os dados experimentais para a temperatura do ar, em cada ponto de medição.
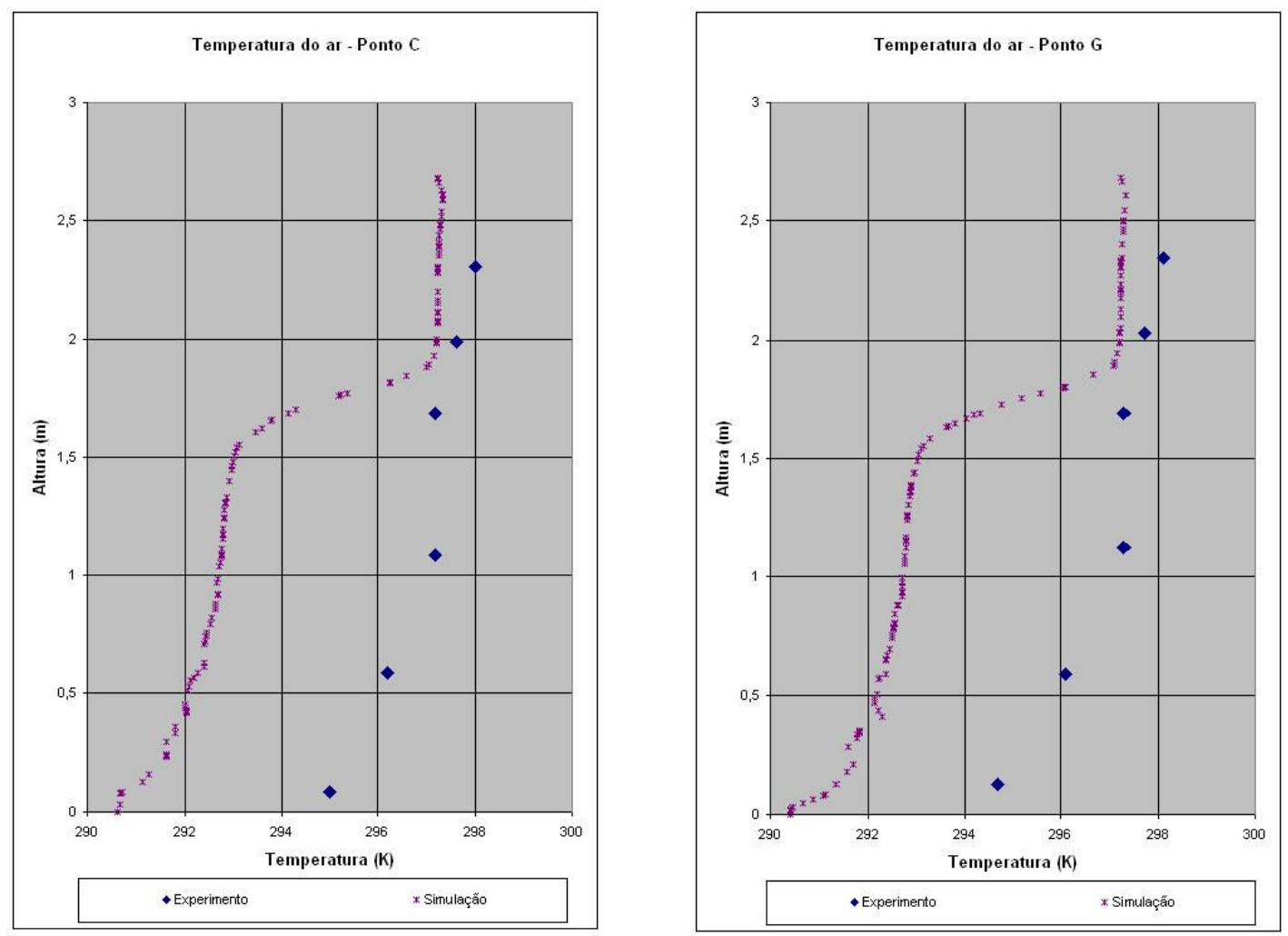

Figura 7.14 - Perfis de temperatura do ar para os pontos C e G 

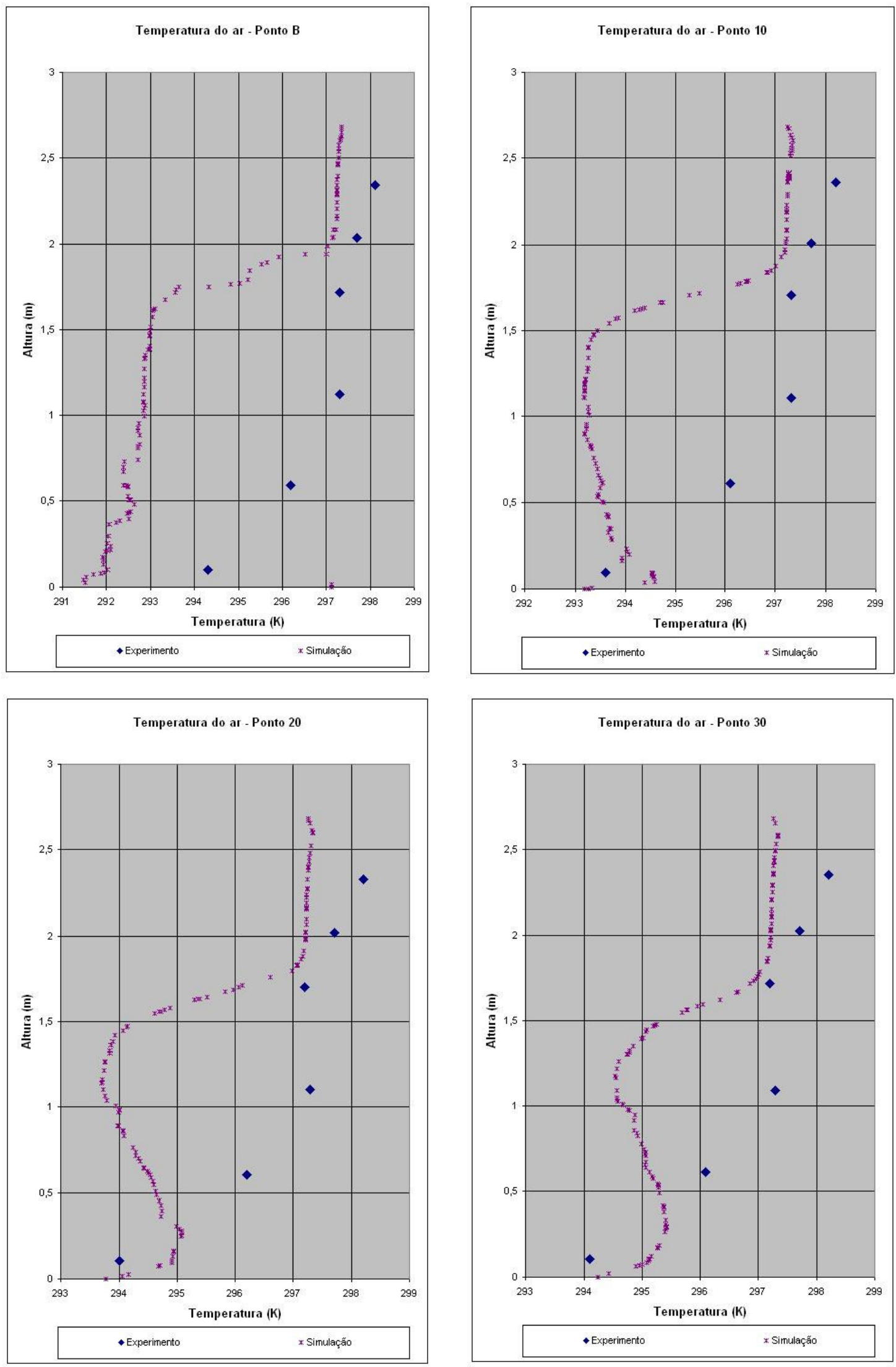

Figura 7.15 - Perfis de temperatura do ar para os pontos B, 10, 20 e 30 

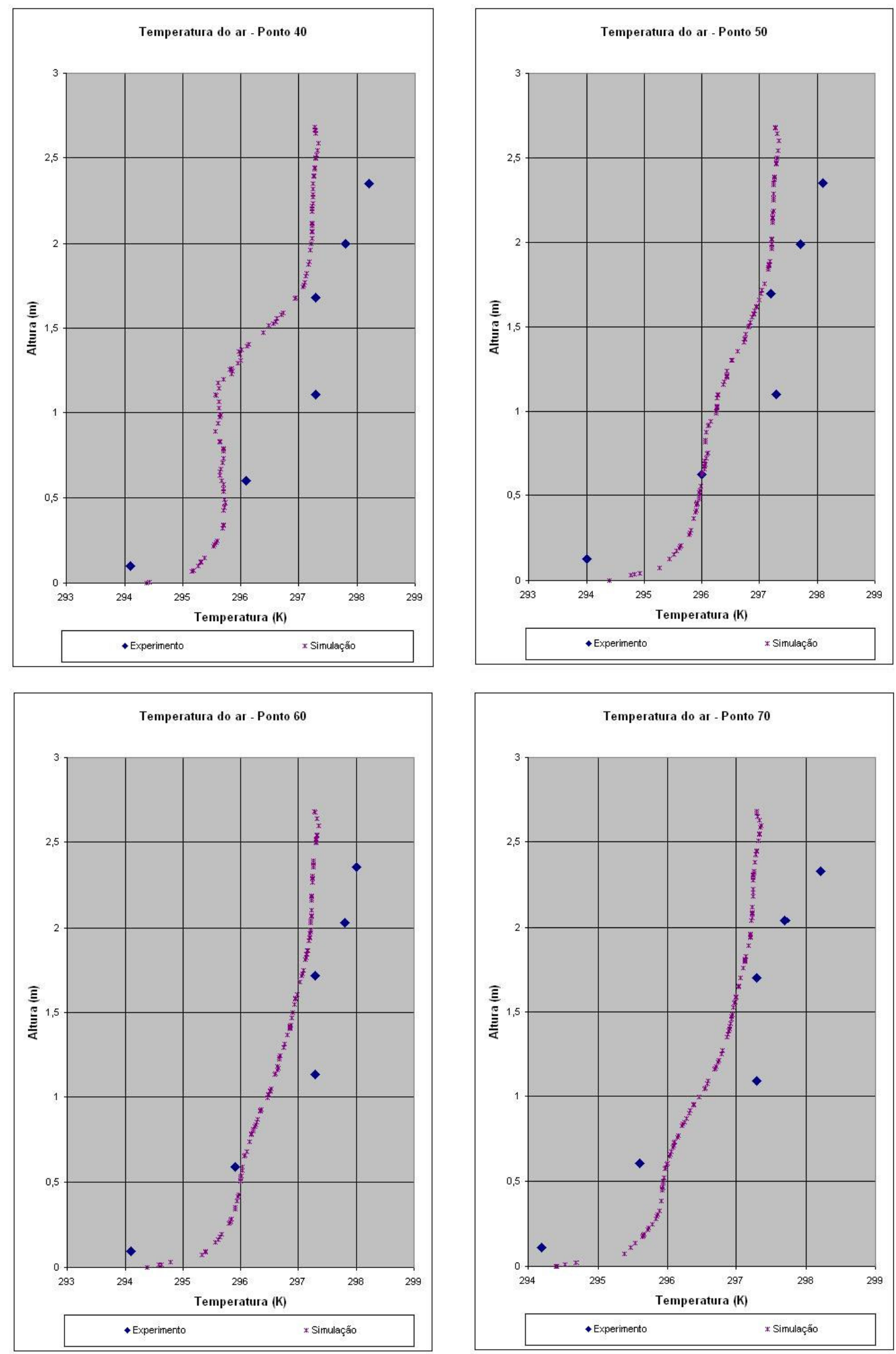

Figura 7.16 - Perfis de temperatura do ar para os pontos 40 a 70 

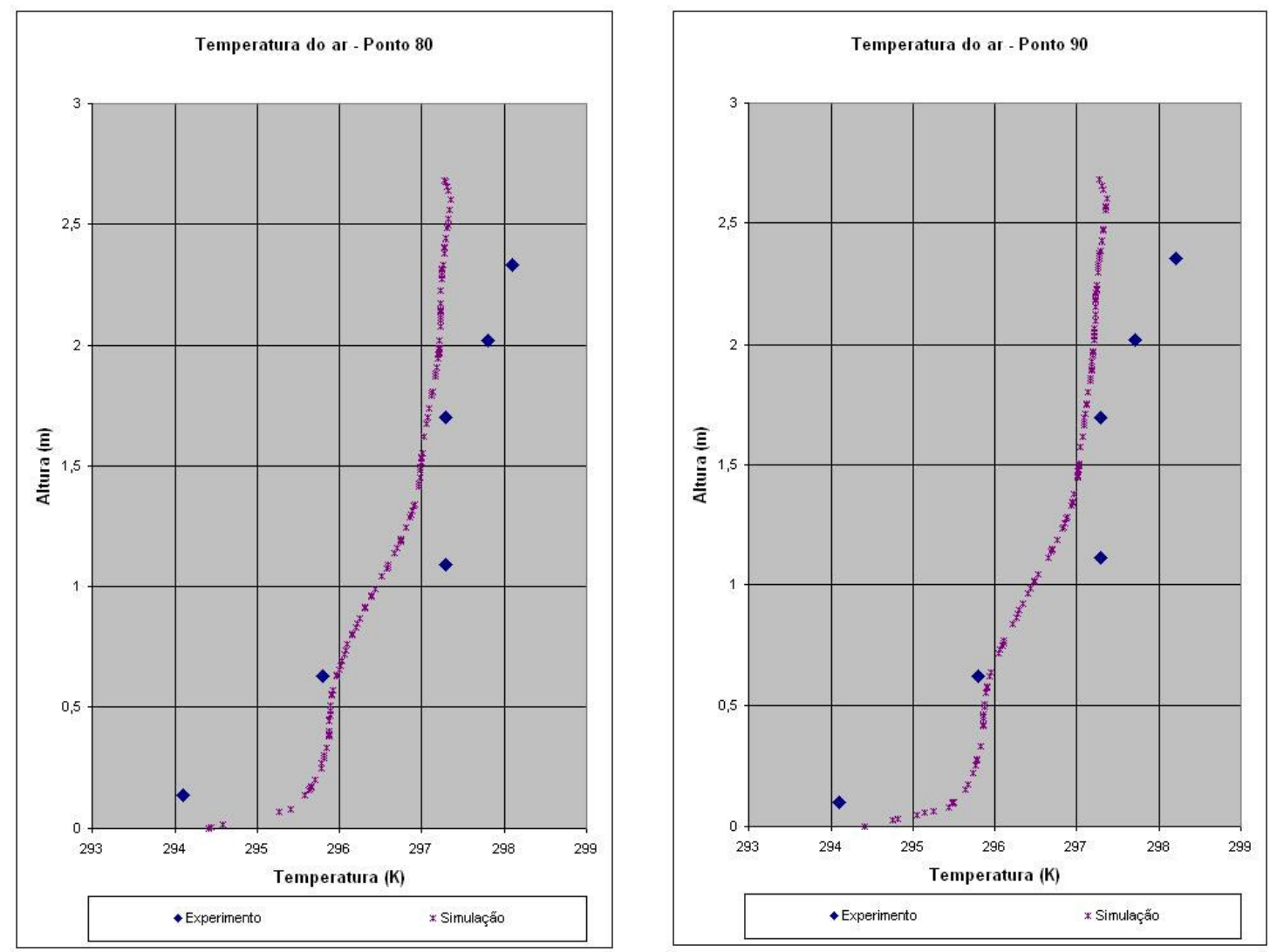

Figura 7.17 - Perfis de temperatura do ar para os pontos 80 e 90

A análise qualitativa dos planos verticais de visualização mostra a tendência de estratificação térmica característica dos sistemas de distribuição de ar pelo piso. A figura 7.7 ilustra a pluma térmica devida à fonte de calor (monitor) e a formação de uma camada de ar aquecido mais próxima ao teto. A influência das fontes de calor no aquecimento do ar pode ser notada também nos planos horizontais. Nos planos mais próximos ao piso, a temperatura média é mais baixa. Na medida em que há uma aproximação ao nível do teto, a temperatura média tende a ser mais elevada.

As figuras 7.14 a 7.17 apresentam uma comparação entre os resultados das simulações com os dados das medições.

Os resultados das simulações nos pontos mais próximos ao centro do difusor de ar (Pontos C, G, B, 10, 20, 30 e 40) são bastante divergentes dos dados experimentais. De fato, a concordância com os dados experimentais nesta região é bastante difícil de ser obtida, dada a complexidade do comportamento do fluxo.

Ainda que os valores de velocidade e temperatura do ar insuflado adotados no experimento não tenham sido exatamente os mesmos que os empregados nas simulações, concordância relativa foi obtida para os pontos 50 a 90 . Nesta região, as 
diferenças entre os valores das simulações com os das medições são de no máximo $1,5^{\circ} \mathrm{C}$, com os piores resultados situados no nível mais próximo ao piso $(10 \mathrm{~cm}$ de distância do piso).

Os valores de temperatura para os pontos localizados a $60 \mathrm{~cm}$ do piso foram os que apresentaram maior proximidade com os dados experimentais. Nos pontos localizados a $110 \mathrm{~cm}$ do piso as diferenças são menores do que $1^{\circ} \mathrm{C}$ entre os resultados das simulações e os dados experimentais.

Para a região acima da zona ocupada (170cm acima do piso) a diferença de temperatura entre os resultados das simulações e os dados experimentais tende a aumentar à medida que há aproximação com o teto. No entanto, essas diferenças não ultrapassam $1^{\circ} \mathrm{C}$.

Segundo Chen (1998), nos problemas de escoamento de ar as diferenças entre os resultados das medições e das simulações freqüentemente têm ocorrido. $O$ autor afirma que na maioria dos casos há boa concordância qualitativa com os dados experimentais, mas para uma concordância quantitativa, o modelo freqüentemente tinha de ser ajustado com dados empíricos, devido à discretização do domínio computacional e ao modelo de turbulência, que são simplificados no problema do escoamento de ar.

Assim, ainda que uma concordância total entre os dados experimentais e os resultados das simulações não tenha sido obtida, é possível notar uma tendência da curva simulada de temperatura do ar bastante próxima à curva medida experimentalmente, ou seja, de fato há uma aproximação qualitativa entre as duas curvas, que sugere que o perfil característico do movimento do ar no interior de um ambiente com o sistema de distribuição de ar frio pelo piso está sendo alcançado.

\subsubsection{VELOCIDADE DO AR}

As figuras 7.18 e 7.19 ilustram os valores da velocidade do ar nos planos verticais $x=130 \mathrm{~cm}$ e $y=130 \mathrm{~cm}$. 


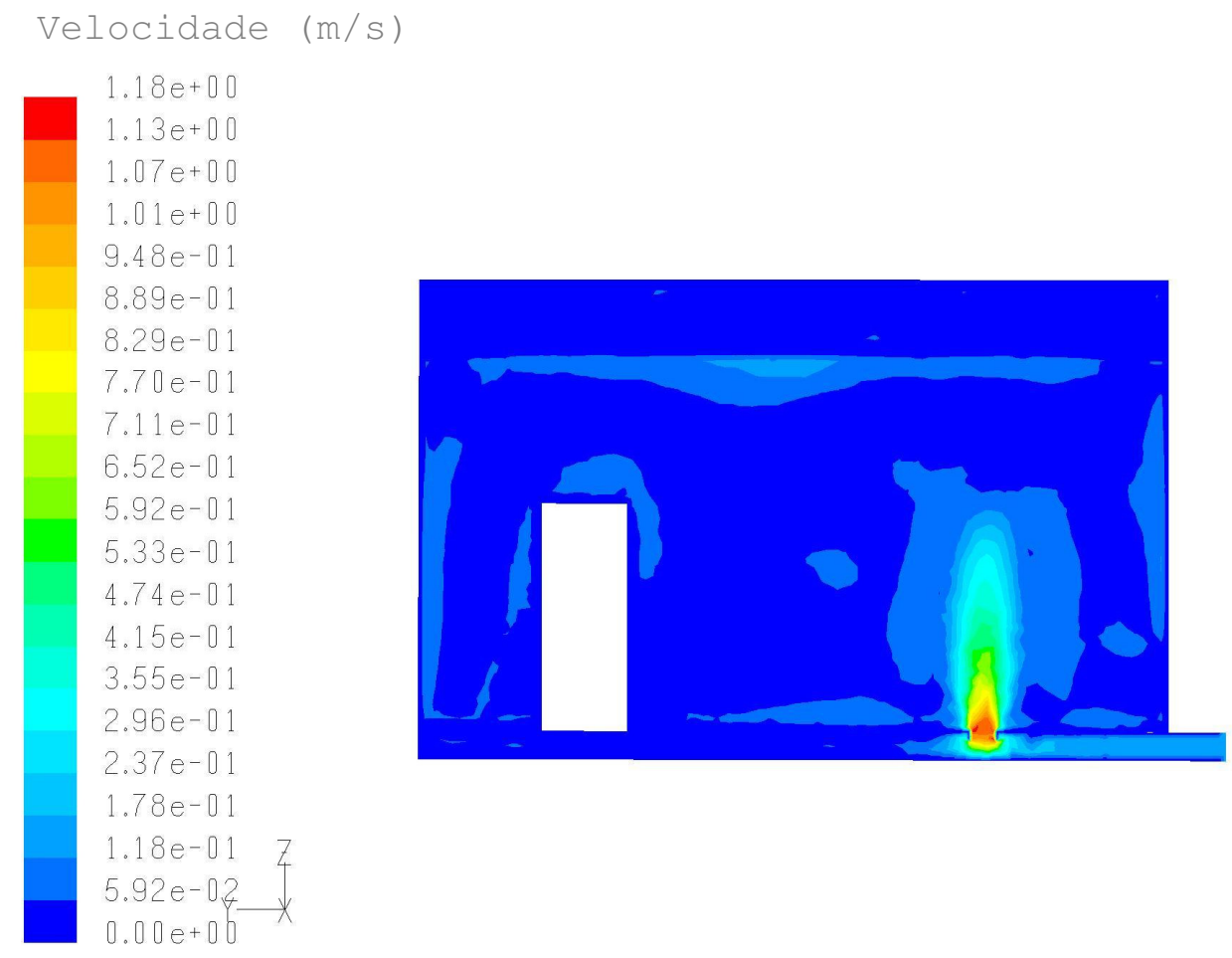

Figura 7.18 - Velocidade do ar $(\mathrm{m} / \mathrm{s})$ no plano $x=130 \mathrm{~cm}$

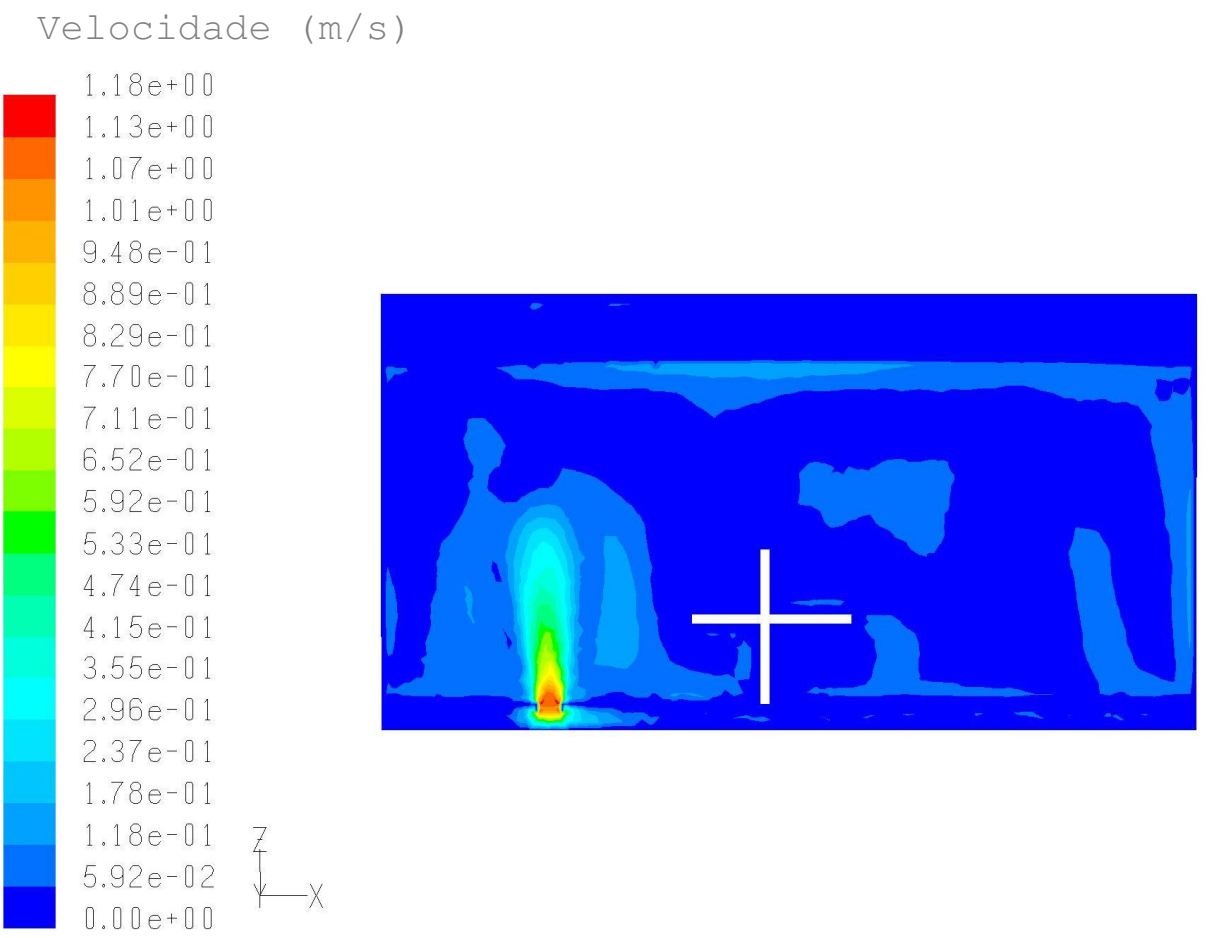

Figura 7.19 - Velocidade do ar $(\mathrm{m} / \mathrm{s})$ no plano $y=130 \mathrm{~cm}$

As figuras 7.20 a 7.25 ilustram os valores da velocidade do ar nos planos horizontais $z=10 \mathrm{~cm}, z=60 \mathrm{~cm}, z=110 \mathrm{~cm}, z=170 \mathrm{~cm}, z=200 \mathrm{~cm}$ e $z=235 \mathrm{~cm}$. 

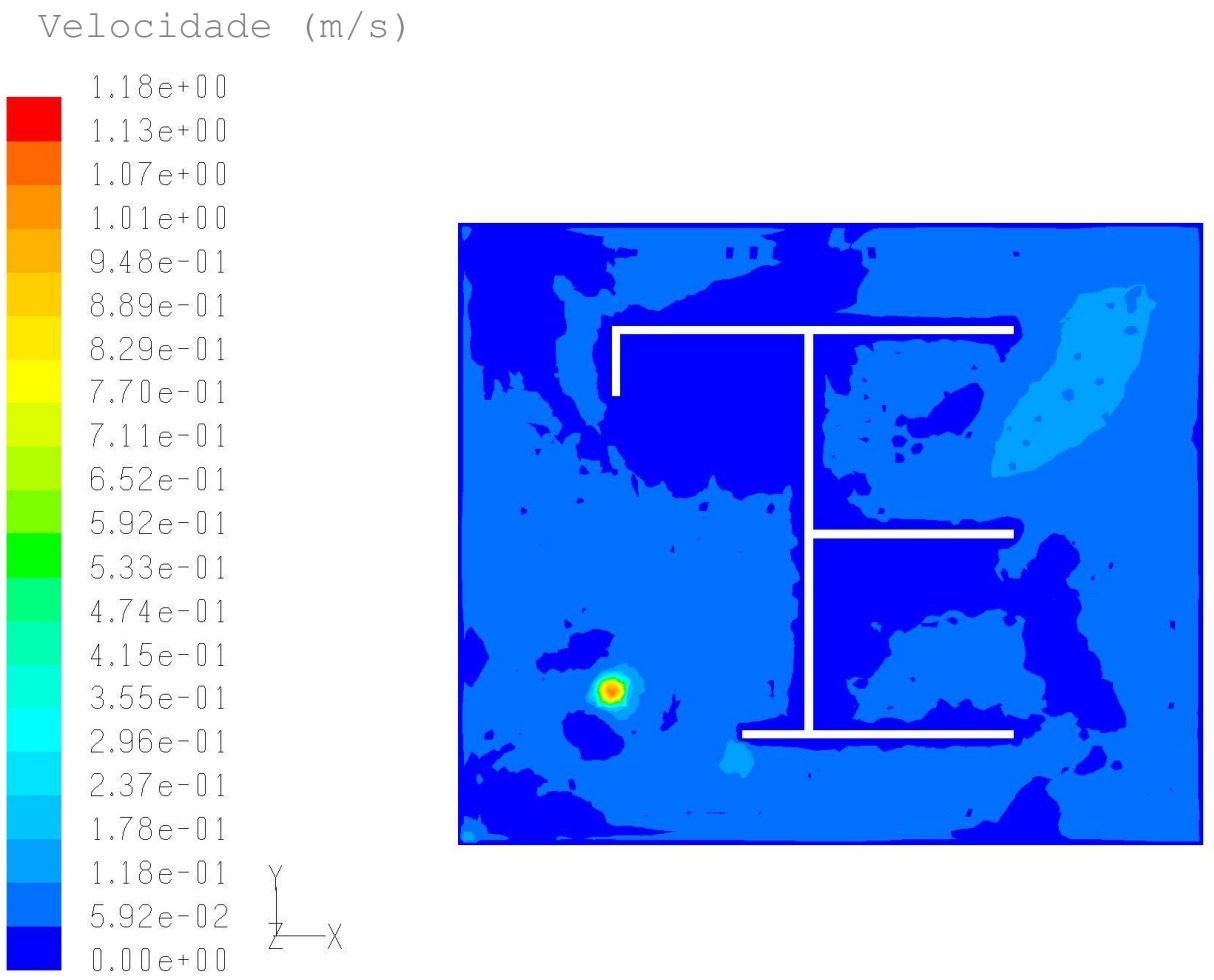

Figura 7.20 - Velocidade do ar $(\mathrm{m} / \mathrm{s})$ no plano $\mathrm{z}=10 \mathrm{~cm}$

Velocidade (m/s)
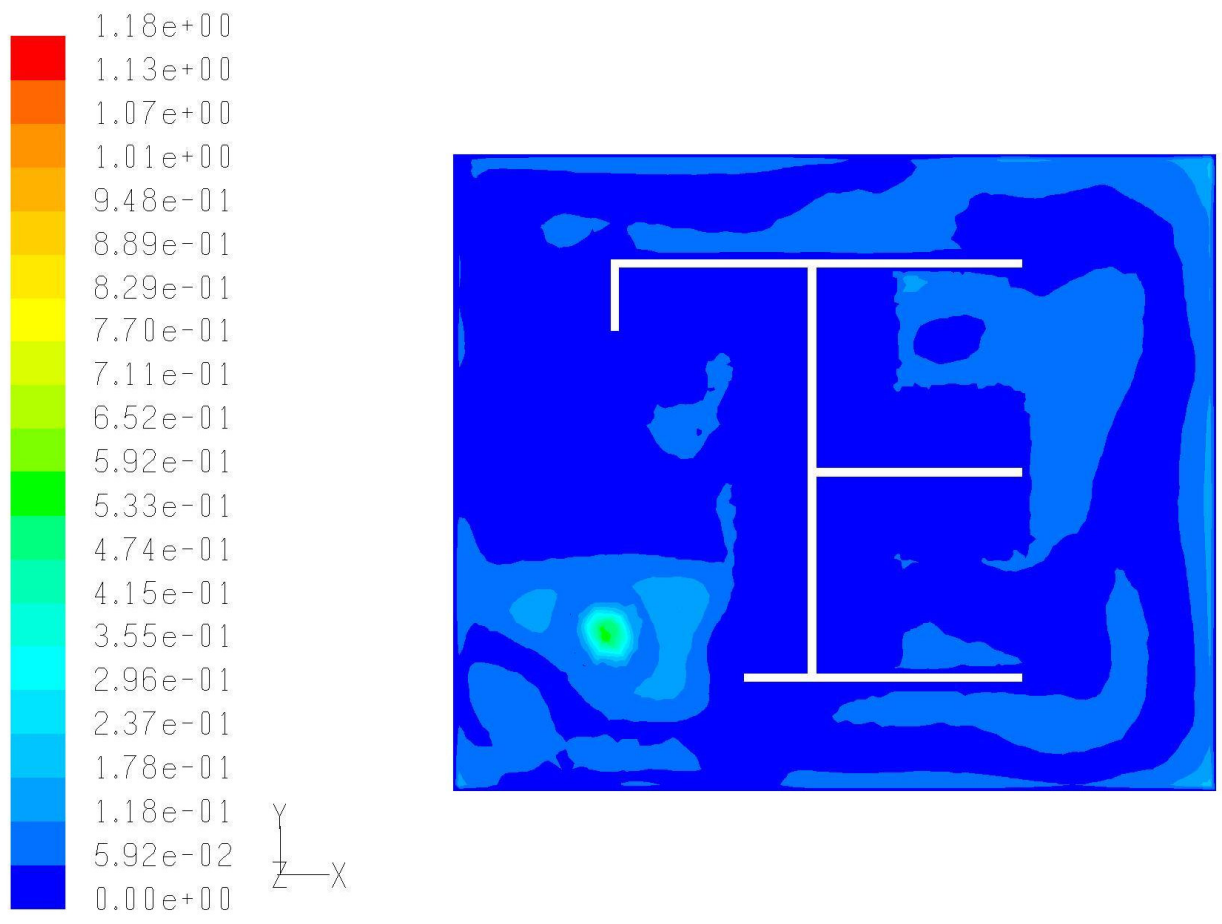

Figura 7.21 - Velocidade do ar $(\mathrm{m} / \mathrm{s})$ no plano $\mathrm{z}=60 \mathrm{~cm}$ 

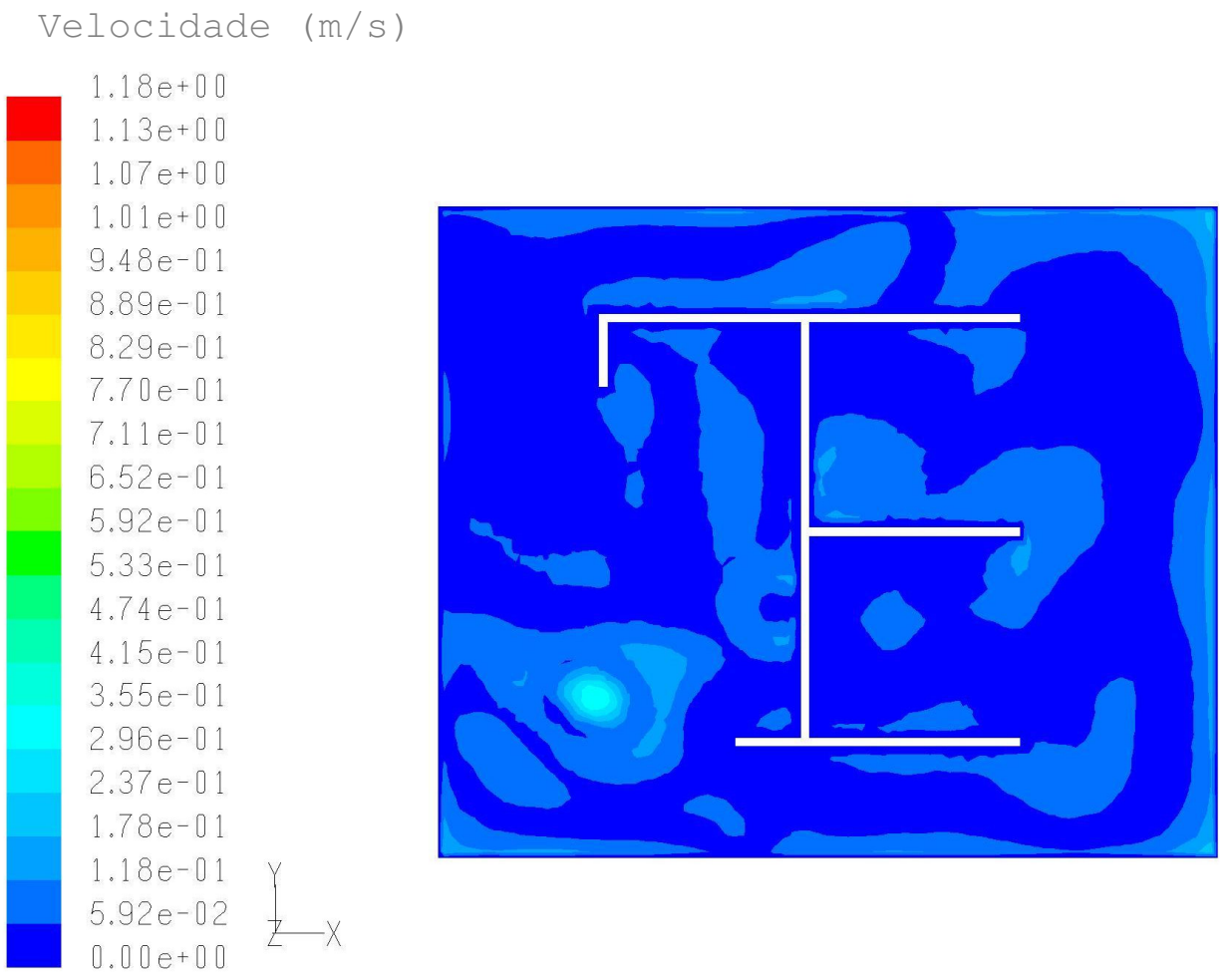

Figura 7.22 - Velocidade do ar $(\mathrm{m} / \mathrm{s})$ no plano $\mathrm{z}=110 \mathrm{~cm}$

Velocidade $(\mathrm{m} / \mathrm{s})$
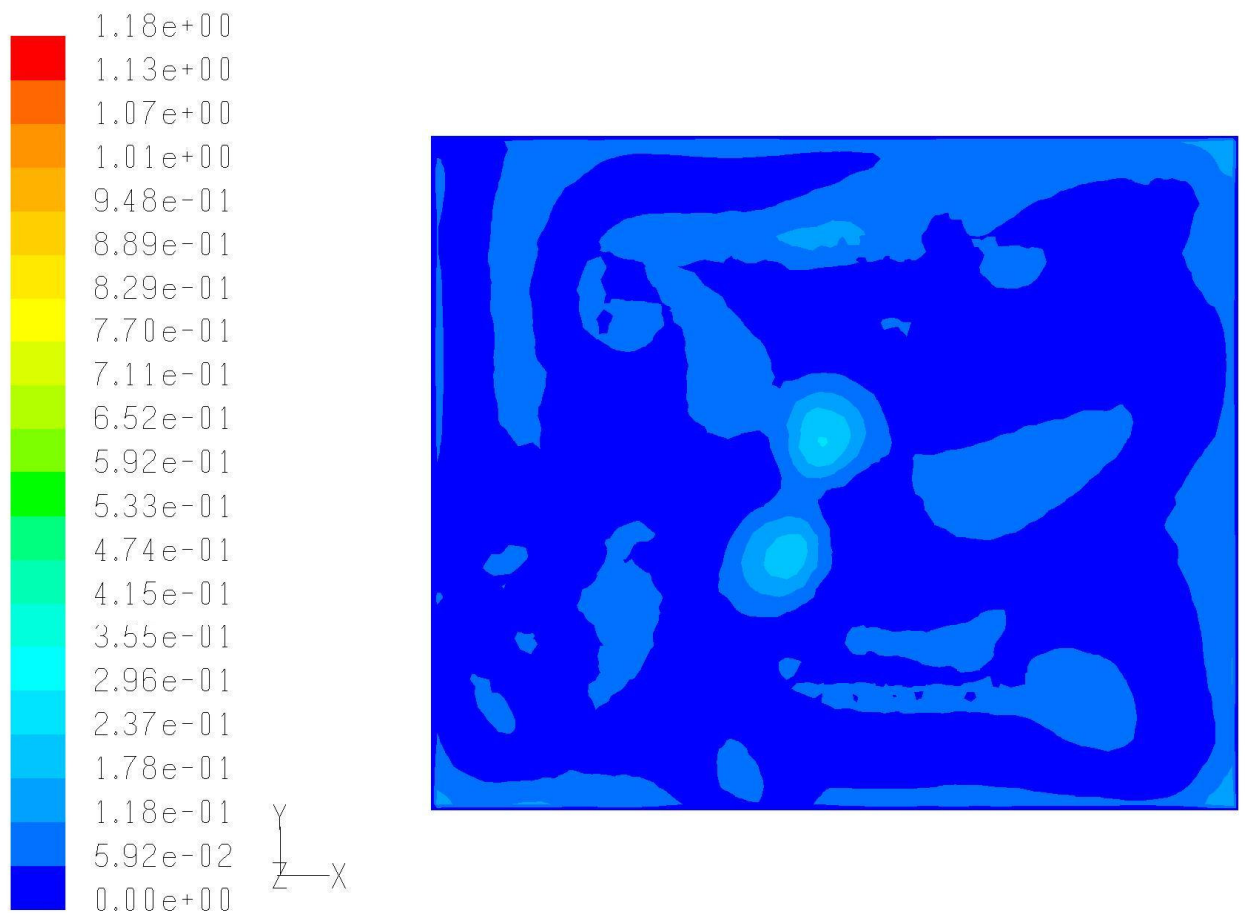

Figura 7.23 - Velocidade do ar $(\mathrm{m} / \mathrm{s})$ no plano $z=170 \mathrm{~cm}$ 


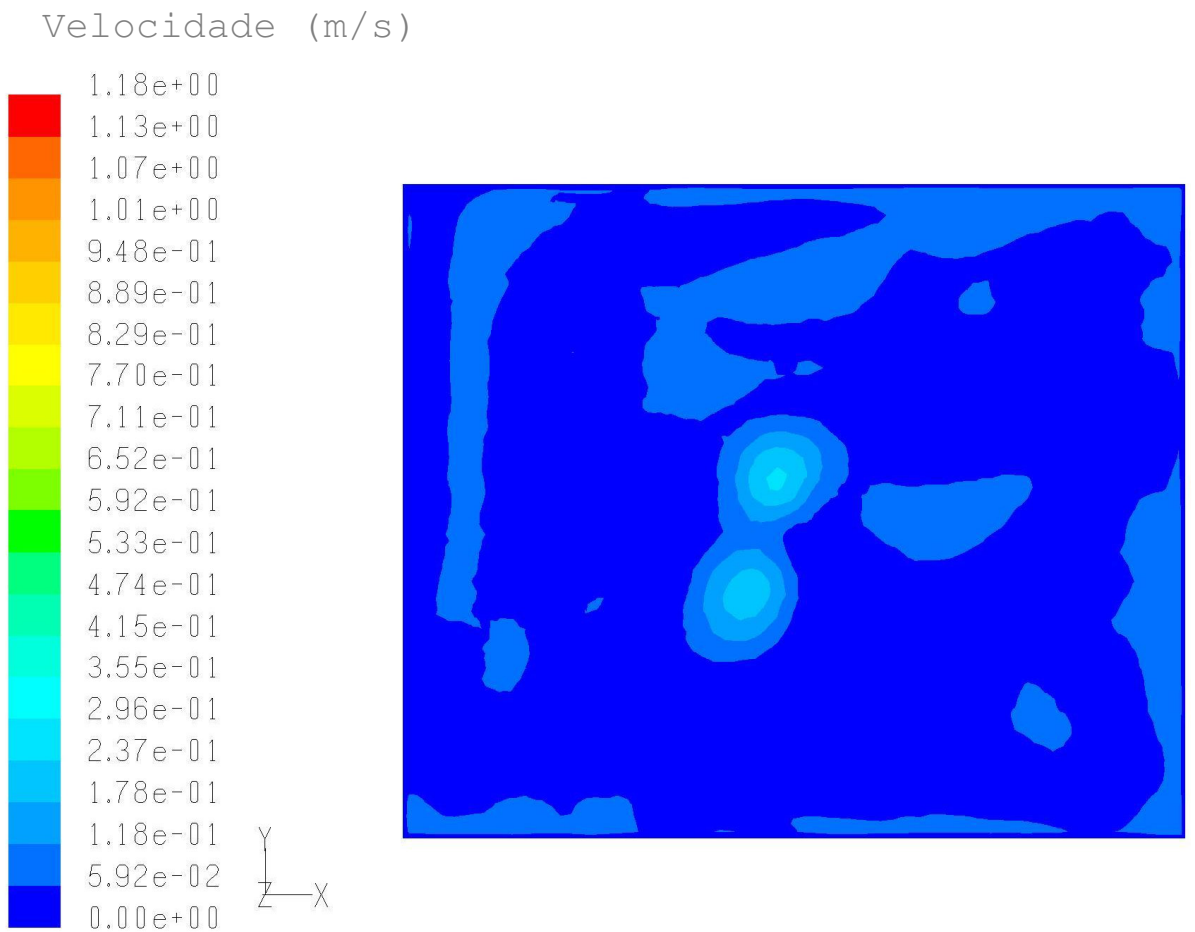

Figura 7.24 - Velocidade do ar $(\mathrm{m} / \mathrm{s})$ no plano $\mathrm{z}=200 \mathrm{~cm}$

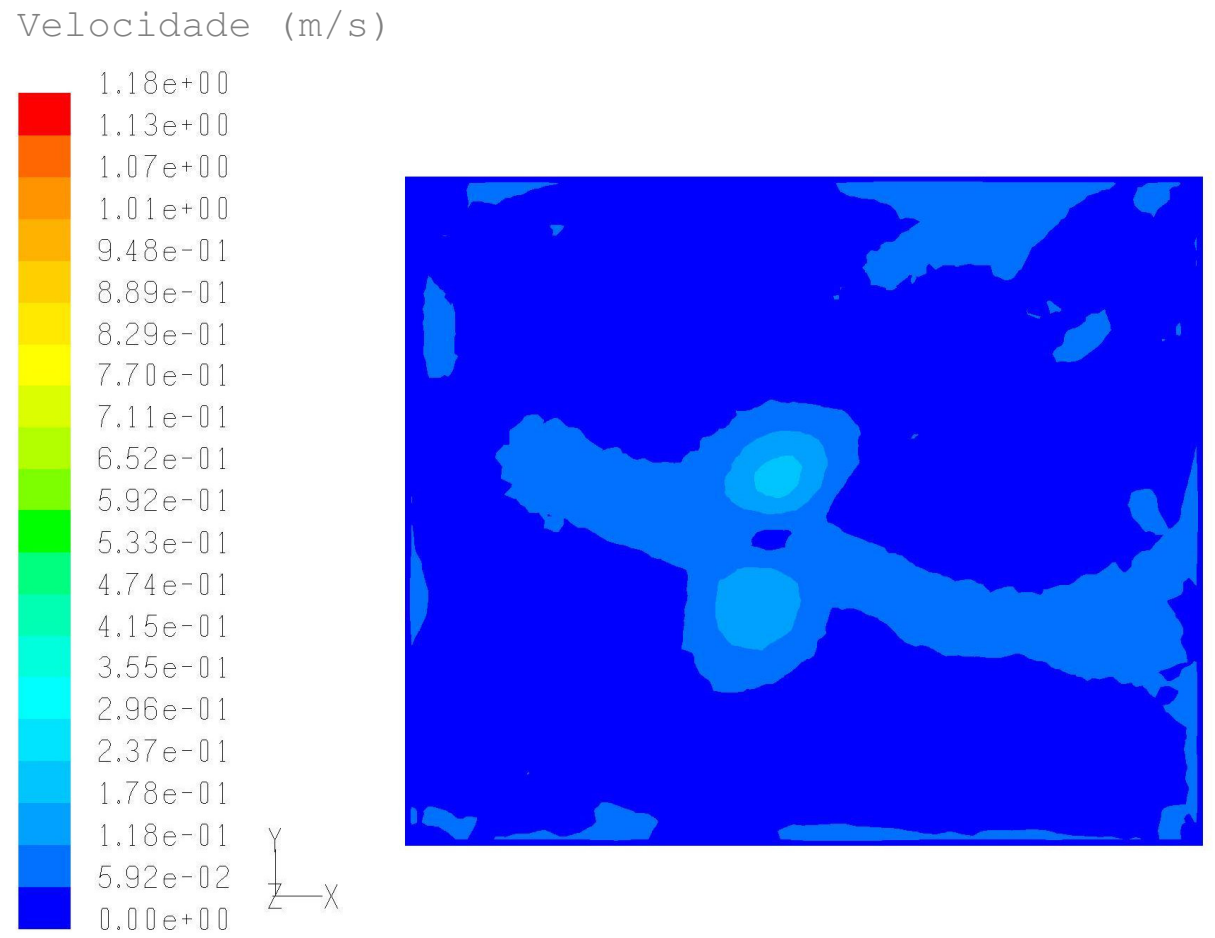

Figura 7.25 - Velocidade do ar $(\mathrm{m} / \mathrm{s})$ no plano $\mathrm{z}=235 \mathrm{~cm}$

As figuras 7.26 a 7.28 ilustram os resultados das simulações comparados com os dados experimentais para a velocidade do ar, em cada ponto de medição. 

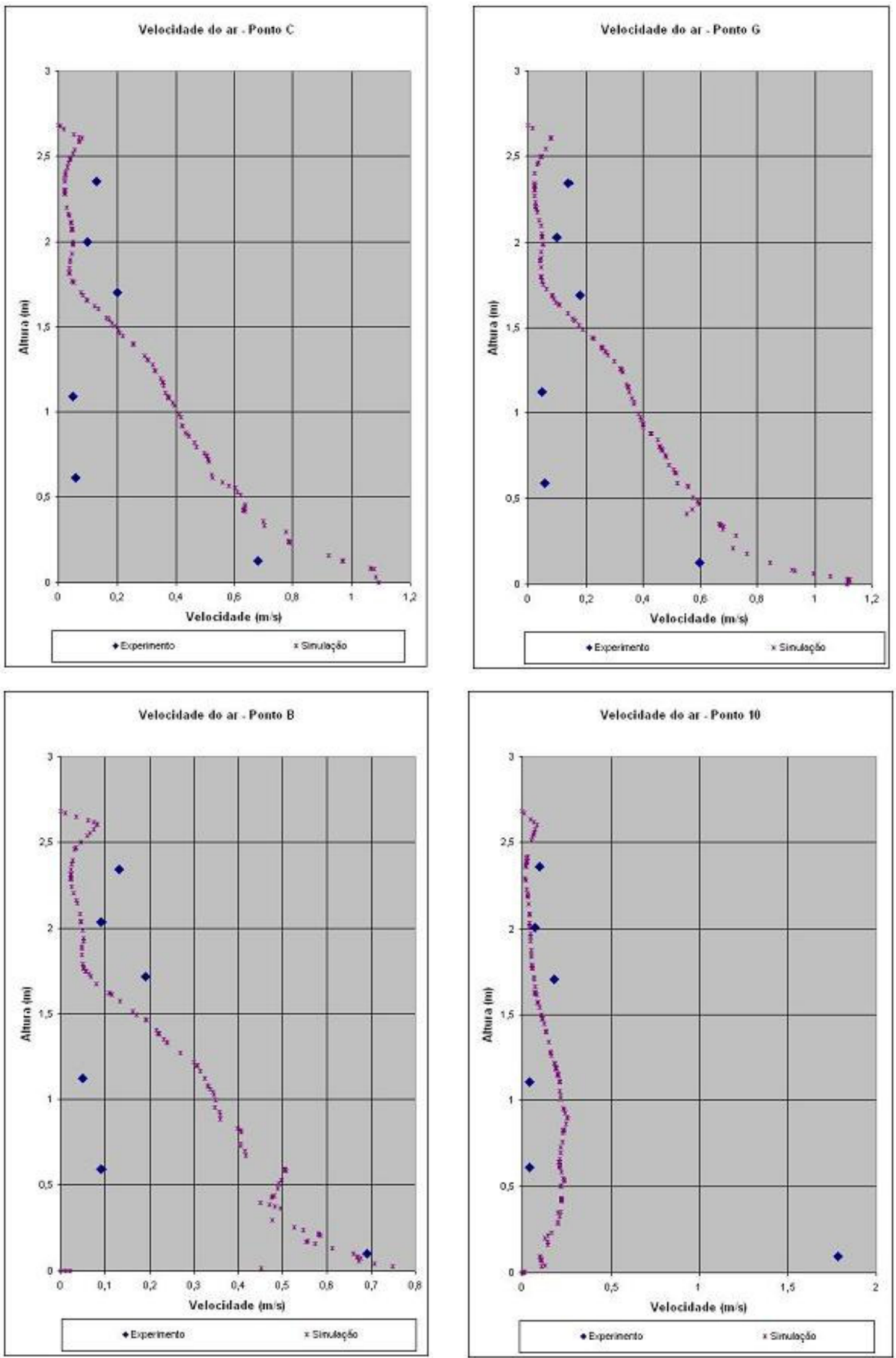

Figura 7.26 - Perfis de velocidade do ar para os pontos C, G, B e 10 

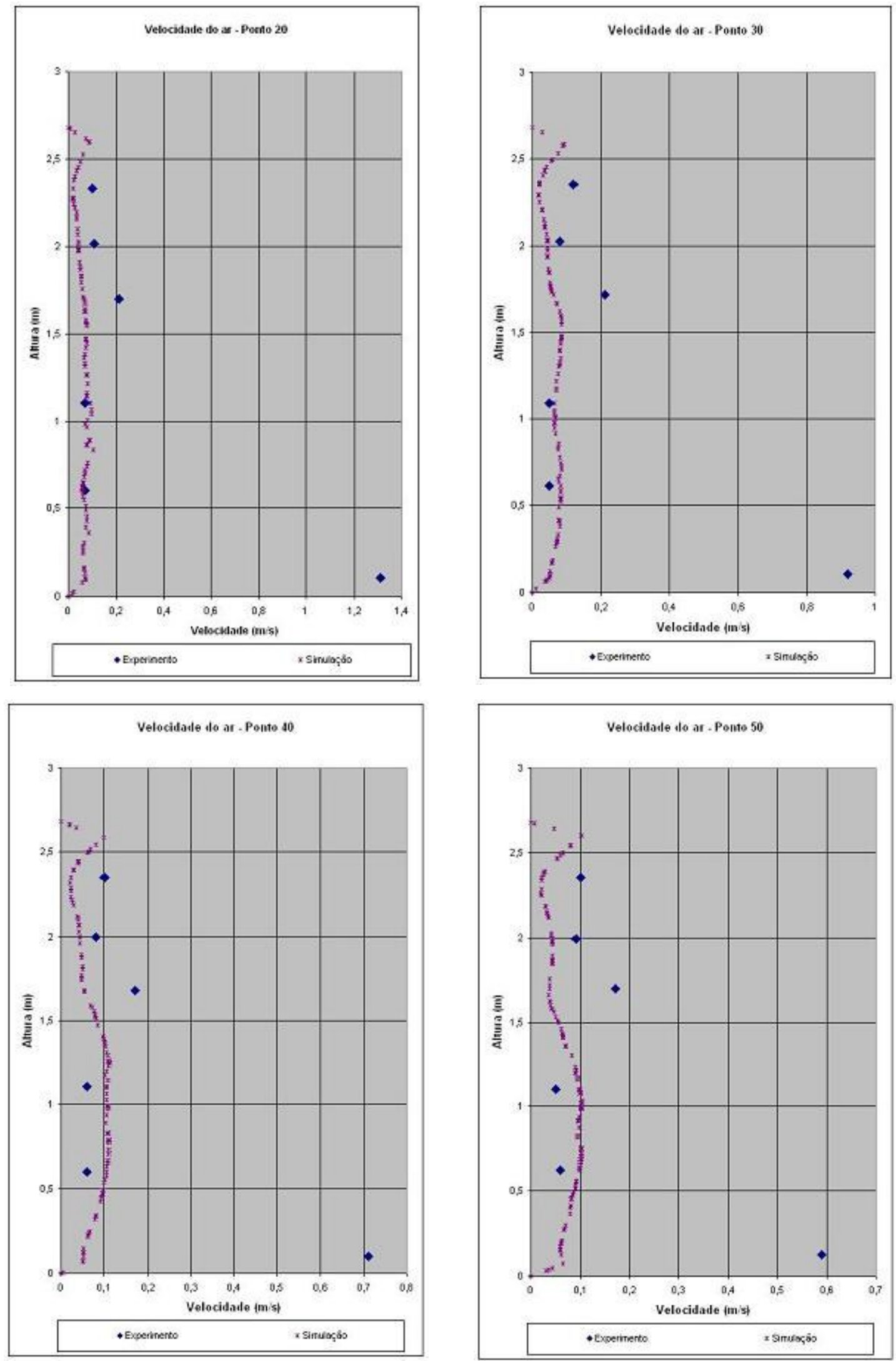

Figura 7.27 - Perfis de velocidade do ar para os pontos 20 a 50 

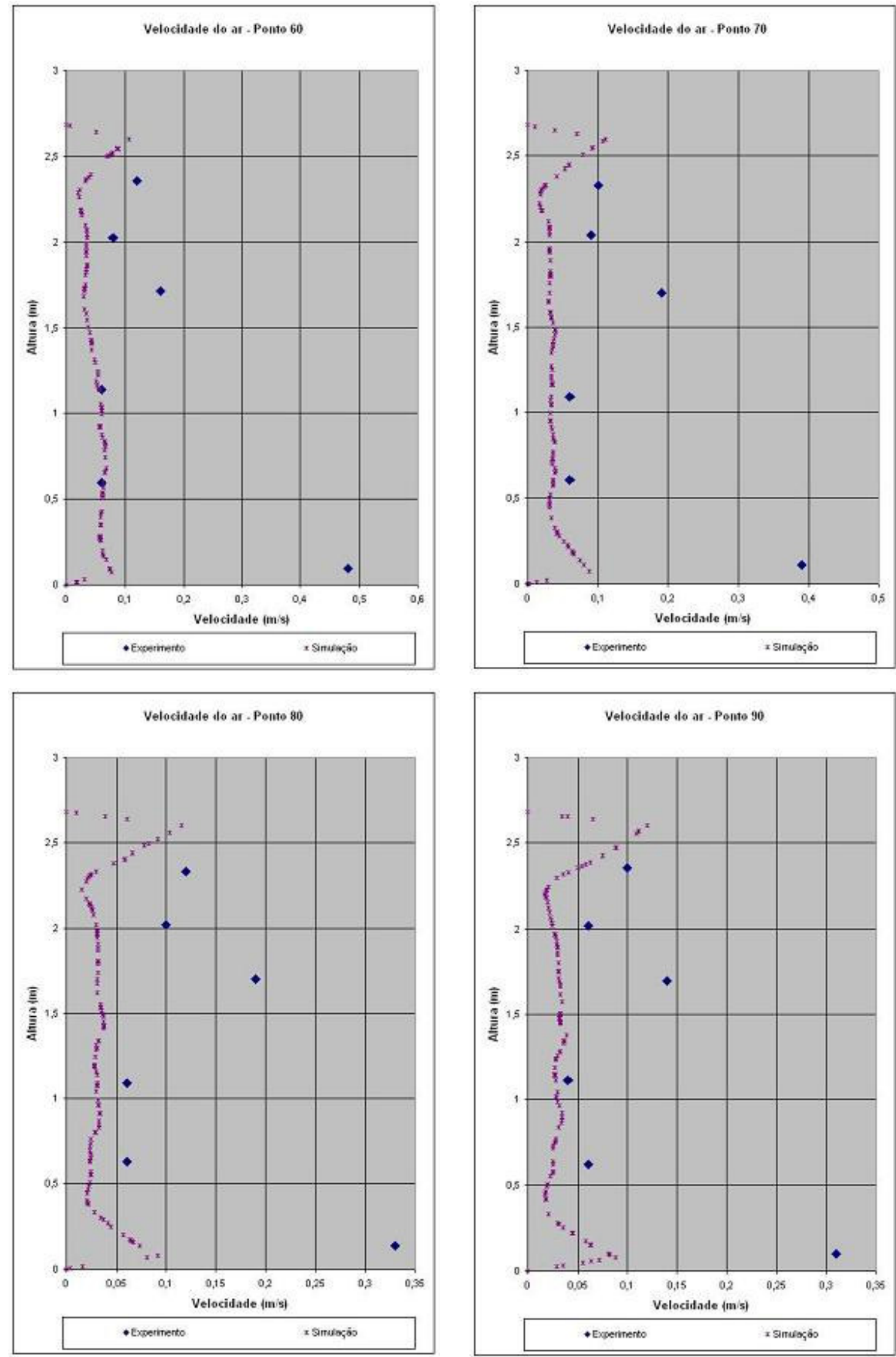

Figura 7.28 - Perfis de velocidade do ar para os pontos 60 a 90 
A análise dos planos verticais e horizontais de velocidade do ar revela a predominância de velocidades muito baixas $(<0,1 \mathrm{~m} / \mathrm{s})$ no modelo, exceto na região próxima ao difusor de ar.

As figuras 7.26 a 7.28 mostram que há uma relativa concordância com os dados das medições a partir do ponto 10, exceto para a região mais próxima ao piso (10 cm de altura). Contudo, da mesma forma que os resultados obtidos por Pustlenik (2005), os valores resultantes das simulações encontram-se dentro da faixa de incerteza de medição da velocidade $( \pm 0,06 \mathrm{~m} / \mathrm{s})$.

\subsection{ANÁLISE DOS MODELOS DE DENSIDADE DO AR}

Em seu estudo, Pustelnik (2005) empregou o modelo de gás ideal, para a densidade do ar. No entanto, no FLUENT, este modelo se aplica aos escoamentos compressíveis, o que contraria a hipótese de escoamento incompressível adotada pelo autor. O modelo descrito no trabalho de Pusltenik (2005) é, assim, válido para simulações que empreguem o mesmo modelo de densidade do ar. Fez-se necessária a comparação entre os modelos de densidade do ar para verificar o impacto que a escolha de diferentes modelos tem na solução do problema.

Assim, no presente estudo, foram realizadas simulações para comparar os resultados do emprego de três modelos de densidade do ar para escoamentos incompressíveis com o modelo de gás ideal.

Além do modelo de Boussinesq, cujas propriedades foram descritas no item 6.6 foram simulados o modelo de gás ideal incompressível e o modelo de densidade variando em função da temperatura (piecewise linear function) de acordo com os pares de dados da tabela 7.1.

Tabela 7.1 - Relação entre a temperatura e a densidade do ar (FONTE: www.wikipedia.org)

\begin{tabular}{|c|c|}
\hline${ }^{\circ} \mathbf{C}$ & $\boldsymbol{\rho}\left(\mathrm{KG} / \mathbf{M}^{3}\right)$ \\
\hline+0 & 1.293 \\
\hline+5 & 1.269 \\
\hline+10 & 1.247 \\
\hline+15 & 1.225 \\
\hline+20 & 1.204 \\
\hline+25 & 1.184 \\
\hline+30 & 1.164 \\
\hline
\end{tabular}


As simulações com diferentes modelos de densidade do ar foram realizadas com os mesmos parâmetros que aqueles empregados na simulação para verificação da estratégia proposta.

\subsubsection{RESULTADOS}

\subsubsection{Temperatura do ar}

Os gráficos das figuras 7.29 e 7.30 ilustram as curvas de temperatura do ar resultantes das simulações para os modelos de densidade do ar empregados, confrontando-os com os dados das medições experimentais, para os pontos $C, 30$, 60 e 90.
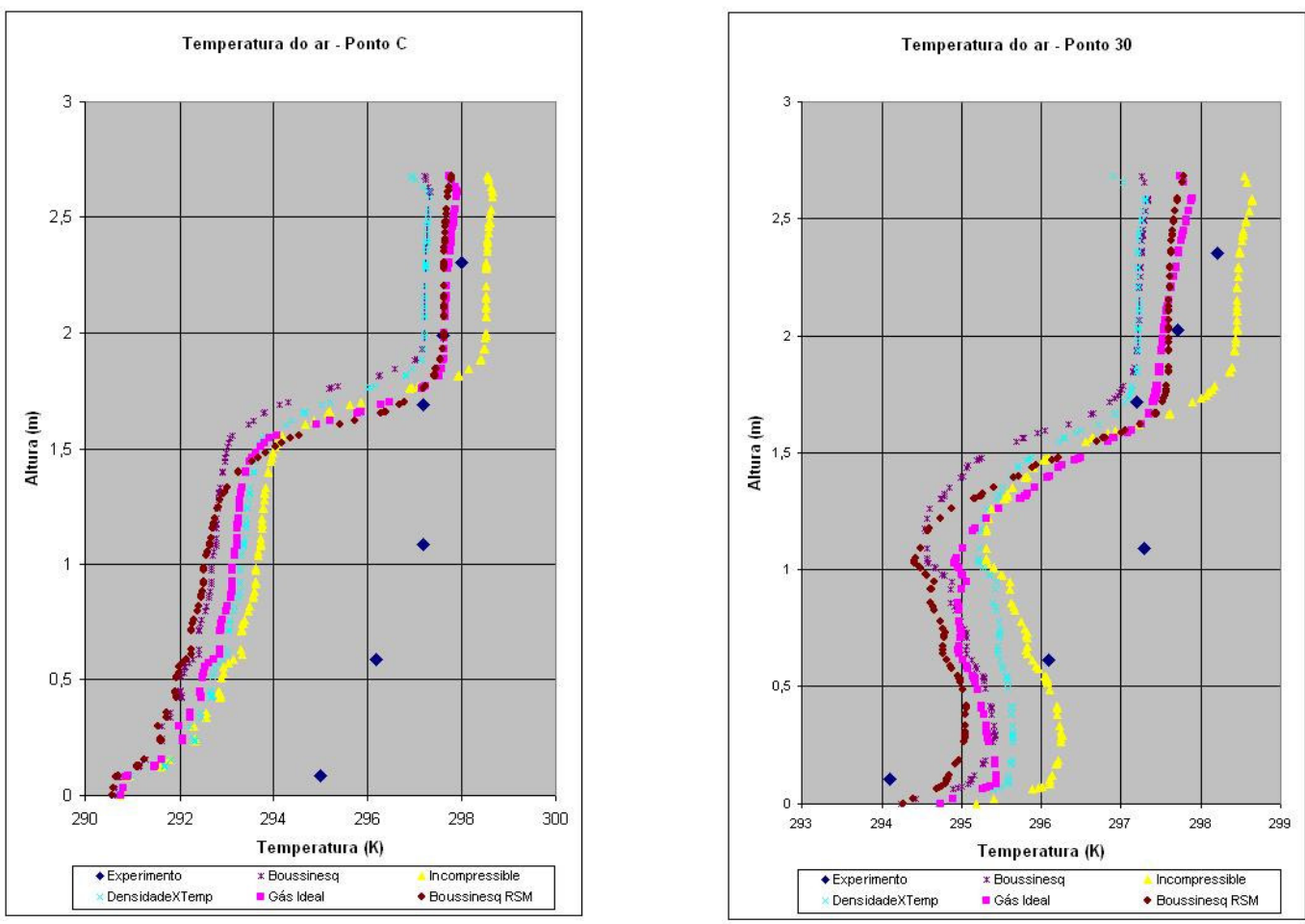

Figuras 7.29 - Perfis de temperatura do ar nos pontos $\mathrm{C}$ e 30 para os modelos de densidade Boussinesq, gás Ideal, gás incompressível e densidade em função da temperatura, e para 0 modelo de turbulência RSM 

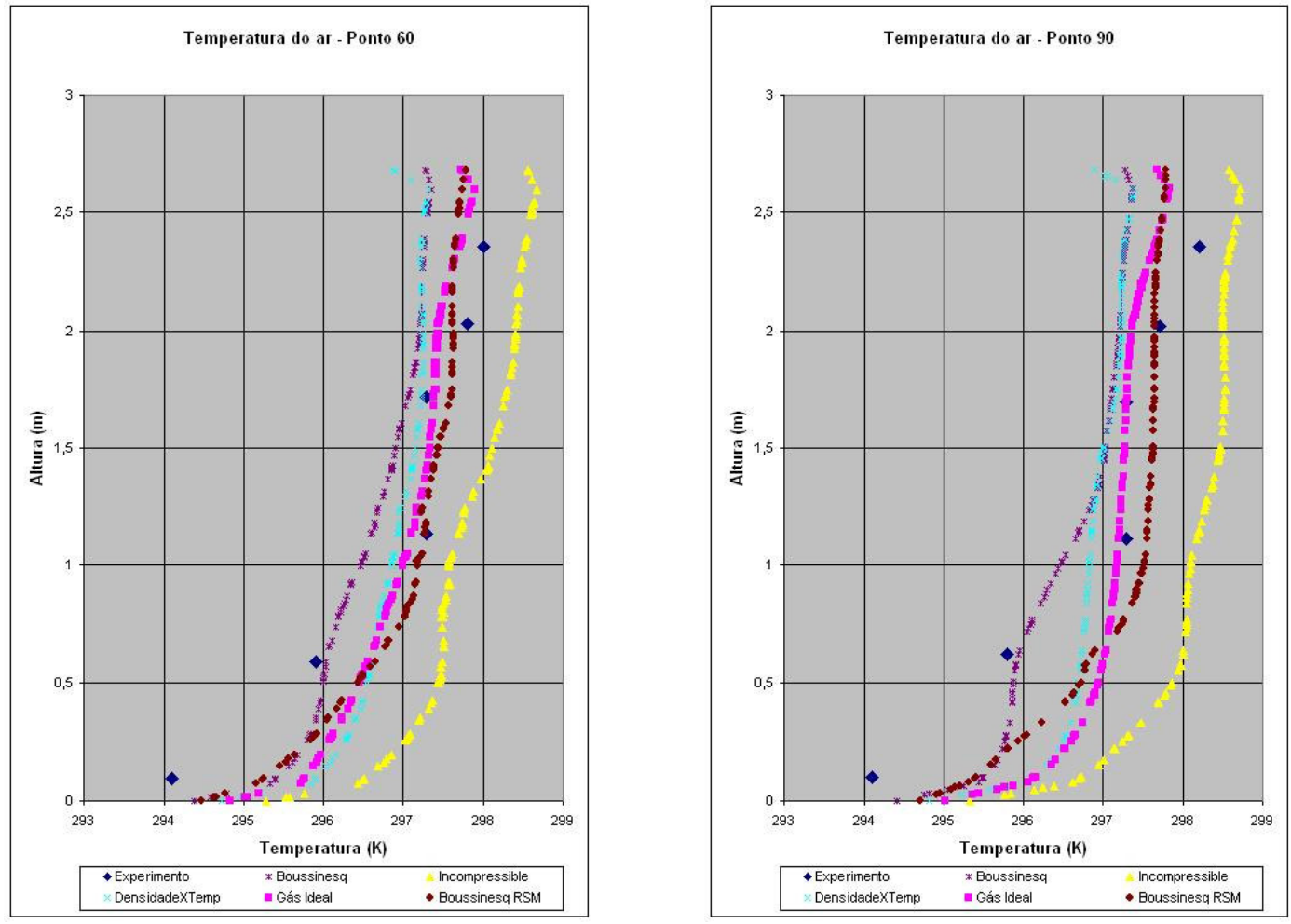

Figuras 7.30 - Perfis de temperatura do ar nos pontos 60 e 90 para os modelos de densidade

Boussinesq, gás Ideal, gás incompressível e densidade em função da temperatura, e para o modelo de turbulência RSM

A comparação entre os resultados do emprego de diferentes modelos de densidade do ar mostra que diferenças podem ser encontradas, dependendo do modelo adotado. No ponto 90 , por exemplo, diferenças de até $2 \mathrm{~K}$ foram registradas a cerca de $70 \mathrm{~cm}$ do piso.

Conforme citado anteriormente, o modelo validado por Pustelnik (2005) empregou o modelo de densidade para gás ideal. Contudo, o modelo de densidade mais comumente empregado em estudos de convecção natural é o modelo de Boussinesq, que foi o modelo empregado para a realização das simulações do presente estudo.

\subsubsection{Velocidade do $\mathrm{Ar}$}

Os gráficos da figura 7.31 ilustram as curvas de velocidade do ar para os pontos C, 30, 60 e 90, resultantes das simulações para os quatro modelos de densidade do ar empregados. As curvas de velocidade do ar resultantes da adoção 
dos três modelos de densidade do ar são praticamente coincidentes, com pequenas diferenças que se encontram dentro do limite de incerteza de medição.
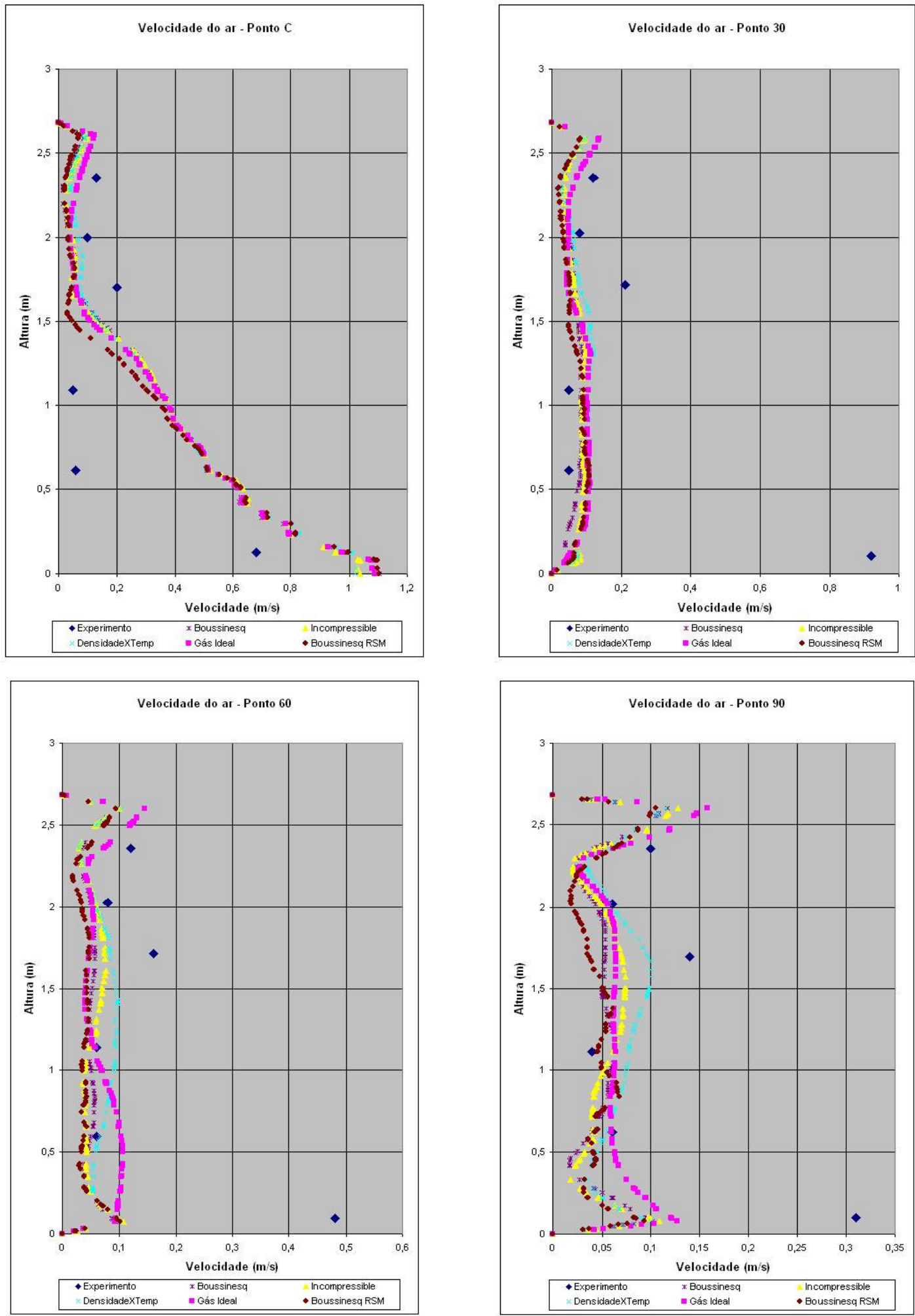

Figuras 7.31 - Perfis de velocidade do ar nos pontos C, 30, 60 e 90 para os modelos de densidade Boussinesq, gás Ideal, gás incompressível e densidade em função da temperatura, e para o modelo de turbulência RSM 


\subsubsection{Pressão}

Comparando-se os valores de pressão estática resultantes da adoção do modelo de gás ideal (figura 7.32) com a figura 6.8, que ilustra os valores de pressão estática para o modelo de Boussinesq, nota-se que a diferença de pressão entre o plenum e o ambiente é a mesma, para os dois modelos, ou seja, 24,8Pa.

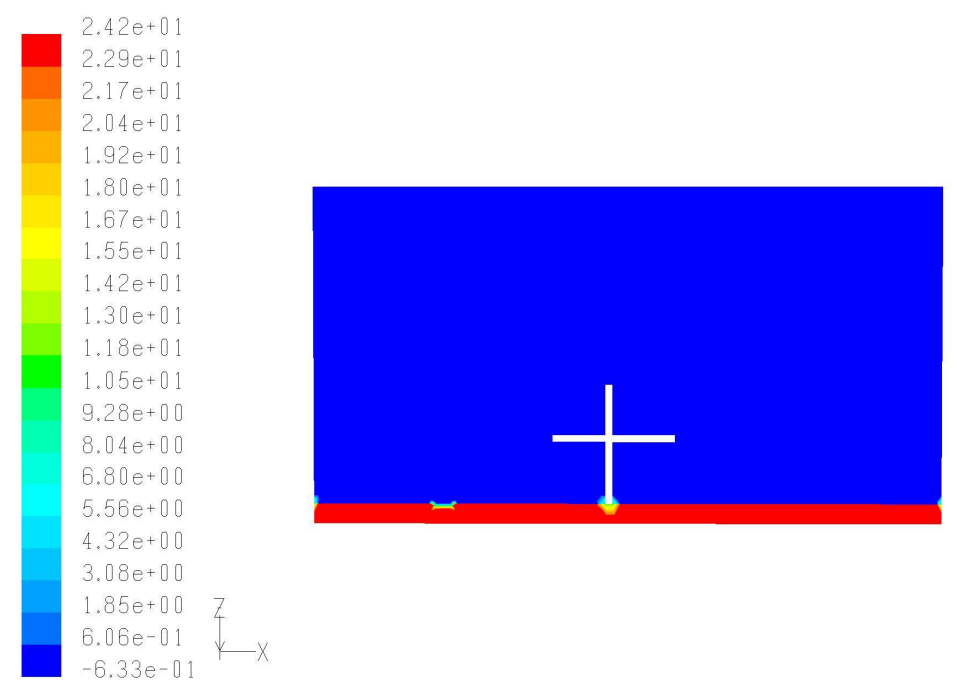

Figura 7.32 - Pressão estática $(\mathrm{Pa})$ para o plano $\mathrm{Y}=130 \mathrm{~cm}$-Modelo de densidade para gás ideal

A comparação dos modelos de densidade do ar mostra que, apesar de não terem sido identificadas diferenças mais significativas entre os modelos comparados, o emprego de um modelo deve ser analisado com base no fenômeno a ser estudado.

Do exposto acima, pode-se concluir que o emprego do modelo de Boussinesq, ao invés do modelo de densidade para gás ideal, validado por Pustelnik, não provoca alterações significativas nos resultados das simulações, podendo assim, ser utilizado em outros estudos do escoamento do ar que empreguem modelo semelhante.

\subsection{MODELO RSM}

Segundo Pustelnik (2005), o modelo de turbulência RSM tende a fornecer resultados mais precisos. Assim, foi realizada uma simulação, adotando-se o modelo de densidade de Boussinesq e o modelo de turbulência RSM. No entanto, a análise dos perfis de velocidade e temperatura do ar, ilustrados nas figuras 7.29 a 7.31 
sugere que, para o presente estudo, não houve alteração significativa do emprego do modelo RSM nos resultados. Portanto, para a estratégia proposta, pode-se empregar o modelo k- $\varepsilon$ padrão nas simulações, já que o mesmo fornece resultados relativamente precisos e consome menos tempo de simulação. 


\section{CONCLUSÕES E CONSIDERAÇÕES FINAIS}

O escoamento do ar em ambientes com o sistema de distribuição de ar pelo piso é bastante complexo. Seu desempenho depende da interação do fluxo de flutuação, das fontes de calor, do momento do ar insuflado e da vazão de ar insuflado. A modificação de um desses parâmetros num determinado ambiente pode resultar na alteração do comportamento do escoamento do ar. Assim, se o momento do ar insuflado for muito baixo, o sistema apresenta o mesmo comportamento do sistema de ventilação por deslocamento. Para momentos elevados, o sistema pode resultar em um escoamento de mistura total.

O presente estudo apresentou uma estratégia para a determinação de interrelações dos principais parâmetros que determinam o escoamento do ar no interior de um ambiente com o sistema de distribuição de ar pelo piso. A análise dessas inter-relações pelo projetista do sistema de ar condicionado possibilita que ele estabeleça as combinações entre os parâmetros de operação para que uma dada condição seja atingida no ambiente.

A análise de diferentes combinações dos parâmetros de operação que resultem numa mesma condição pode ser bastante proveitosa, por exemplo, se conjugada com a análise do desempenho energético do sistema.

A estratégia também possibilita a determinação de intervalos dentro dos quais os parâmetros de operação do sistema podem ser mantidos. Esses intervalos podem ser facilmente utilizados para o controle e operação do sistema de distribuição de ar pelo piso, já que para manter constante um dos parâmetros, os demais devem ser mantidos dentro de um intervalo. Assim, conforme citado anteriormente, para manter o diferencial de pressão em 25Pa, há possibilidade de escolha de diversas combinações de temperatura e vazão.

O trabalho realizado mostra que as ferramentas de dinâmicas dos fluidos computacional podem ser amplamente utilizadas em estudos sobre o escoamento do ar no interior de ambientes. O uso de uma ferramenta de CFD ao invés da realização de experimentos é vantajoso do ponto de vista de economia de tempo e dinheiro. Inúmeras combinações podem ser testadas em um curto prazo de tempo, ao contrário do que seria esperado caso os testes fossem realizados experimentalmente. 
Vale destacar, porém, que a realização de simulações numéricas não é tarefa fácil. Ao se empregar programas computacionais para tentar simular situações reais, devem-se tomar precauções para se obter resultados confiáveis, pois, não necessariamente o resultado da simulação é real ou fisicamente possível. Portanto, todo cuidado é necessário e realizar comparações entre dados obtidos experimentalmente e os fornecidos pelo simulador tem importância fundamental. Deve-se assegurar que estas ferramentas computacionais sejam utilizadas e testadas adequadamente.

Diversas dificuldades foram encontradas durante as etapas das simulações numéricas. A primeira dificuldade foi a construção da malha, já que no interior do ambiente podem ser encontrados elementos de escalas de grandezas bastante diferentes, ou seja, elementos com dimensões de alguns centímetros, como a espessura das mesas, e elementos com dimensões de alguns metros, como a extensão das paredes. Esse fato prejudica a qualidade dos elementos que compõem a malha, dificultando a sua construção.

Uma outra dificuldade foi o estabelecimento das condições de contorno. A determinação das condições de contorno que devem ser impostas para a correta predição do escoamento do ar é, certamente, uma das principais dificuldades das simulações numéricas. Neste caso, a condição de contorno no difusor de ar, foi extremamente difícil de ser imposta.

O tipo de difusor de ar e os parâmetros de insuflação de ar do difusor geralmente determinam a distribuição do ar em uma sala. Assim, descrições suficientes da informação do fluxo para o difusor são muito importantes para a predição do fluxo de ar em toda a sala (HU, 2003).

A inserção da geometria real dos difusores de ar, como os do tipo "swirl' é extremamente complexa devido à dificuldade de modelagem dos seus componentes e também à geração da malha que certamente apresentaria elementos de escala de grandeza muito diferentes da escala do ambiente (milímetros vs. metros). Dada a complexidade da estrutura dos difusores de ar, a realização de simulações numéricas que incluam sua geometria no domínio computacional, com os recursos computacionais disponíveis atualmente, é praticamente inviável.

Para o presente estudo, foi usada uma geometria bastante simplificada na modelagem do difusor de ar. Dada a dificuldade de caracterização do fluxo de ar que corresponda exatamente ao escoamento real, o resultado da simulação pode conter 
erros, principalmente na região de maior turbulência do fluxo de ar (região próxima ao centro do difusor).

Além disso, no caso de simulações numéricas do escoamento do ar no interior de ambientes, a complexidade aumenta devido aos diversos fatores que influenciam esse escoamento, como a geometria do ambiente, as propriedades das superfícies internas, a posição dos difusores de ar, a distribuição do mobiliário, as propriedades do ar insuflado, o número de ocupantes e sua posição no ambiente.

Segundo Loomans (1998), na maioria dos estudos sobre escoamento do ar em que se utilizam técnicas de CFD, a solução qualitativa encontra-se de acordo com os dados experimentais, mas isso não ocorre para a solução quantitativa, havendo a necessidade de realizar ajustes do modelo com dados empíricos.

De fato, os resultados das simulações mostram que a concordância total entre os resultados das medições e os valores simulados não foi obtida. Ainda que erros possam ter ocorrido durante a fase experimental, mais estudos são necessários para verificar se a inclusão da geometria real do difusor de ar no modelo simulado resultaria em maior concordância dos resultados das simulações com os dados experimentais, ou ainda se outros fatores como o modelo de turbulência e o modelo de densidade do ar empregados, dentre outros fatores, são adequados ao fenômeno físico em estudo.

Conforme citado anteriormente, no presente estudo, considerou-se que o modelo empregado foi validado no trabalho desenvolvido por Pulstelnik (2005). Deve-se salientar, contudo, que o autor destacou diversas dificuldades encontradas durante o desenvolvimento das simulações, e, similarmente, não obteve êxito total na realização das simulações.

Tanto o presente trabalho, como o estudo desenvolvido por Pustelnik (2005) mostram que é grande o desafio de realizar simulações numéricas. Os trabalhos, contudo, indicam que há possibilidades de uso de ferramentas de CFD para o estudo do escoamento do ar no interior de ambientes e abrem caminho para a realização de diversas outras pesquisas, na medida em que sugerem temas a serem pesquisados, tanto relacionados às simulações numéricas quanto ao sistema de distribuição de ar frio pelo piso.

As dificuldades encontradas durante a realização das simulações tendem a ser minimizadas à medida em que mais estudos forem realizados. A estratégia 
desenvolvida é apenas uma das diversas possibilidades de emprego de ferramentas de CFD, que agilizam o processo de projeto e o estudo dos sistemas de ventilação.

Ainda que a estratégia apresentada seja bastante simples, pode ser amplamente utilizada, não somente pelo operador de sistemas de distribuição de ar pelo piso, mas também para o controle de sistemas de distribuição de ar convencionais. A estratégia ainda pode ser empregada na fase inicial de projeto, para análise do impacto de um parâmetro de operação nos demais. Além disso, mais simulações podem ser realizadas com variação da quantidade e posição de cargas térmicas no interior do ambiente e seu impacto nos parâmetros de operação do sistema.

Do exposto acima, nota-se que há diversas aplicações para a estratégia desenvolvida. Mais estudos são necessários para o aprimoramento da estratégia e para a verificação de sua aplicação em situações reais. Contudo, a estratégia é o passo inicial para o desenvolvimento de diversas outras pesquisas relacionadas, tanto ao sistema de distribuição de ar pelo piso como às simulações numéricas e inclusive ao controle de sistemas de ar condicionado.

\subsubsection{SUGESTÕES PARA TRABALHOS FUTUROS}

Além do estudo proposto acima, são apresentadas algumas sugestões de estudos sobre o sistema de distribuição de ar pelo piso em ambientes de escritórios que podem ser realizados por meio de simulações numéricas:

- No presente estudo verificou-se a diferença de pressão entre o interior do plenum do piso e o ambiente varia quase que exclusivamente conforme a vazão de ar insuflado, tendo a temperatura influência praticamente nula. Contudo, não se pode afirmar que essa condição deve se repetir para todos os casos. Isso porque a diferença de pressão entre o interior do plenum do piso e o ambiente pode ser resultado de diferentes valores de pressão em cada volume, ou seja, a diferença de pressão de 25Pa pode ser resultado de um valor de pressão de 30Pa no plenum e 5Pa no ambiente, ou de 35Pa no plenum e 10Pa no ambiente e assim por diante. Embora a diferença de pressão seja a mesma, a condição no ambiente pode ser totalmente diferente 
nos dois casos. Assim, mais estudos são necessários para avaliar esse parâmetro de operação.

- Comportamento do escoamento do ar no interior do plenum, principalmente com relação à posição da entrada de ar frio no plenum;

- Acoplamento de programas de CFD com programas de avaliação de desempenho energético;

- Compatibilização entre a distribuição dos difusores de ar no piso e o layout de mobiliário, para o estabelecimento de diretrizes de projeto;

- Análise da variação da carga térmica interna no comportamento do escoamento do ar;

- Avaliação da qualidade do ar interior, por meio do estudo de dispersão de partículas;

- Desenvolvimento de estratégias para controle da condição térmica resultante, por meio do estudo de posicionamento ótimo de sensores no interior do ambiente;

- Estudo do impacto que a alteração das condições (ajuste ou reposicionamento do difusor de ar) em uma estação de trabalho provoca nas estações de trabalho vizinhas;

- Uso de ferramentas de simulação numérica para o projeto de novos modelos de difusores de ar. 


\section{REFERÊNCIAS}

ABANTO, J. et al. Airflow modelling in a computer room. Building and Environment, Oxford, v. 39, p.1393-1402, 2004.

ADDISON, M. S.; NALL, D. H. Cooling via underfloor air distribution: current design issue and analysis options. In: COOLING FRONTIERS: THE ADVANCED EDGE OF COOLING RESEARCH AND APPLICATIONS IN THE BUILT ENVIRONMENT, 2001, Tempe. Proceedings... Arizona: Arizona State University, 2001. Disponível em: $<$ http://www.doe2.com/Download/Docs/Addison-Nall UnderfloorAirDistPaper Rev1. pdf>. Acesso em: 07 jun. 2005.

AKIMOTO, T; NOBE, T; TAKEBAYASHI, Y. Experimental study on the floor-supply displacement ventilation system. ASHRAE Transactions, Atlanta, v. 101, pt. 2, p.912-925, 1995.

ARNOLD, D. Raised floor air distribution: a case study. ASHRAE Transactions, Atlanta, v. 96, pt. 1, p.665-669, 1990.

ASSOCIAÇÃO BRASILEIRA DE NORMAS TÉCNICAS. NBR 6401: instalações centrais de ar condicionado para conforto: parâmetros básicos de projeto. Rio de Janeiro, 1980.

BAUMAN, F. S. et al. Performance testing of a floor-based, occupant-controlled office ventilation system. ASHRAE Transactions, Atlanta, v. 97, pt. 1, p. 553-565, 1991.

Testing and optimizing the performance of a floor-based task conditioning system. Energy and Buildings, Lausanne, v. 22, n. 3, p.173-186, 1995.

.; WEBSTER, T. Outlook for underfloor air distribution. ASHRAE Journal, New York, v. 43, n. 6, p. 18-25, 2001.

BAUMAN, F. Underfloor air distribution (Ufad) design guide. Atlanta: American Society of Heating, Refrigeration and Air Conditioning, 2003. 243 p.

.; PECORA, P.; WEBSTER, T. How low can you go?: air flow performance of low-height underfloor plenums. Center for the Built Environment, Berkeley, 24 p., 1999. Summary Report. 
BEAUSOLEIL-MORRISON, I. The adaptive coupling of computational fluid dynamics with the whole-building thermal simulation. In: INTERNATIONAL IBPSA CONFERENCE, 7., 2001, Rio de Janeiro. Building simulation '01. Rio de Janeiro: Organizing Committee of Building Simulation '01: IBPSA Brazil, c2001. p. 1259-1265. Disponível em: <http://www.hvac.okstate.edu/pdfs/bs01/BS01_1259_1266.pdf> Acesso em: 16 mar. 2005.

BIELLI, E. UFAD: Floor supply and floor return for excellent indoor air quality and thermal comfort. In: INTERNATIONAL CONFERENCE ON AIR DISTRIBUTION IN ROOMS, 8., 2002, Copenhagen. Proceedings... Denmark: The Technical University of Denmark and Danvak, 2002. p. 449-452.

CHAE, Y. T. et al. Experimental comparison of thermal environment between ceilingbased and floor-based system with CAV HVAC system. In: INTERNATIONAL CONFERENCE ON AIR DISTRIBUTION IN ROOMS, 9., 2004, Coimbra.

Proceedings... Coimbra: Universidade de Coimbra, 2004. 1 CD-ROM.

CHAO, C. Y. H.; WAN, M. P. Airflow and air temperature distribution in the occupied region of an underfloor ventilation system. Building and Environment, Oxford, v. 39, n. 7, p. 749-762, 2004.

CHARLES, K. E. Office air distribution systems and environmental satisfaction. Ottawa, Canada: National Research Council of Canada, Institute for Research in Construction and Public Works \& Government Services, 2002. 23 p. (Relatório técnico IRC-RR-161). Disponível em: <http://irc.nrccnrc.gc.ca/pubs/fulltext/rr/rr161/rr161.pdf>. Acesso em: 21 set. 2005.

CHEN, Q.. et al. Prediction of room thermal response by CFD technique with conjugate heat transfer and radiation models. ASHRAE Transactions, Atlanta, v. 101 , pt. 2, p. 50-60, 1995.

; XU, W. A zero-equation turbulence model for indoor airflow simulation.

Energy and Buildings, Lausanne, n. 28, p.137-144, 1998.

CHOU, P. C.; CHANG, K. F.; CHIANG, C. M. Performances on Indoor Air Quality and Energy Consumption in the Working Spaces using Underfloor Air Distribution (UFAD) System. In: INTERNATIONAL CONFERENCE ON AIR DISTRIBUTION IN ROOMS, 9., 2004, Coimbra. Proceedings... Coimbra: Universidade de Coimbra, 2004. 1 CDROM. 
COLLIGNAN, B.; COUTURIER, S.; AKOUA, A. A. Evaluation of ventilation system efficiency using CFD analysis. In: INTERNATIONAL CONFERENCE ON AIR DISTRIBUTION IN ROOMS, 8., 2002, Copenhagen. Proceedings... Copenhagen: The Technical University of Denmark and Danvak, 2002. p. 77-80.

CORGNATI, S. P.; PERINO, M. Thermal comfort, IAQ and air distribution analysis in open-space offices with underfloor air distribution. In: INTERNATIONAL CONFERENCE ON AIR DISTRIBUTION IN ROOMS, 9., 2004, Coimbra. Proceedings... Coimbra: Universidade de Coimbra, 2004. 1 CD-ROM.

DALY, A. Underfloor air distribution: lessons learned. ASHRAE Journal, New York, v. 44, n. 5, p. 21-24, 2002.

DE CARLI, M. et al. Analysis of air velocity and temperature distribution in furnished rooms with underfloor air diffusers. In: INTERNATIONAL CONFERENCE ON AIR DISTRIBUTION IN ROOMS, 7., 2000, Reading. Proceedings... Reading: Elsevier Science, 2000. 1 CD ROM.

DEUTSCHES INSTITUT FÜR NORMUNG. DIN 4715: chilled surfaces for rooms: part 1: measuring of the performance with free flow. 1995.

DJUNAEDY, E. et al. Numerical modeling of air supply diffusers for room air distribution. In: APPLICATIONS OF HIGH PERFORMANCE COMPUTING, 1999, Singapore. Proceedings... Singapore: National University of Singapore, 1999. p.5059.

DJUNAEDY, E.; HENSEN, J. L. M.; LOOMANS, M. G. L. C. Development of a guideline for selecting a simulation tool for airflow prediction. In: INTERNATIONAL IBPSA CONFERENCE, 8., 2003, Eindhoven. Proceedings... Eindhoven, 2003. p.267-274. Disponível em: < http://www.ibpsa.org/proceedings/BS2003/BS03 0267 274.pdf > Acesso em: 16 mar. 2005.

ENERGY DESIGN RESOURCES. Underfloor air distribution and acess floors. eNews for designers, Issue 36, 2004. Disponível em: <http:// http://www.energydesignresources.com>. Acesso em: 16 mar. 2005.

FAULKNER, D.; FISK, W. J.; SULLIVAN, D. P. Indoor airflow and pollutant removal in a room with floor-based task ventilation: results of additional experiments. Building and Environment, Oxford, v. 30, n. 3, p. 323-332, 1995. 
FLUENT INC. Fluent 6.1: tutorial guide. Lebanon, NH, 2003a. CD-ROM.

. Fluent 6.1: user's guide. Lebanon, NH, 2003b. CD-ROM.

. Gambit 2.1: modeling guide. Lebanon, NH, 2003c. CD-ROM.

. Gambit 2.1: tutorial guide. Lebanon, NH, 2003d. CD-ROM.

Gambit 2.1: user's guide. Lebanon, NH, 2003e. CD-ROM.

FORTUNA, A. O. Técnicas computacionais para dinâmica dos fluídos: conceitos básicos e aplicações. São Paulo: EUSP, 2000. 426 p.

FUKAO, $\mathrm{H}$.; et al. Comparison of underfloor versus overhead air distribution systems in an office building. ASHRAE Transactions, Atlanta, v. 108, pt. 1, p. 64-71, 2002.

GAN, G. Evaluation of room air distribution system using computational fluid dynamics. Energy and Buildings, Lausanne, v. 23, n. 1, p.83-93, 1995.

GAO, N.; NIU, J. CFD study on micro-environment around human body and personalized ventilation. Building and Environment, Oxford, v. 39, n. 7, p. 795-805, 2004.

GENTER, R. E. Air distribution for raised floor offices. ASHRAE Transactions, Atlanta, v. 95, pt. 2, p.141-146, 1989.

HANZAWA, H.; NAGASAWA, Y. Thermal comfort with underfloor air-conditioning systems. ASHRAE Transactions, Atlanta, v. 96, pt. 2, p. 696-698, 1990.

HEINEMEIER, K. E.; SCHILLER, G. E.; BENTON, C. C. Task conditioning for the workplace: issues and challenges. ASHRAE Transactions, Atlanta, v. 96, pt.2, p. 678-689, 1990.

HU, S. C. Airflow characteristics in the outlet region of a vortex room air diffuser. Building and Environment, Oxford, v. 38, n. 4, p. 553-561, 2003.

KIM, I. G.; HOMMA. H. Distribution and ventilation efficiency of CO2 produced by occupants in upward and downward ventilated rooms. ASHRAE Transactions, Atlanta, v. 98, pt. 1, p. 242-250, $1992 a$. 
Possibility for increasing ventilation efficiency with upward

ventilation. ASHRAE Transactions, Atlanta, v. 98, pt. 1, p. 723-729, $1992 \mathrm{~b}$.

KIM, Y.; LEE, K.; CHO, H. Experimental study of flow characteristics of a diffuser for under floor air-conditioning system. ASHRAE Transactions, Atlanta, v. 107, pt. 1, p. 230-236, 2001.

LEITE, B. C. C. Análise do desempenho de edifícios de escritórios automatizados através da avaliação pós-ocupação. 1997. 385 f. Dissertação (Mestrado) - Faculdade de Arquitetura e Urbanismo, Universidade de São Paulo, São Paulo, 1997.

. Relatório de teste. São Paulo: EPUSP, 2004. 9 p.

Sistema de ar condicionado com insuflamento pelo piso em ambientes de escritórios: avaliação do conforto térmico e condições de operação. 2003. 162 f. Tese (Doutorado) - Escola Politécnica, Universidade de São Paulo, São Paulo, 2003.

.; MENDES JÚNIOR, C.; TRIBESS, A. Underfloor air conditioning systemoperational conditions for comfort in office environments. In: INTERNATIONAL CONGRESS OF MECHANICAL ENGINEERING, 17., 2003, São Paulo.

Proceedings... Rio de Janeiro: ABCM, 2003. p.

.; TRIBESS, A. Analysis of the underfloor air distribution system: thermal comfort and energy consumption. In: INTERNATIONAL CONFERENCE ON AIR DISTRIBUTION IN ROOMS, 8., 2002, Copenhagen, DK. Proceedings... Copenhagen, DK: Technical University of Denmark, 2002a. p. 245-248.

;

Analysis of thermal comfort in office environment with underfloor air supply in tropical climate. . INTERNATIONAL JOURNAL OF HEATING VENTILATING AIR CONDITIONING AND REFRIGERATING RESEARCH, Atlanta, v. 12, n. 2, 2006. p. 215-229.

; . Conforto térmico em ambientes de escritórios com distribuição de ar pelo piso. In: CONGRESSO BRASILEIRO DE REFRIGERAÇÃO, VENTILAÇÃO E CONDICIONAMENTO DE AR, 7., 2001, São Paulo. Anais... São Paulo, 2001. p. 119-127.

; _ Determinação de parâmetros de conforto térmico e condições de operação de sistema de ar condicionado com insuflamento pelo piso. In: CONGRESSO NACIONAL DE ENGENHARIA MECÂNICA, 2., 2002, João Pessoa. 
Anais... Rio de Janeiro: ABCM, 2002b. CD-ROM.

; _ _ _ ORNSTEIN, S.W. Work Environment Thermal Evaluation with Underfloor Air Supply Applied to a Commercial Building in Rio de Janeiro, Brazil. In: International Conference on Air Distribution in Rooms, 7, Kidlington. Proceedings... Kidlington: Elsevier, 2000. p. 989-994.

LIN, Y.J.; LINDEN, P. F. A model for an under floor air distribution system. Energy and Buildings, Lausanne, v. 37, n. 4, p. 399-409, 2005.

LIN, Z. et al. CFD study on effect of the air supply location on the performance of the displacement ventilation system. Building and Environment, Oxford, v. 40, n. 8, p. 1051-1067, 2005a.

LIN, Z. et al. Comparison of performances of displacement and mixing ventilations. Part I: thermal comfort. International Journal of Refrigeration, Oxford, v. 28, p. 276-287, 2005b.

LINDEN, P. F.; KANDA, I.; YAMAGUCHI, D. Flow in an underfloor plenum. In: SIMBUILD 2004 - BUILDING SUSTAINABILITY AND PERFORMANCE THROUGH SIMULATION, 2004, Boulder. Proceedings... Colorado: IBPSA-USA, 2004. Disponível em: <http://ceae.colorado.edu/ibpsa/ocs/viewpaper.php?id=67\&cf=1>. Acesso em: 16 mar. 2005.

LOOMANS, M. G. L. C. Study on the applicability of the desk displacement ventilation concept. ASHRAE Transactions, Atlanta, v. 105, pt. 2, p. 759-768, 1999.

. The measurement and simulation of indoor air flow. 1998. Thesis (PhD)

- University of Technology, Eindhoven, Netherlands, 1998.

LOUDERMILK, K. J. Temperature control and zoning in underfloor air distribution systems. ASHRAE Transactions, Atlanta, v. 109, pt. 1, p. 307-313, 2003.

. Underfloor air distribution solutions for open office applications. ASHRAE Transactions, Atlanta, v. 105, pt. 1, p. 605-613, 1999.

LUO, S; ROUX, B. et al. Modeling of the HESCO nozzle diffuser used in IEA Annex20 experiment test room. Building and Environment, Oxford, v. 39, p. 367-384, 2004 
MALISKA, C. R. Transferência de calor e mecânica dos fluidos computacional: fundamentos e coordenadas generalizadas. Rio de Janeiro: LTC, 1995. 424 p.

MATSUMOTO, H., MATSUSAKI, A.; OHBA, B. CFD simulation of air distribution in displacement ventilated rooms with a moving object. In: INTERNATIONAL CONFERENCE ON AIR DISTRIBUTION IN ROOMS, 9., 2004, Coimbra. Proceedings... Coimbra: Universidade de Coimbra, 2004. 1 CD-ROM.

MATSUNAWA, K; IIZUKA, H.; TANABE. S. Development and application of an underfloor air-conditioning system with improved outlets for a "smart" building in Tokyo. ASHRAE Transactions, Atlanta, v. 101, pt. 2, p. 887-901, 1995.

McCARRY, B. T. Underfloor air distribution systems: benefits and when to use the system in building design. ASHRAE Transactions, Atlanta, v. 101, pt. 2, p. 902-911, 1995.

MURAKAMI, S.; KATO, S.; SUYAMA, Y. Numerical study on diffusion field as affected by arrangement of supply and exhaust openings in conventional flow type clean room. ASHRAE Transactions, Atlanta, v. 95, pt. 2, p. 113- 127, 1989.

.; __ _ TANAKA, T. The influence of supply and exhaust openings on ventilation efficiency in an air-conditioned room with a raised floor. ASHRAE Transactions, Atlanta, v. 98, pt. 1, p.738-755, 1992.

NIELSEN, P. V. Computational fluid dynamics and room air movement. Indoor Air, Copenhagen, v. 14, n. 7, p.134-143, 2004.

. The selection of turbulence models for prediction of room airflow. ASHRAE Transactions, Atlanta, v. 104, pt. 1B, p. 1119- 1127, 1998.

ORNSTEIN, S. W.; ANDARDE, C. M.; LEITE, B. C. C. Office workplaces in São Paulo, Brazil: some buildings performance considerations. In: ANNUAL CONFERENCE OF THE ENVIRONMENTAL DESIGN RESEARCH ASSOCIATION, 30., 1999, Orlando. Proceedings... Oklahoma: Environmental Design Research, 1999. p. 254-254.

NAKAMURA, Y.; FUJIKAWA, A. Evaluation of thermal confort of inhomogeneous thermal environment created by task-ambient air conditioning system using floor outlet. In: INTERNATIONAL CONFERENCE ON AIR DISTRIBUTION IN ROOMS, 9., 
2004, Coimbra. Proceedings... Coimbra: Universidade de Coimbra, 2004. 1 CDROM.

POSNER, J. D.; BUCHANAN, C. R.; DUNN-RANKIN, D. Measurement and prediction of indoor air flow in a model room. Energy and Buildings, Lausanne, $v$. 35, n. 5, p. 515-526, 2003.

POTTER, M. C; WIGGERT, D. C. Mecânica dos Fluidos. São Paulo, Pioneira Thomson Learning, 2004. $688 \mathrm{p}$.

PUSTELNIK, M. Avaliação numérica de ambientes com insuflamento de ar frio pelo piso. 2005. 129 f. Dissertação (Mestrado) - Escola Politécnica, Universidade de São Paulo, São Paulo, 2005.

ROSA, J. A. Determinação dos campos de velocidade e temperatura em ambientes ventilados. 2001. 90 f. Dissertação (Mestrado) - Escola de Engenharia, Universidade Federal do Rio Grande do Sul, Rio Grande do Sul, 2001.

SEKHAR, S. C.; CHING, C. S. Indoor air quality and thermal comfort studies of an under-floor air-conditioning system in the tropics. Energy and Buildings, Lausanne, v. 34, n. 5, p. 431-444, 2002.

SHUTE, R. W. Integrated access floor HVAC. ASHRAE Transactions, Atlanta, v. 98, pt. 1, p. 730-736, 1992.

. Integrated access floor HVAC: lessons learned. ASHRAE Transactions, Atlanta, v. 101, pt. 2, p. 877-886, 1995.

SODEC, F.; CRAIG, R. The underfloor air supply system: the European experience. ASHRAE Transactions, Atlanta, v. 96, pt. 2, p. 690-695, 1990.

SPOORMAKER, H. J. Low-pressure underfloor HVAC system. ASHRAE Transactions, Atlanta, v. 96, pt. 2, p. 670-677, 1990.

TEODOSIU, C. et al. Numerical prediction of indoor air humidity and its effect on indoor environment. Building and Environment, Oxford, v. 38, n. 5, p. 655-664, 2003.

TIBAUT, P.; WIESLER, B. Thermal comfort assessments of Indoor environments by means of CFD. In: INTERNATIONAL CONFERENCE ON AIR DISTRIBUTION IN ROOMS, 8., 2002, Copenhagen. Proceedings... Copenhagen: The Technical 
University of Denmark and Danvak, 2002. p. 97-100.

TUDDENHAM, D. A floor-based approach. ASHRAE Journal, Atlanta, p. 18-28, Jul. 1986.

VERSTEEG, H. K.; MALALASEKERA, W. An introduction to computational fluid dynamics: the finite volume method. London: Longman Scientific \& Technical, 1995. $257 \mathrm{p}$.

VISCHER, J. C. Environmental quality in offices. New York: Van Nostrand Reinhold, 1989. 250 p.

WAN, M. P.; CHAO, C. Y. Numerical and experimental study of velocity and temperature characteristics in a ventilated enclosure with underfloor ventilation systems. Indoor Air, Copenhagen, v. 15, p.342-355, 2005.

WEBSTER, T. et al. Thermal stratification performance of underfloor air distribution (UFAD) systems. In: INDOOR AIR 2002, 2002, Monterey. Proceedings... Monterey, CA, 2002a. 6 p.

; BAUMAN, F. S.; REESE, J. Underfloor air distribution: thermal stratification. ASHRAE Journal, Atlanta, v. 44, n. 5, p. 28-33, 2002b.

XU, H. T.; NIU, J. L. A new method of CFD simulation of airflow characteristics of swirling floor diffusers. In: INTERNATIONAL IBPSA CONFERENCE, 8., 2003, Eindhoven. Proceedings... Eindhoven, 2003. p.1429-1433. Disponível em: <http://www.ibpsa.org/\%5Cproceedings\%5CBS2003\%5CBS03 1429 1434.pdf> Acesso em: 16 mar. 2005.

$\therefore \quad$ CFD analysis of two different supply diffusers in underfloor air distribution systems. In: INTERNATIONAL CONFERENCE ON AIR DISTRIBUTION IN ROOMS, 9., 2004, Coimbra. Proceedings... Coimbra: Universidade de Coimbra, 2004. 1 CD-ROM.

XU 2005

ZENG , J.; SHAW, C. Y.; MACDONALD, R. A. Indoor climate in an open plan office: a comparison between measurements and CFD simulations. Canada: National Research Council of Canada, Institute for Research in Construction and 
Public Works \& Government Services Canada, 2001. 9 p. (Relatório técnico NRCC44733). Disponível em: <http://irc.nrccnrc.gc.ca/pubs/fulltext/nrcc44733/nrcc44733.pdf>. Acesso em: 07 dez. 2005.

ZHAO, B.; LI, X.; YAN, Q. A simplified system for indoor airflow simulation. Building and Environment, Oxford, v. 38, n. 4, p. 543-552, 2003.

ZUKOWSKI, M. A new formula for determining a minimum recommended value of inlet air velocity from UFAD system to prevent occupants from draught risk. Building and Environment, Oxford, Article in press, 2005. 